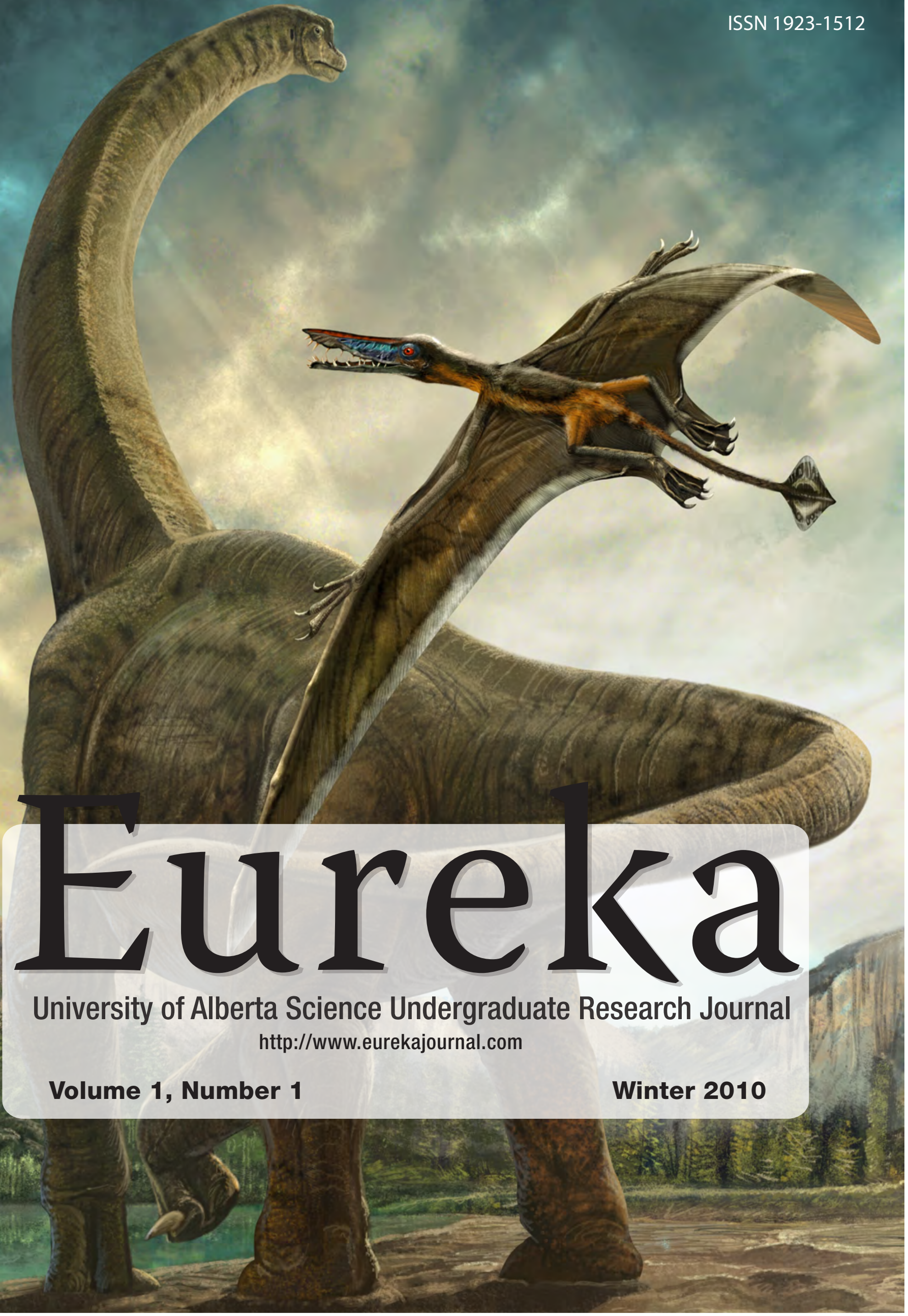




\section{Eureka \\ Volume 1, Number 1 (2010)}

Want to contact us?

http://www.eurekajournal.com

eureka@ualberta.ca

\section{$\underline{\text { Editorial Board }}$}

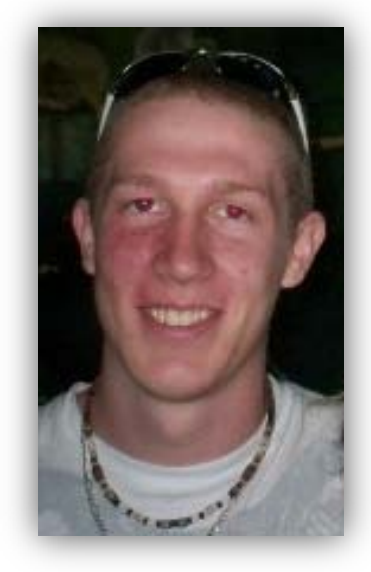

\section{Braden Teitge (Founder E Editor-in-Chief)}

I started Eureka because I thought that the undergraduate experience at the University of Alberta could be, and should be, better. I hope that this journal will help disseminate the incredible science that is being done by undergraduates at this university. I hope that Eureka will be a tool that undergraduates can use to see what research is being done by their peers, see how to get involved with research, and meet the professors doing work of interest to you. As a University of Alberta science undergraduate you have everything in place to help you succeed in science, medicine, or industry, and I hope that this journal will assist you in achieving your goals.

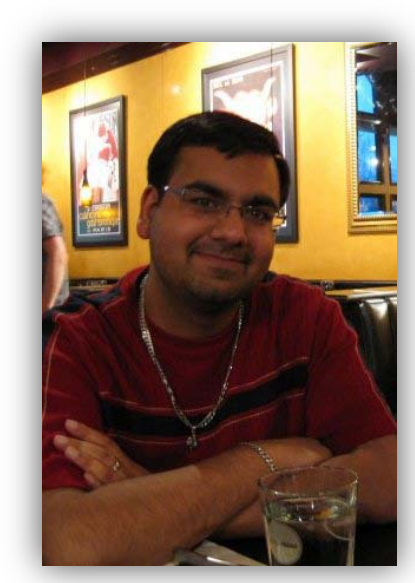

\section{Christopher Madan (Editor-in-Chief)}

I co-founded Eureka as I know first-hand that undergraduates can carry out outstanding research - however, it is rare to get a chance to really showcase your work until after you are a graduate student. We hope Eureka can serve as a medium for undergraduates at the University of Alberta to communicate the great discoveries and accomplishments they make during this extremely formative stage of their research career. While I am currently a PhD student, however, not that long ago I was an undergraduate as well and would have loved for an opportunity to publish in a journal such as Eureka.

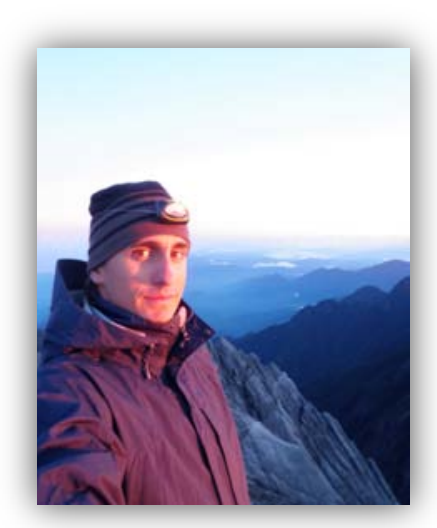

\section{Patrick Jones (Managing Editor)}

Hello, my name is Patrick Jones, a graduate from the University of Alberta Faculty of Science and managing editor of Eureka. In my mind, the main reason why we have created Eureka is to give undergraduate students another aspect on how research works. Eureka will also praise undergraduate students for their hard work and determination rather than just receiving an exceptional grade. Only if Eureka was in place when I was an undergraduate! 


\section{Carmen Chu (Editor)}

I'm in my final undergraduate year in the Immunology and Infections program and will continue to graduate studies in Physiology at the University of Alberta. I think Eureka is a good way to help undergraduates get a taste of what the world of research can be like, and certainly gain some skills essential to pursuing research as a career.

\section{Helen Zakrzewski (Editor)}

I am a third year undergraduate student in the Faculty of Science. I signed on to work with Eureka because I believe that research offers a unique perspective to undergraduate education. I feel that Eureka provides an exceptional means of showcasing the work of students that resultantly comes from these experiences.

\section{Graphic Design \& Illustrations}

Dr. Andrew Derocher

Christopher Madan

Laura Stanton

Lida Xing

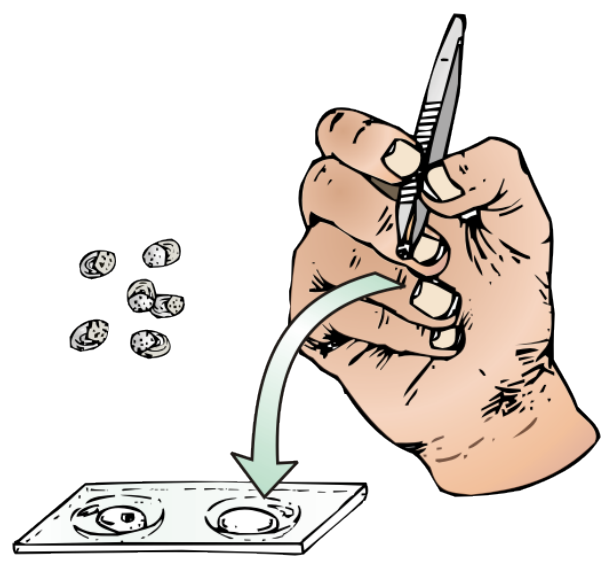

\section{Library Advisor \& Logistical Support}

University of Alberta Libraries

Leah Vanderjagt

Pam Ryan

\section{Faculties of Science \& Medicine - Faculty Reviewers and Supporters}

Dr. Robert Luth. Associate Chair Undergraduate EAS.

Dr. Roger Moore. Associate Chair Undergraduate Physics.

Dr. James Lewis. Associate Chair Undergraduate Math \& Statistics.

Dr. Christopher Cairo. Department of Chemistry.

Dr. John Locke. Department of Biological Sciences (Genetics).

Dr. Jens Roland. Department of Biological Sciences (Population Ecology).

Dr. Stan Boutin. Department of Biologial Sciences (Zoology).

Dr. Larry Heaman. Associate Dean (Research).

Dr. Elena Nicoladis. Associate Chair Undergraduate Psychology.

Dr. Clayton Dickson. Departments of Psychology, Physiology, \& Neuroscience.

Dr. Ian Winship. Centre for Neuroscience Honors Program Coordinator.

Dr. Emmanuelle Cordat. Department of Physiology.

Dr. Todd Alexander. Departments of Pediatrics \& Physiology.

Dr. Randall Irvin. Departments of Microbiology \& Immunology.

Dr. Gerda de Vries. Department of Mathematical \& Statistical Sciences. 


\section{About the Front Cover}

\section{Artist Bio: Lida Xing}

My calling as an artist started over a decade ago, at the Beijing Museum of Natural History. Here, I looked up at the skeleton of Mamenchisaurus, its long neck was almost touching the ceiling several stories high. This was the first time I had ever seen a dinosaur in person - I could even touch it.

Later that year I started a brand new website in China for the promotion of popular palaeontology. The website is still running today, and I get an incredible joy from educating children and inspiring wonder about the world of dinosaurs.

In the same year, I enrolled under the tutelage of Professor Shimming Dong, referred to as "the dinosaur godfather” in China. Indeed, Professor Dong has named the most dinosaurs of any palaeontologist! Under his direction, I began to study dinosaur fossils and tracks. I kept up with my artwork all the while because it truly helps me to visualize what I think a dinosaur looks like, and how they may have interacted. Furthermore, it gave me a great advantage professionally, as my work would come to be profiled by the scientific community.

As a graduate student, I formed a professional team for dinosaur illustration with a number of friends. Together, we have produced hundreds of illustrations, some of which were adopted as the cover by Nature, others exhibited in PNS. It is very satisfying to make official illustrations; it has allowed me to communicate with the best palaeontologists worldwide, and has certainly opened many doors. It is a wonderful experience to witness a dinosaur being brought back to life by ones brush and pencil.

A number of years

after working with Professor Dong, a dream came true and I was able to study in Canada, under Dr. Philip Currie. I am now an MSc student, on my way to becoming a palaeontologist. I love what I do, and I feel that my artistic endeavours have certainly helped me to achieve some of my goals. I would encourage anyone in the sciences to get involved with the arts for this same reason, and for the joy of creating something beautiful.

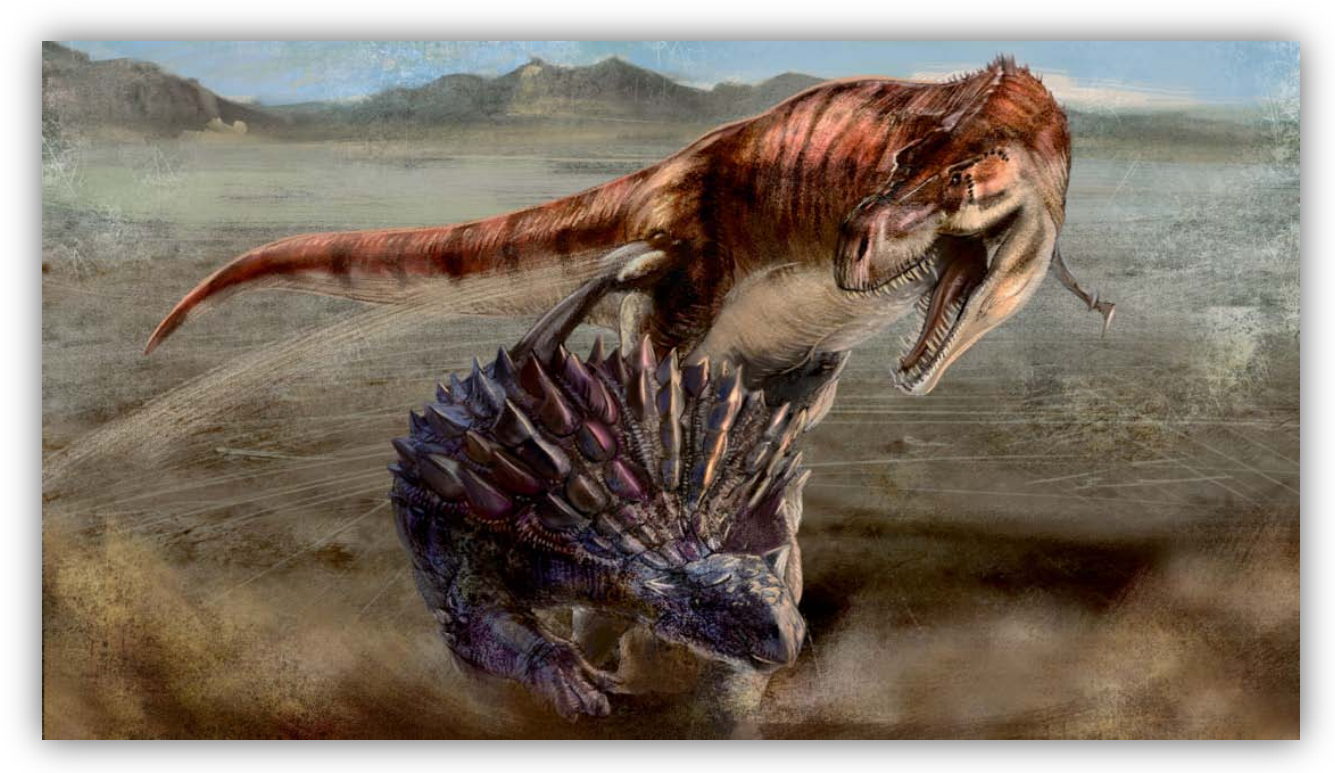

\section{About the Back Cover}

Photos kindly provided by Dr. Andrew Derocher. 
Table of Contents

\section{Forward}

INTRODUCTION TO EUREKA

Teitge

\section{Interviews}

THE CORDAT LAB

INTERVIEW WITH DR. DAVID SCHINDLER

1000 PLANTS: AN INTERVIEW WITH DR. GANE WONG

\begin{tabular}{|lc|}
\hline \multicolumn{2}{|c|}{ Published Abstracts } \\
\hline iGEM 2009: THE BIOBYTES METHOD & $5-6$ \\
UofA iGEM Team & \\
VIRTUAL ENVIRONMENTS AS MEMORY MNEMOICS & $7-9$ \\
Ng, Legge, Caplan & \\
INADEQUACIES OF COLONOSCOPY PROCEDURE REPORTS IN A COLORECTAL & 10 \\
CANCER SCREENING PROGRAM & \\
Diaz, Fedorak, Wong
\end{tabular}

\section{Articles}

\section{Bmpr1bb IS A NOVEL GENE INVOLVED IN RETINOIC ACID INDUCED PATTERNING OF} THE ZEBRAFISH HINDBRAIN

Teitge

IMMOBILIZED ARTIFICIAL MEMBRANE (IAM) LIQUID CHROMATOGRAPHY AS A MODEL FOR ANTIMICROBIAL PEPTIDE PARTITIONING INTO CELL MEMBRANES: AN EVALUATION

Benesch, Lewis, McElhaney

\section{Reviews}

NEUROMARKETING: THE NEXT STEP IN MARKET RESEARCH?

Madan

REAL RESEARCH OR SHAM SCIENCE? A REVIEW OF JAPAN'S SCIENTIFIC WHALING Robertson

\section{Other}

Research/Funding Related Opportunities

Eureka Team 


\section{INTRODUCTION TO EUREKA}

Eureka is a student-founded and student-run initiative whose mission is to promote the world class undergraduate research done in the Faculty of Science. This journal offers undergraduate scientists the unique opportunity to share their discoveries with the scientific world, while learning the peer review process. Most undergraduate students do not get to experience the publication process as part of their scientific education. Eureka is an educational institution, with a diverse team of reviewers from many scientific backgrounds. Through clear, effective scientific writing students will be able to work together with faculty members to promote University of Alberta science. Eureka serves to recognize, encourage, and reward intellectual activity in science. Each year hundreds of undergraduate students complete honours projects and write thesis of their work. Eureka will take this one step further by allowing students to learn clear scientific writing, in addition to an educational taste of the peer review process. In addition to primary research, Eureka will also be publishing interviews and biographies with various members of the faculty to help bridge the gap between faculty and the undergraduate students. Eureka is beneficial to the faculty as it is beneficial to the student population. In addition to being an invaluable educational tool, this journal brings a sense of community to the Faculty of Science through the exchange and dissemination of research and ideas. Eureka's breadth covers all disciplines of science, increasing faculty awareness of the research being done at the University of Alberta. While this is an educational tool aimed at undergraduates in their higher years, this journal serves to promote scientific research to the entire faculty. An awareness of quality research only serves to promote science further by attracting better students.

In my first year of university the faculty of science decided to help bridge the gap between the undergraduate experience and involvement in research by hosting a number of key speakers to my first year class. I was lucky enough to be in a seminar of a world-renowned expert of... insects. While I praise the effort that the Faculty of Science made to get me and my peers involved with research this experience only served to further alienate me more from basic research. "Research for research' sake" seemed to involve pulling bugs apart, and that did not satisfy what I wanted to accomplish in science. For the rare student I am sure this was the chance of a lifetime, to hear from an expert in a field that inspired and amazed them. My own involvement in research happened by chance, which is something I hope to change for students in years to come. As for basic research - that "insect researcher" happened to be Dr. Reuben Kaufman, who studies the physiology of ticks. Years after first hearing him speak I considered joining his team, when my grandfather was diagnosed with Lyme disease, a disease carried by a tick vector.

If you are a student in this faculty, you have already been given the tools to succeed in science, medicine or industry. Being a student in a research-intensive university allows you to be at the cutting edge of groundbreaking research. Taking that first step in research, be it a summer job, an honours thesis or volunteer work is easier than you might think. Most professors are happy to talk to you about research (even more so about their research), and often the first step is finding an email online and simply going to meet them. Have an area that you are interested in? Every department has an exhaustive list of their faculty members and their research interests through the Faculty of Science website.

\section{Braden Teitge}

Eureka Founder \& Editor-in-Chief

teitge@ualberta.ca 


\section{THE CORDAT LAB}

\section{Eureka}

Eureka Team

Emmanuelle Cordat is an assistant professor in the Department of Physiology. A recent paper of hers was accepted by Biochemical Journal Feb 2010: "Band 3 Edmonton I, a novel mutant of the anion exchanger 1 causing spherocytosis and distal renal tubular acidosis". Below is a review from the lead author of this paper, Carmen Chu.

Distal renal tubular acidosis is a disease of the kidney that leads to formation of kidney stones, failure in urine acidification, failure to thrive and eventually renal failure. There is no treatment for this disease. Spherocytosis is a disease of the red blood cells, causing the affected individual to become anemic and to require regular blood transfusions until removal of the spleen eventually resolves the anemia problem. This novel mutant of the anion exchanger 1 (AE1) was characterized from a patient of the University of Alberta Stollery Children's Hospital. Studying the trafficking patterns of the mutant anion exchanger I in cell lines proteins revealed that the localization of the mutated protein was different from the wildtype, and that abnormal localization correlated to the disease phenotypes displayed by the patient and family members. Due to its abnormal localization in cells, this novel mutant is likely unable to perform normal function in the kidney and thus causes the disease in this patient. This investigation was led by Dr. Emmanuelle Cordat, and the Cordat lab are now working on other aspects of the anion exchanger I.

Currently, the lab is working on several aspects of the kidney anion exchanger I (kAEI). The restoration of intracellularly retained mutant kAEI trafficking to the plasma membrane is one area of interest. Indeed, re-establishment, even if partial, of normal trafficking may restore partial function of the protein and improve physiological conditions of affected individuals. Inspiration as to which small molecules to test first were drawn from those that restored trafficking of $\triangle F 508$ CFTR, vasopressin 2 receptor (V2R), and aquaporin 2 mutants. Results thus far have shown success in rescue for some mutants of kAEI, thus bringing potential opportunities for new therapies for these patients. The affect of these small molecules on the interaction of kAEI with chaperone proteins are also being studied.

Another area of research in the Cordat lab is looking at is the role of interacting proteins of AEI on trafficking. The mutant forms of AEI may be localized to the wrong place in cells because they are unable to interact with trafficking proteins or in contrast, because they are interacting too strongly with some others. Such interactions could explain the mistargeting of various mutant proteins. Studying these proteins' interactions will give clues as to how mistargeting of mutant proteins can be repaired.

Finally, previous studies have shown that the C-terminus of kAEI has important interacting partners that are crucial to proper targeting of kAEI. One such protein that we are studying is the adaptor protein 1A (AP-1A), which resides in the Golgi and endosomes. We suspect that the lack of interaction between AP-1A and kAE1 mutants could cause distal renal tubular acidosis in certain patients.

Stay tuned for more updates on the Cordat lab!! 


\section{INTERVIEW WITH DR. DAVID SCHINDLER}

Eureka Team
Eureka

Volume 1, Number 1 (2010)

Dr. David Schindler's career as an environmental scientist has been extraordinary. He has been recognized with premier scientific awards in Canada and around the world, and is well known for his work with the Experimental Lakes Project. In a dimly lit room near the top of the zoology wing I met with Dr. Schindler to discuss all things science: from what he looks for in a young scientist to how he trains them to carry the torch of competent environmental decision making.

\section{Fire \& Curiosity}

Young scientists drive research at any academic university. Ask any successful scientist and they will tell you that first and foremost, recruiting the best people makes for the best research. If that is indeed true, Dr. Schindler has certainly had some great students. "Fire and curiosity. Of course grades are always important, but I want to see a real knowledge of the subject area - for example why a student wants to work with me". He takes this further to point out that shy students have trouble. "My students are my colleagues, and I do not pamper them. I expect them to think for themselves." "Creativity is incredibly important in science. I want my students to accomplish the job with limited instruction - somebody that can think on their feet. If a piece of equipment stops working in the middle of nowhere I expect them to rig it back together". This may be attributed to Schindler's upbringing on a farm. His grandfather's tractor broke down once, and he took a wheel off his model $\mathrm{T}$ and ran it anyways. Schindler got his academic career started with a bang; his first paper was accepted by Science while he was an undergraduate. From there, he was convinced by his supervisor to apply for the Rhodes Scholarship, which brought him to Oxford. He attributes the faculty and culture there as instrumental to his success. "I found out [in Oxford] what intelligence is all about. The idea in the UK was that the best scientific instrument was the one between your ears, so you had better learn to use it. I would engage in conversation with some of the best academic minds. When I said something wrong, the next day they would come to me with a dusty paper or book chapter to set me straight”. In fact, it was his graduate experience in the UK that he uses in his own approach to training scientists. "Things I copied are things I liked in Oxford. They left me my independence but were always available”.

\section{Government, Science and Water}

Our current governments are reluctant to accept environmental science and put that into public policy. "The USA has had a huge turnaround with Obama, as he has a stellar group of academic advisors". It was for these same reasons that Schindler left the department of Fisheries and Oceans two decades ago, because "the advisory system was a long line of whispers". "The government is squashing good science. It is the worst I have ever seen it”. Global warming is careening out of control, and Canada is seen worldwide as a pariah on the climate change front. Indeed, Dr. Schindler's latest paper in the Proceedings of the National Academy of Sciences USA blew the whistle on oil sands pollution in Alberta. When asked about climate change and water he shakes his head, "Yes, we should be worried. Canada is in trouble. People do not realize how dependent we are on glacier and snow water from the Rockies. Water is tremendously slowly renewed, and our use is exceeding renewal rates". Environmental decision making should depend on good science, yet this does not seem to be the case. When asked to contrast environmental governmental policy in the USA and Canada, he laughs. "Harper does not welcome science. The people at the top of government are not even aware of their own scientists in their administration. We must figure out a way to inject more science into Canadian decision making. Young scientists need to do this, and the good students try. Above all we should back policy with good science”. 


\section{PLANTS:}

\section{AN INTERVIEW WITH DR. GANE WONG}

Eureka Team

Eureka

Volume 1, Number 1 (2010)

Dr. Gane Ka-Shu Wong, an internationally renowned scientist at the University of Alberta has taken the initiative to sequence 1000 plants $(1 \mathrm{kp})$. The project will involve both fundamental questions of plant biology and applied questions - medicinal and agricultural. But why sequence 1000 plants?

As the Alberta government looks to broaden its industrial scope away from fossil fuels, it has to look to new technologies. Information technology and applied life sciences both fall into the category of this investment. Dr. Wong has already attracted a half million dollars in funding from private venture capitalists, so clearly he is not alone in thinking this project is feasible in creating start-up companies. The fundamental plant biology questions are clear; a plant genome will tell you about plant phylogeny and their evolution. The goal of the basic research questions he is undertaking is to "make a splash" in the scientific field, creating noise and buzz about what the University of Alberta and Dr. Wong are undertaking. The second question is on how to apply the data generated.

A good example on applying genomic data into effective therapies comes from a recent synthesis of the plant based anti-malaria drug, artemisinin, by Dr. Jay Keasling's group at Berkeley. Following up on his promise of mass-producing this drug from simple, single celled yeast, he was able to reduce the cost of producing artemisinin by an order of magnitude. In essence, he took plant DNA sequences and put them into single celled organisms, and got them to perform the same reaction that would happen in a plant cell. Like a microscale artemisinin factory. What Dr. Wong wants to do is open this possibility for thousands of other drugs that depend on the genes expressed in plant cells.

A fundamental facet of this project is that transcriptomes are being sequenced, not genomes. This means that the active genes in the plant are sequenced. While this is imperfect, it will provide a snapshot of gene expression for well over ten thousand genes - a massive improvement to the small handful of genes sequenced in most of the plants chosen for this project. The feasibility of this idea is possible because of a recent demonstration of this technology on rice, in which the computational technology developed by BGI Shenzhen was proven highly efficient. Indeed, Dr. Wong's longstanding appointment as an associate director of the BGI institute is what makes him confident in his ability to see this project through to completion.

In biology, it is often the most uncommon of organisms that make the best teachers. Dr. Wong uses the word "extremophytes" to describe another component of his sequencing effort, plants with weird and fascinating properties. Plants that can spontaneously combust, plants that produce oil, and carnivorous plants are some of the behaviours that he hopes to unlock with his project. But what he and the province of Alberta are both looking for is to jump start Alberta genomics - turning it into translational research that will benefit the local economy. 


\section{iGEM 2009: THE BIOBYTES METHOD}

Kalon Armstrong*, Eric Bennett*, Max Buchko*, Oscar Cortes*, Ahn Dao*, Uche Davidson*, Justin Fedor*, Erin Garside*, Stephen Jahns*, Eric Leung*, Davd Lloyd*, Emera Nguyen*, Mitch Paquette*, Amber Paul*, Julia Pon*, Alina Ponomarev*, Kelly Robinson*, James Rodway*, Zach Wiltshire*, Jennifer Yau*, James Maclagan, Doug Ridgway, Mike Ellison

*Authors contributed equally to this work.

JM, DR and ME are part of the supervisory committee.

\section{Foreword}

The following work was completed by the 2009 University of Alberta iGEM team. iGEM, or the internationally genetically engineered machines jamboree is a challenge to build biological systems and operate them in living cells. iGEM is a great opportunity for undergraduates to become involved in synthetic biology.

\section{Introduction}

Synthetic biology needs more than minor modifications to existing evolutionary plans. We've developed a method of gene assembly allowing complete genome re-design, so termed BioBytes. The speed and automation of the BioBytes method makes possible the maximization of modularity on a grand scale. Imagine a synthetic genome grouping common pathway components and components with similar levels of expression. This degree of organism control would be a milestone marking synthetic biology as a mature field. The BioBytes method of gene assembly allows us to efficiently test, optimize, and correct genome scale design principles. There are currently two alternatives for gene assembly. The first, BioBricks, is modular but slow. The second, the use of unique long sticky ends for each piece, is fast but nonmodular.

\section{The BioBytes Method}

The BioBytes method begins with BioBytes: segments of DNA ranging from tens to hundreds of base pairs, each encoding a specific cellular instruction. Both ends of a BioByte have 12bp single stranded overhangs. Single stranded overhangs only anneal if they have complementary sequences. Our method uses only two pairs of end sequences, $A / A^{\prime}$ and $B / B^{\prime}$, and BioBytes are assembled with alternating $\mathrm{A}$ and $\mathrm{B}$ junctions. Only A ends may attach to each other and likewise only B ends may link to each other. To control which end of a growing DNA construct a BioByte is added to, one end of the construct is anchored to a paramagnetic streptavidin coated bead through a DNA anchor (See Figure 1).

Once completed, the construct can be released from the bead by enzyme digestion and, if a terminator BioByte was used, will circularize. As the terminator is added last, only full length constructs will circularize and can be selected for by transformation into E.coli. The BioBytes themselves are produced by ligating DNA into a BioBytes universal plasmid, performing PCR on plasmid using our universal primers, and digesting the product with the USER system to produce single stranded ends.

To develop the BioBytes method, we performed optimization experiments on assembly conditions, bead binding capacity, anchor release, BioByte production and overhang construction. We successfully produced a five byte construct 
using the BioBytes method on the benchtop, and repeated this construction at a microfluidic scale. Moreover, we constructed and tested a robot for automation, determined operon position using the BioBytes method, and began multiplexing BioByte constructs.

\section{A novel algorithm for predicting essential genes}

Next, we explored the BioByte method in its application to the construction of an artificial E.coli genome. Using a novel computer modeling approach, we determined which genes would need to be retained for a functional metabolism in different environments, identifying 117 genes never previously considered essential. We designed and tested primers for hundreds of essential genes, the first step of making them BioBytes. These primers and all components needed for the BioBytes method were documented and submitted to the BioBricks Foundation for public use. In total, we submitted 442 parts.

\section{Conclusion}

BioBytes has the potential to accelerate synthetic biology toward the grand vision of an artificial cell. Unlike the previously developed BioBrick DNA assembly method, genes produced in the BioByte format can be assembled rapidly in vitro, in any desired order, with great precision and yield. With cycle times approaching 20 minutes for the addition of each new gene, BioByte assembly rates exceed their BioBrick counterparts by 200 -fold. This level of improvement immediately opens the door towards the synthesis of simple chromosomes that can be tested and optimized at unprecedented speed. Finally, the BioByte assembly system requires a fraction of the equipment found in a conventional gene lab. This advantage, combined with sheer simplicity, greatly extends its utility. The BioBytes method is already in use by researchers at the National Institute for Nanotechnology.

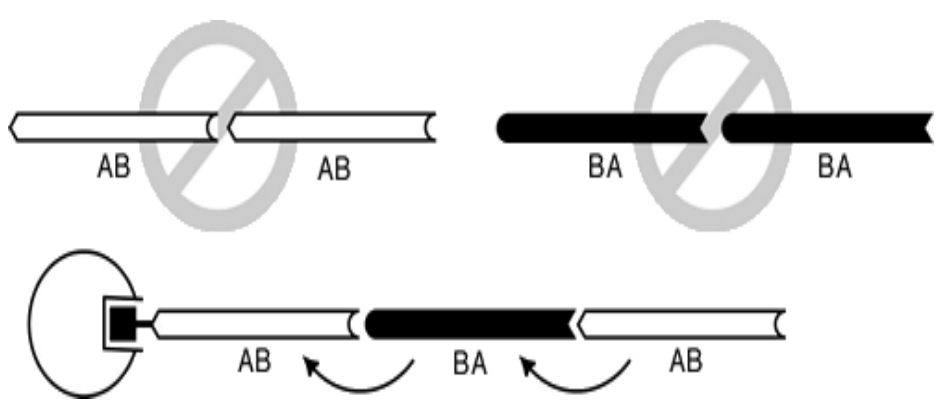

Figure 1. Each end of a BioByte has $12 \mathrm{bp}$ single stranded DNA overhangs with alternating ends termed $A$ or $B$. The BioByte assembly is initiated through a streptavidin anchor, and then alternating $A B-B A-A B$ ligations extend the sequence. 


\section{VIRTUAL ENVIRONMENTS AS MEMORY MNEMONICS}

Enoch Ng, Eric L Legge, Jeremy B Caplan

Department of Psychology, University of Alberta

\section{Eureka}

Volume 1, Number 1 (2010)

\section{Introduction}

Since before written history, many different techniques have been used to enhance memory. One of the most prevalent of these techniques, known as mnemonics, was the Method of Loci (Yates, 1966). There were many different forms of this mnemonic, but all involved the use of an environment to aid in item-order recall. Many memory experts practiced a complex form of the Method of Loci where they would have extensive spatial and navigational knowledge of the environment and also be able to picture the blueprint of the environment (looking into the environment from a bird's eye or omnipotent view). This allowed them to zoom in and focus in on specific portions of their chosen environment, using the complexity and spatial richness of the specific portion to associate with the ideas or items to be remembered. The overall ability to focus and use small portions and specific details of the environment to aid in memory allowed these memory experts to memorize virtually infinite lists of ideas and/or items within a single environment. A single environment could even be used for multiple lists because of the special way in which memory experts were trained to expand, isolate, and focus in on specific portions of the environment. However, a more common form required less extensive training. First, the person would objectify the items within a list and place them around a familiar environment. Then, to recall the list in order, the person would imagine navigating the environment along the same path that he or she travelled while placing down the items of the list (Yates, 1966).

While the Method of Loci has not been shown to be a better mnemonic then other methods (e.g. peg method), previous studies have shown that is significantly better than rote repetition or imagery, where words items are objectified and sometimes linked to other words within the same list (Roedgier, 1980; de Beni \& Cornoldi, 1985; Wang \& Thomas, 2000; Verhaeghen \& Kliegl, 2000). Later studies have also concluded that high concreteness words have a recall advantage over low concreteness words for the Method of Loci (Wang \& Thomas, 2000). As well, since the Method of Loci is a mnemonic strategy that requires the visualization and navigation of an environment to aid in item and

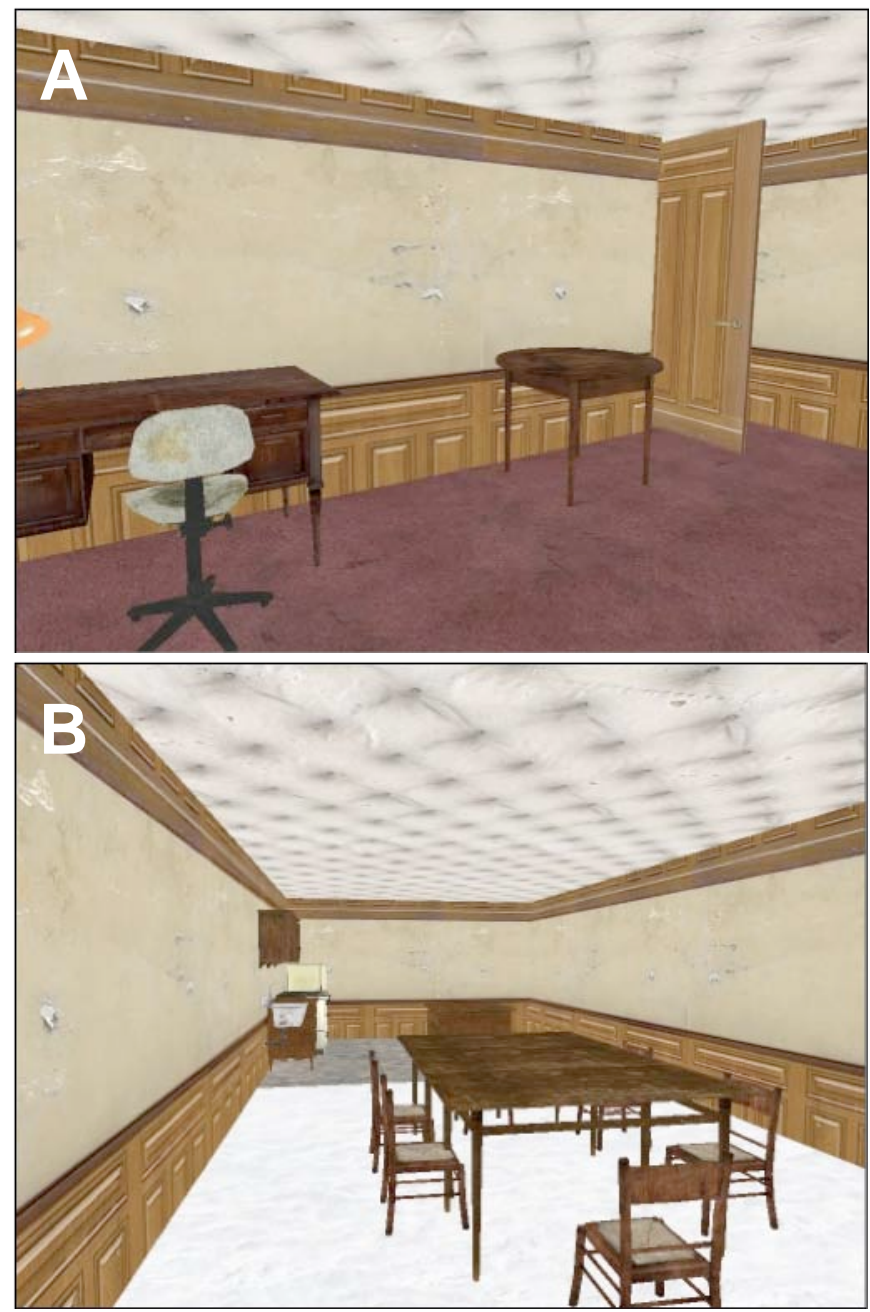

Figure 1. Two screenshots of a virtual environment participants were required to familiarize themselves with. The environment was modeled after a house. 
order recall, one could assume that the use of the same loci for multiple items within different lists would cause interference between lists. This was shown to be untrue by several studies finding that the use of a loci location for multiple items does not compromise the effectiveness of the Method of Loci (de Beni \& Cornoldi, 1985), and that the Method of Loci is not more susceptible to proactive interference than the rehearsal method (Massen \& Vaterrodt-Plunnecke, 2006). Other studies have also found that the Method of Loci requires "a well-memorized Loci pathway, the creation of good images of the items to be memorized and their adequate insertion in each locus” (Moe \& de Beni, 2005). In essence, while the Method of Loci requires a well-known environment, the items within the list to be memorized must be definitively objectified into strong and easily recognizable images and also must be strongly associated with the environment used to aid memory recall.

\section{Methods}

We conducted a serial recall paradigm with typed response varying concreteness per list. A 3 x 2 x 5 factorial design was used, manipulating instructions between groups, word concreteness, and list. Participants randomly assigned to one of three groups: Method of Loci (traditional), Method of Loci (Virtual), and uninstructed. Every participant was given five minutes to navigate and familiarize themselves with a virtual environment created in Half Life 2 (see Figure 1). There were three environments, and participants were randomly assigned to one of them. Afterwards, participants were given memory instructions according to their assigned group with the Method of Loci groups given a description of the Method of Loci paraphrased from The Art of Memory (Yates, 1966) and the uninstructed group was given no specific memory method instruction. The traditional Loci group was instructed to use their home whereas the virtual Loci group was instructed to use the environment they had just familiarized themselves with as the environment for their memory strategy. After being given the instructions and indicating their understanding, participants were presented with a memory task consisting of ten lists, with recall immediately after each list and the lists alternative between high and low concreteness. All participants were asked to verbally express their strategy while they were using it during the memory task (e.g., participants within both Method of Loci groups were to verbally express how they were associating the words in the lists with the environments, while participants within the uninstructed group were free to use any strategy so long as they verbally expressed this method while using it) and every participant was audio recorded during the memory task. At the end of the task, participants were given a questionnaire to complete which included measures for gaming experience, prior knowledge of the Method of Loci, and compliance to memory method instructions for number of lists presented. Data was analyzed according to the strategy the participants used rather than the group the participant was assigned to.

\section{Results and Discussion}

The results of our study indicate that using an unfamiliar virtual environment is not significantly different than using a real and familiar environment for the Method of Loci. Our results also affirm previous research findings that the Method of Loci is an effective memory mnemonic for both item and order recall, and that it is more effective for concrete words than abstract words (See Figure 2). We also found that the Method of Loci is neither more nor less susceptible to proactive interference than uninstructed memory. However, we found that a fair proportion of participants were not compliant with their instructed memory strategy according to audio verification (from the audio recordings) as well as on the self report questionnaires.

These findings suggest that the virtual variant of the Method of Loci can function as effectively as its traditional counterpart and that 
participant compliance to experimental instructions should be verified for research data.

\section{References}

De Beni, R., \& Cornoldi, C. (1985). Effects of mnemotechnique of loci in the memorization of concrete words. Acta Psychologica, 60, 11-24.

Massen, C., \& Vaterrodt-Plunnecke, B. (2006). The role of proactive interference in mnemonic techniques. Psychology Press, 2, 189 - 196.

Moe, A., \& De Beni, R. (2005). Stressing the efficacy of the loci method: oral presentation and the subjectgeneration of the loci pathway with expository passages. Applied Cognitive Psychology, 19, 95-106.
Roediger, H. L. (1980). The effectiveness of four mnemonics in ordering recall. Journal of Experimental Psychology, 6, 558 - 567.

Verhaegen, P., \& Kliegl, R. (2000). The effects of learning a new algorithm on asymptotic accuracy and execution speed in old age: a reanalysis. Psychology and Aging, 15, 648 - 656.

Wang, A. Y., \& Thomas, M. H. (2000). Looking for long-term mnemonic effects on serial recall: the legacy of simonides. The American Journal of Psychology, 113, 331 - 340.

Yates, F. A. (1966). The art of memory. United Kingdom: Routledge and Kegan Paul.

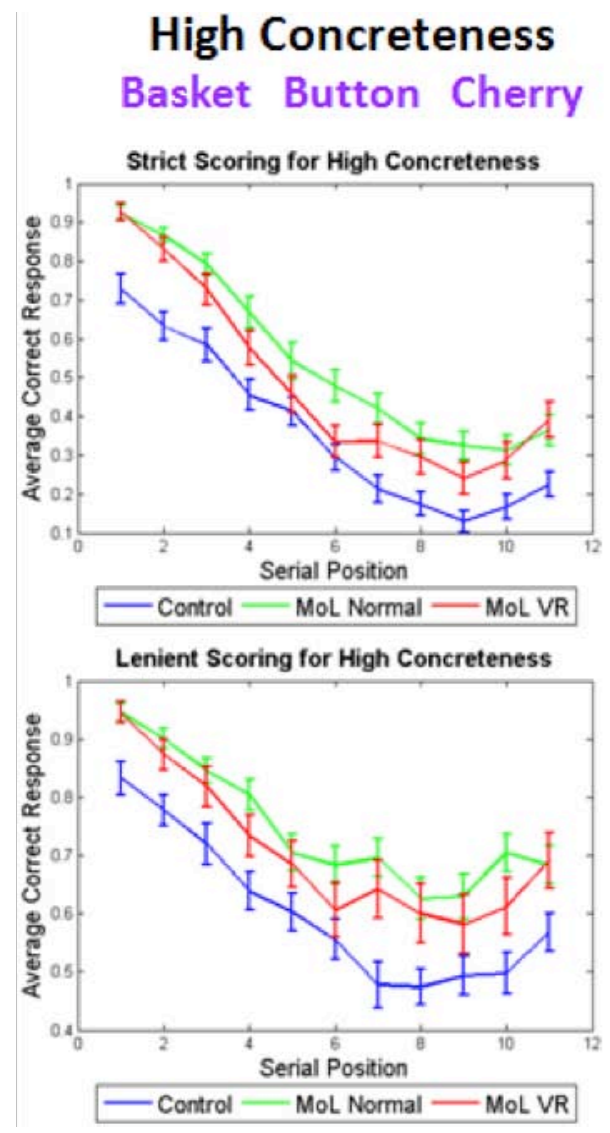

\section{Low Concreteness}

\section{Irony Pause Midst}
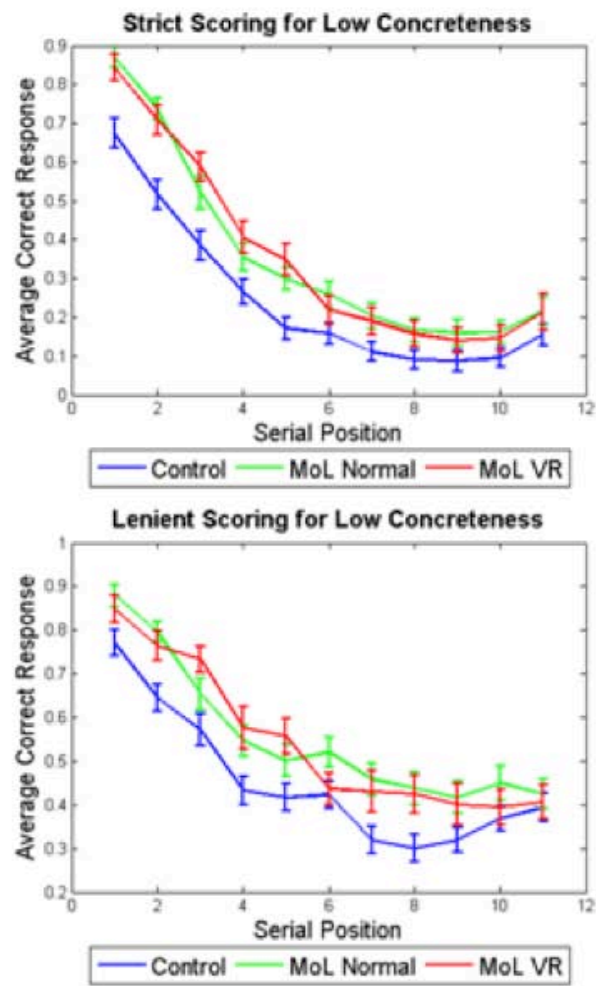

Presented

A B C D E

Recalled

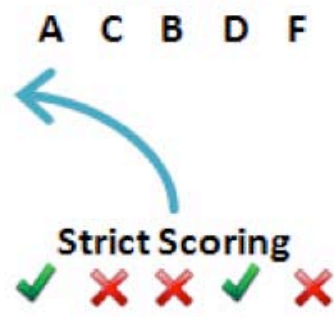

Lenient Scoring

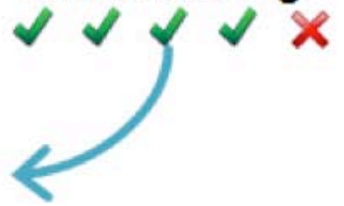

Figure 2. Summary figure of results for both item (lenient scoring) and order (strict scoring) memory across high concreteness and low concreteness lists. 


\section{INADEQUACIES OF COLONOSCOPY PROCEDURE REPORTS IN A COLORECTAL CANCER SCREENING PROGRAM}

Mark Diaz, Richard N Fedorak, Clarence KW Wong

Division of Gastroenterology, University of Alberta

Aim

Colonoscopy is currently the most effective screening method for the detection and prevention of colorectal cancer (CRC). Guidelines by the ASGE and GRS (Global Rating Scale) quality initiative describe colonoscopy specific quality indicators. Of these, proper documentation in procedure reports is essential to measure the quality of colonoscopy. In Canada, a standardized reporting format currently does not exist. We aim to evaluate the quality of colonoscopy procedure reports in a formalized colorectal cancer screening program.

\section{Method}

The SCOPE Colorectal Cancer Screening Program is an initiative based in Edmonton supported by Alberta Health Services and the University of Alberta. Its goal was to increase awareness and operationalize a population based CRC screening program. Through SCOPE, a sample of colonoscopies performed from MayAugust 2008 and February-June 2009 by experienced gastroenterologists at regional hospitals was reviewed. Expert gastroenterologists were supplied with a standardized procedure template, but reporting method varied between dictation and an endoscopic software-based system. Procedure reports were reviewed to verify the documentation of key quality indicators.

\section{Results}

525 colonoscopy procedure reports were reviewed. The overall cecal intubation rate for screening was $98.3 \%$ (516/525). Overall, only
$71.8 \% \quad(377 / 525)$ of reports included documentation of bowel preparation quality or described the extent of procedure visibility. Documentation of cecal landmarks was absent from $8.5 \% \quad(44 / 516)$ and use of photodocumentation to confirm cecal intubation was found in only $44.0 \%(227 / 516)$ of reports. When polyps were found, 25.9\% (56/216) of reports did not indicate polyp size. As well, the method of polypectomy was not stated in 10.5\% (22/209) of these cases. Documentation with endoscopy reporting software was used in $24.2 \%$ $(127 / 525)$ of colonoscopies. In comparison with dictation based reporting, cases using a softwarebased system increased cecal landmarks documentation from $90.7 \%$ to $93.7 \%$ (119/127), bowel prep quality from $69.8 \%$ to $77.8 \%$ (99/127) and photodocumentation from $26.2 \%$ to 98.4\% (125/127), respectively.

\section{Conclusion}

In a formalized, systematic CRC screening program, colonoscopy procedure reports were not reaching recommended guidelines for inclusion of quality indicators. Even with a standardized template, experienced gastroenterologists may still fail to include important quality indicators when dictating reports. The quality of reporting appeared to be higher for physicians utilizing dictation software. The application of software based or synoptic procedure reporting, with a standardized structure, may be the best method of optimizing colonoscopy documentation. 


\title{
Bmpr1bb IS A NOVEL GENE INVOLVED IN RETINOIC ACID INDUCED PATTERNING OF THE ZEBRAFISH HINDBRAIN
}

Braden D Teitge

Department of Biological Sciences, University of Alberta

Eureka

Volume 1, Number 1 (2010)

\begin{abstract}
Retinoic acid signalling plays a critical role during zebrafish development. The teratogenic effects of retinoic acid have been demonstrated by embryonic deformation resulting from insufficient or excessive levels of this vitamin A derivative. During embryogenesis, bone morphogenetic proteins are closely linked to the physiological interpretation of RA gradients, particularly in the hindbrain. We describe an uncharacterized gene, Bmpr1bb, as being significantly downregulated in response to retinoic acid treatment. In situ expression demonstrates that Bmpr1bb is expressed ubiquitously at $10 \mathrm{hpf}$, and is slowly downregulated until 48hpf where the expression is concentrated in the hindbrain. We propose that Bmpr1bb is a downstream target of RA signalling, strongly downregulated during embryogenesis and specified to a specific region of the hindbrain.
\end{abstract}

\section{Introduction}

Retinoic acid (RA) plays an important part in the development of pattern in the zebrafish hindbrain, a fact that has been appreciated since early studies of its teratogenic effects in vivo. RA also plays an important role in developing the anterior-posterior axis, inducing a combinatorial expression of Hox genes in the hindbrain (Kessel, Gruss 1991). Evidence for a RA gradient comes from studies demonstrating that excess of retinoic acid during embryogenesis disrupts development of the anterior hindbrain as a potent dorsalizing signal (Wilson et al. 2007), (Durston et al. 1989). RA deficiency also has teratogenic effects, most clearly demonstrated by vitamin A deficient animal models (White et al. 2000). Despite the importance of RA signalling in vertebrates, only a handful of genes are known to be involved in RA signalling (Duester 2008). To this end, we aimed to identify and characterize novel downstream targets of RA signalling in the vertebrate hindbrain. Based on RA/RA-antagonist microarray data, we hypothesize that we can identify and characterize a candidate gene that is part of a network of downstream targets responsive to RA levels.

Within the cell, RA levels are tightly controlled, being either degraded by CYP26 in nontarget tissues, or bound to retinoic acid receptor (RAR) - retinoid X receptor (RXR) heterodimers and functioning as nuclear receptors (Fig 1) (Mark,
Ghyselinck \& Chambon 2009, Abu-Abed et al. 2001, Sakai et al. 2001). RA signalling in the developing hindbrain is intimately related to its effects on Hox gene function. Several Hox genes are direct targets of RA, and contain retinoic acid response elements (RAREs) in their promoter regions (Simeone et al. 1990) (also see (Langston, Gudas 1994) and references therein). Only a few direct targets of RA signalling have been described: Hox1, a small number of transcription factors (HNF-3 $\alpha, C d x 1)$, and a number of genes directly involved in retinoid metabolism (CRABP1, CRABP2) (Balmer, Blomhoff 2002).

Patterning of the embryonic dorsoventral axis of vertebrates requires signalling through bone morphogenetic proteins (BMPs). BMP ligands BMP2 and BMP7 function as heterodimers, catalyzing the assembly of a quadripartite transmembrane serine-threonine kinase receptor complex consisting of two type I and two type II receptors. Once the receptors are complexed, a phosphorylation cascade activates BMP-responsive Smads1/5 which act as transcription factors eliciting the downstream response (Feng, Derynck 2005). BMP signalling in vertebrates is tightly linked to RA levels. Indeed, exogenous RA has been shown to directly downregulate BMPs (Thompson et al. 2003). Bone morphogenetic protein receptors (BMPRs) are also ideal gene candidates for RA signalling, based on evidence for RA-induced 


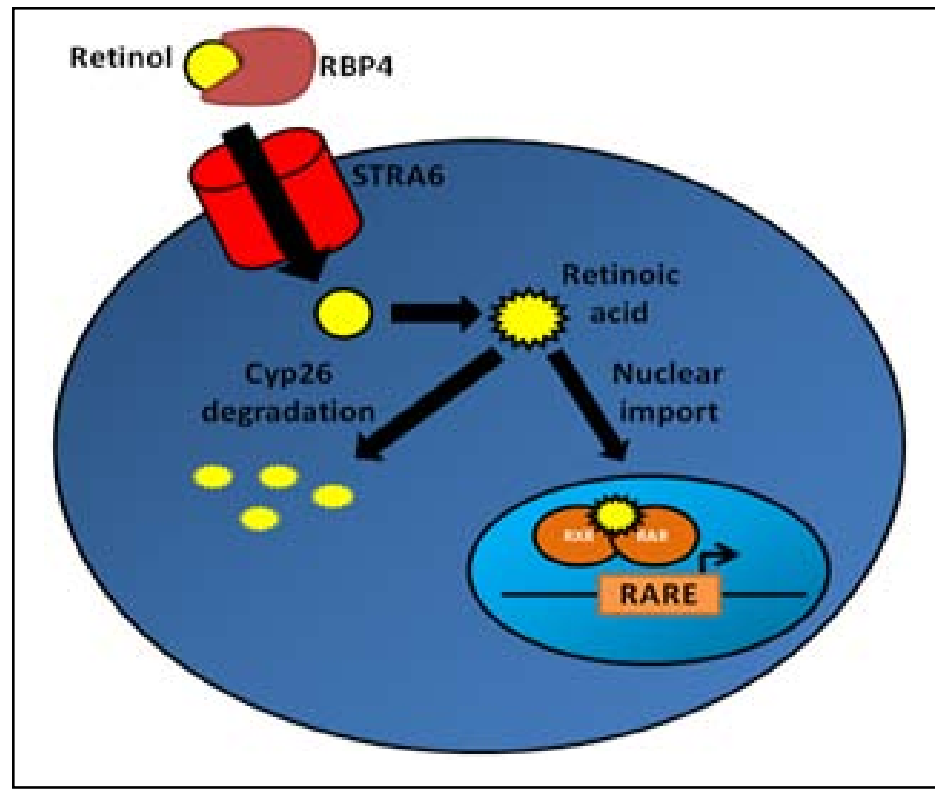

Figure 1. Schematic diagram of retinoic acid synthesis and signalling. Carried from the liver, retinol is bound by RBP4, and imported into the cell by the RA receptor STRA6. Inside the cell, RA is either A) degraded in non-target tissues by CYP26, or $\mathrm{B})$ transported into the nucleus and bound to RAR-RXR heterodimers. RXR-RAR proteins bind retinoic acid response elements, and either transcriptional activate or inhibit gene transcription through co-repressors or co-activators. Based off of Duester, 2008.

BMPR signalling (Wan et al. 2006), and regulatory interpretation of RA gradients (Norlin et al. 2001). In order to elucidate RA target genes, Feng et al used a microarray-based approach to identify genes whose expression differed under RA treatment and RA inhibition (Feng et al. 2009). They describe Dhrs3a as a regulator of RA biosynthesis but the vast majority were uncharacterized. From this data set we selected Bmpr1bb as a candidate gene for interpretation of RA signalling. We hypothesize that $B m p r 1 b b$ is a candidate gene for direct response to the RA level in the developing zebrafish hindbrain. The developmental expression of Bmpr1bb was analyzed using Northern blotting and quantitative PCR (qPCR), and found to be significantly upregulated from the $50 \%$ epiboly to the $12 \mathrm{hpf}$ stage in addition to being strongly downregulated by RA. In situ expression analysis confirmed these results, demonstrating a ubiquitous expression of Bmpr1bb at the 10hpf stage, and a dynamic regulation specifying it to the hindbrain at 48hpf. These results suggest that $B m p r 1 b b$ is a good candidate for interpreting the RA-gradients present during zebrafish development.

\section{Results}

\section{Gene selection}

A microarray of zebrafish cDNA identified several hundred genes whose expression was significantly altered by RA, a RA antagonist, or both(Feng et al. 2009). From this data set, we chose Bmpr1bb (probe set ID: Dr.8289.1.S1_at) as a candidate gene involved in the RA response in the zebrafish hindbrain; Bmpr1bb is highly downregulated upon RA treatment, and upregulated upon treatment with a RA antagonist (control:1.0, RA fold change:0.5, RA-antagonist:1.3). Additional BMPs were identified by the microarray (Bmp2b, Bmper, Bmp7a), providing further evidence that RA may play an important role in the regulation of BMPs.

\section{Validation of the Bmpr1bb transcript}

The reported cloning of Bmpr $1 b b$ has recently been described, but with little other information reported (Little, Mullins 2009). Bmpr1bb is a 1994bp mRNA transcript, but the full transcript is likely longer than this because the 3' UTR is unknown (NCBI Gene ID: 100149664). Given the incomplete nature of this gene, it was necessary to validate the transcript. The duplicate co-ortholog Bmpr1b shares $81 \%$ homology with Bmpr1bb, and given that Bmpr $1 b b$ has been predicted from a single contig we treated the sequence with scepticism. Only 634bp have been mapped to a contig, with a significant portion of the 5' UTR not present (Fig 2). This 5' fragment of the gene maps to the distal tip of chromosome 10 whereas Bmpr1b is on chromosome 5, supporting the distinction of these two transcripts. There are 


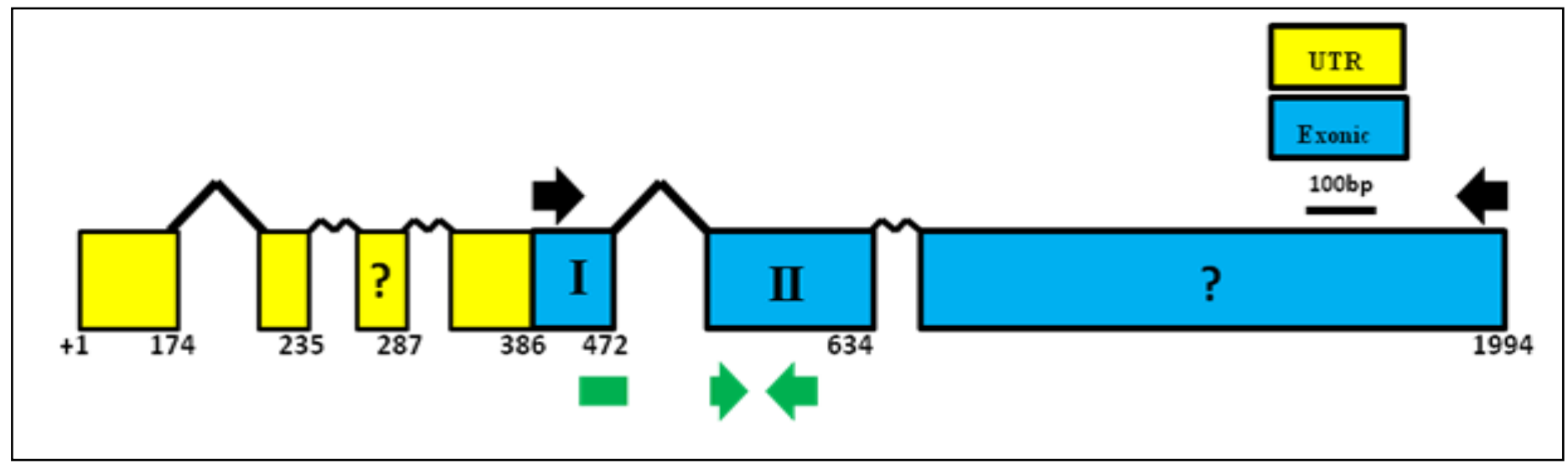

Figure 2. The Bmpr1bb gene has largely been constructed from a single contig (NW001882198.1) that is not annotated on the zebrafish genome. A blast analysis of the contig maps to the distal tip of chromosome 10 . Prediction for the gene is from conserved homologues in other species. The UTR region from 236-287bp is not mapped and has likely been lost in zebrafish. Similarly, the majority of exonic sequence is not mapped in the genome, as it lies outside the contig. The 3'UTR is unknown, and the Bmpr1bb mRNA transcript is expected to be longer than 1994bp. Primer sites used to amplify the open reading frame are shown in black, and for the qPCR analysis in green.

two known splice sites in Bmpr1bb, joining exons 1 and 2 in the 5'UTR, and exons 2 and 3 in the ORF. The gene is not annotated to a genomic location, and there are no known splice junctions after the third exon. Much of the gene prediction came from conserved homologous sequences, only some of which map to the single contig. There are no known expressed sequence tags for this gene, which is likely due to the incomplete nature of the transcript and high degree of homology with Bmpr1b, confusing the large-scale bioinformatics approach. The coding DNA sequence of Bmpr1bb specifies a 535AA protein with a membrane targeting signal, and a single predicted transmembrane domain (Fig 3). Through functional domain prediction, we support that Bmpr1bb is a type I BMP-receptor, because of the conserved QS motif (Fig 3). The Bmpr1bb protein is highly conserved, and contains a number of key functional domains that support its designation as a type I BMPR (Fig 4). Surprisingly, the membrane targeting sequence is not present in the human homolog, and the activin receptor domain is divergent. Bmpr1bb was successfully cloned using full length ORF primers (see Fig 2), and sequencing verified that $B m p r 1 b b$ is indeed a real transcript distinct from Bmpr1b.

\section{Northern blotting of Bmpr1bb expression}

In order to determine the presence of alternative transcripts, the length of the Bmpr1bb 3' UTR, and the developmental expression of the gene, we first performed a Northern blot on various stages of zebrafish development. As seen in Fig 5, Bmpr1bb was detected at $2700 \mathrm{bp}$, suggesting that this gene might have a long 3’UTR ( 700bp). Bmpr1bb was detected at 50\% epiboly, 10hpf, 24hpf, and at the adult developmental stage. No Bmpr1bb expression was detected at 10hpf with RA treatment, consistent with the microarray data suggesting its downregulation in the presence of RA. The Northern blot did not reveal the presence of alternative splicing, but did demonstrate a possible dynamic developmental regulation of $B m p r 1 b b$. To investigate this further with a finer measure of expression, we therefore performed a qPCR analysis. 


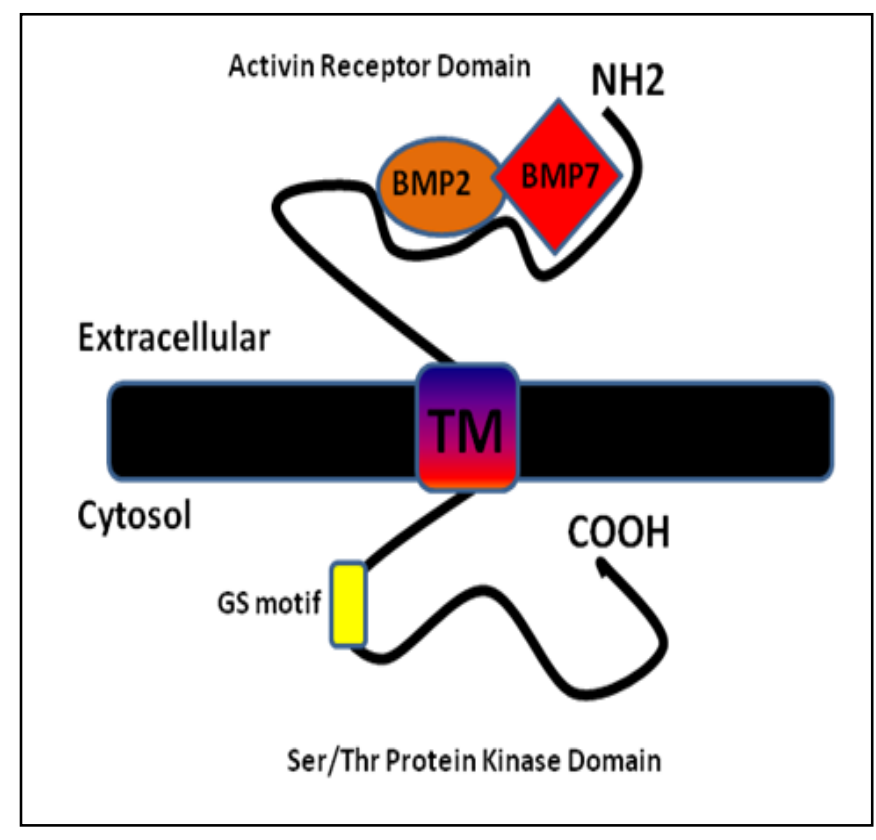

\section{Quantitative PCR}

To complement the Northern blot results, we next analyzed the expression of Bmpr1bb over several developmental stages to establish how expression of this gene might be regulated during embryogenesis. As shown in Fig 6a, Bmpr1bb has a low expression at the $50 \%$ epiboly stage, increasing to a maximum at $12 \mathrm{hpf}$. The expression slowly decreases throughout the remainder of the developmental stages analyzed (24hpf, 48hpf). We next compared Bmpr1bb with and without the addition of RA (Fig 6B). Bmpr1bb expression is significantly reduced upon RA treatment, which is consistent with the Northern blot results and the microarray data. These three pieces of evidence strongly suggest that Bmpr1bb is downregulated in response to RA. To verify the results in vivo, we next analyzed Bmpr1bb expression with an in situ hybridization.

\section{Bmpr1bb is expressed ubiquitously and then specified to the hindbrain}

The results reported thus far have established that Bmpr $1 b b$ is expressed maximally at $10 \mathrm{hpf}$, and is further downregulated as development continues (18hpf, 24hpf, 48hpf). The control in situ probe, Vhnf1, is expressed at the rhombomere 4/5 boundary, and is expanded along the AP axis upon RA treatment (Hernandez et al. 2004). We confirmed these results, affirming that our RA
Figure 3. Proposed model for the Bmpr1bb protein. Transmembrane topology prediction supports a model with a membrane targeting sequence (AA 13-32) and a single transmembrane domain. This model places the conserved activin receptor domain extracellular, and the Ser/Thr kinase domain intracellular. A GS motif is the phosphorylation target for the BMPR type II receptor, specifying an active state to the protein. A BMP2-BMP7 heterodimer binds to Bmpr1bb, activating the intracellular phosphorylation cascade. Domain prediction was made with InterProScan, and membrane topology prediction with TMHMMv2.0.

treatment was successful (Fig 7A, B). We have here within described the RA-induced downregulation of Bmpr1bb at the 12hpf stage, and consistent with the results from the microarray analysis, Northern blot and qPCR, Bmpr $1 b b$ is downregulated upon RA treatment (Fig 7C, D). Consistent with the developmental expression profile established by the qPCR data, Bmpr $1 b b$ expression decreases as the zebrafish develops: from a maximum expression at $10 \mathrm{hpf}$ to a minimal, restricted level at 48hpf (Fig 8A-D). Bmpr1bb maintains ubiquitous expression at $18 \mathrm{hpf}$, becoming restricted to the hindbrain region at 24hpf, and finally a distinct boundary in the hindbrain at 48hpf. These results suggest a dynamic regulation of Bmpr1bb during development, leading to a distinct expression in the hindbrain where Bmpr $1 b b$ signalling may be integral to pattern development.

\section{Discussion}

Approximately 600 genes have been shown to be RA-responsive at the 2-4 somite stage in zebrafish (Feng et al. 2009), and the vast majority of these are yet to be characterized. A number of these genes are regulated directly by RA-bound receptors, a classic example being the Hox genes (Langston, Gudas 1994). Both RA excess and deficiency can cause malformation in the embryo, so it is important to understand the regulation of RA on both upregulated and downregulated RA-responsive 


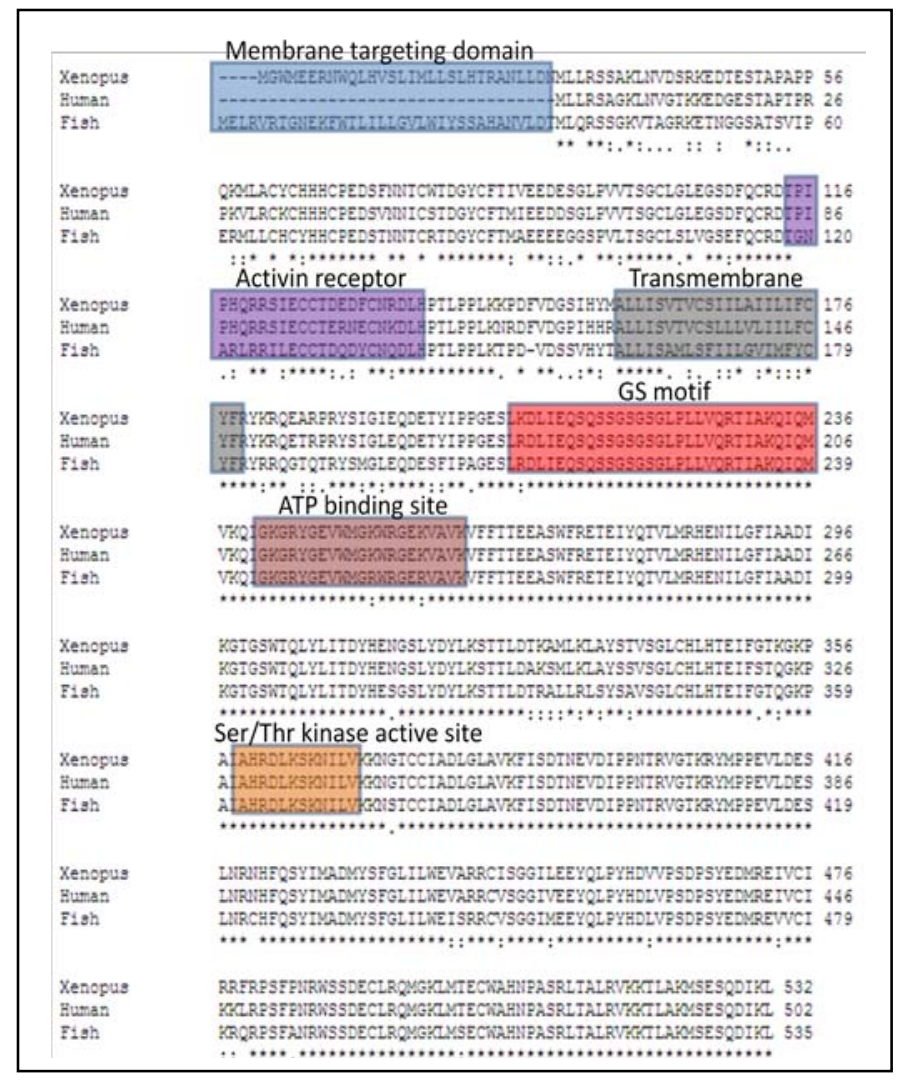

Figure 4. Sequence comparison of related Bmpr1b proteins demonstrates a high degree of conservation. A divergent $\mathrm{N}$ terminus does not appear to be in a functional domain based on protein topology prediction, and may be the membrane target sequence. “*” denotes an invariant AA,":" denotes conservative substitution “." denotes semiconservative substitution. Sequences were aligned with ClustalW2, and domains were predicted as described above. GeneID: Xenopus 780089, Human 658, Fish 100149664.

genes. The results described here suggest that Bmpr1bb is strongly downregulated by RA during early embryogenesis, and the dynamic expression observed over the remainder of developmental stages observed could be characteristic of a RAinduced downregulation. Further studies should include analyzing the expression of this gene at these developmental stages with the addition of excess RA and a RA-inhibitor.
Bmpr1bb shows a dynamic expression pattern during embryogenesis, yet the mechanism of this downregulation remains unresolved. Further characterization is needed at the molecular level to determine how RA has such a potent affect on several different BMPs, and how this regulation is variable in different tissues. RA induced downregulation of Bmpr1bb may be accomplished in a number of ways, the obvious way being transcriptional repression (RAR-RXR heterodimers with a co-repressor). Yet, RA is known to have unconventional affects on gene expression. A recent study demonstrated that RA bound RAR $\alpha$ is capable of direct translational repression (Poon, Chen 2008). Finally, the wide range of gene regulation induced by RA might occur through transrepression of other nuclear receptors (Gupta et al. 2008). Future studies would involve a close inspection of the promoter region for RARE. In addition to the transcriptional control and expression pattern of RA on Bmpr1bb, it may have an effect on the Bmpr1bb protein as well. RARRXR heterodimers can alter protein kinase activity (Alsayed et al. 2001), and RAR proteins have recently been reported in the cytosol and membranes of some cells, suggesting a new paradigm by which RARs could integrate cytoplasmic events (Masia et al. 2007). The molecular function of the Bmpr1bb protein remains undetermined. Bmpr1bb's high degree of homology with other type-I BMPRs suggests it is an effector kinase that activates SMADs $1 / 5$, and antibody immuno-stain for these activated kinases with and without RA is certainly a key question of interest.

A recent study showed that Bmpr $1 b b$ is involved in establishing the dorsoventral pattern in zebrafish, redundant with its duplicate coorthologue Bmpr1b. The authors established that the knockdown of Bmpr1b/Bmpr1bb, along with Bmpr1a, caused increasingly dorsalized phenotypes. (Little, Mullins 2009). Despite the functional redundancy proposed for zebrafish, slight differences in knockout phenotypes in mouse suggests that these genes might have evolved independent functions which are yet to be 

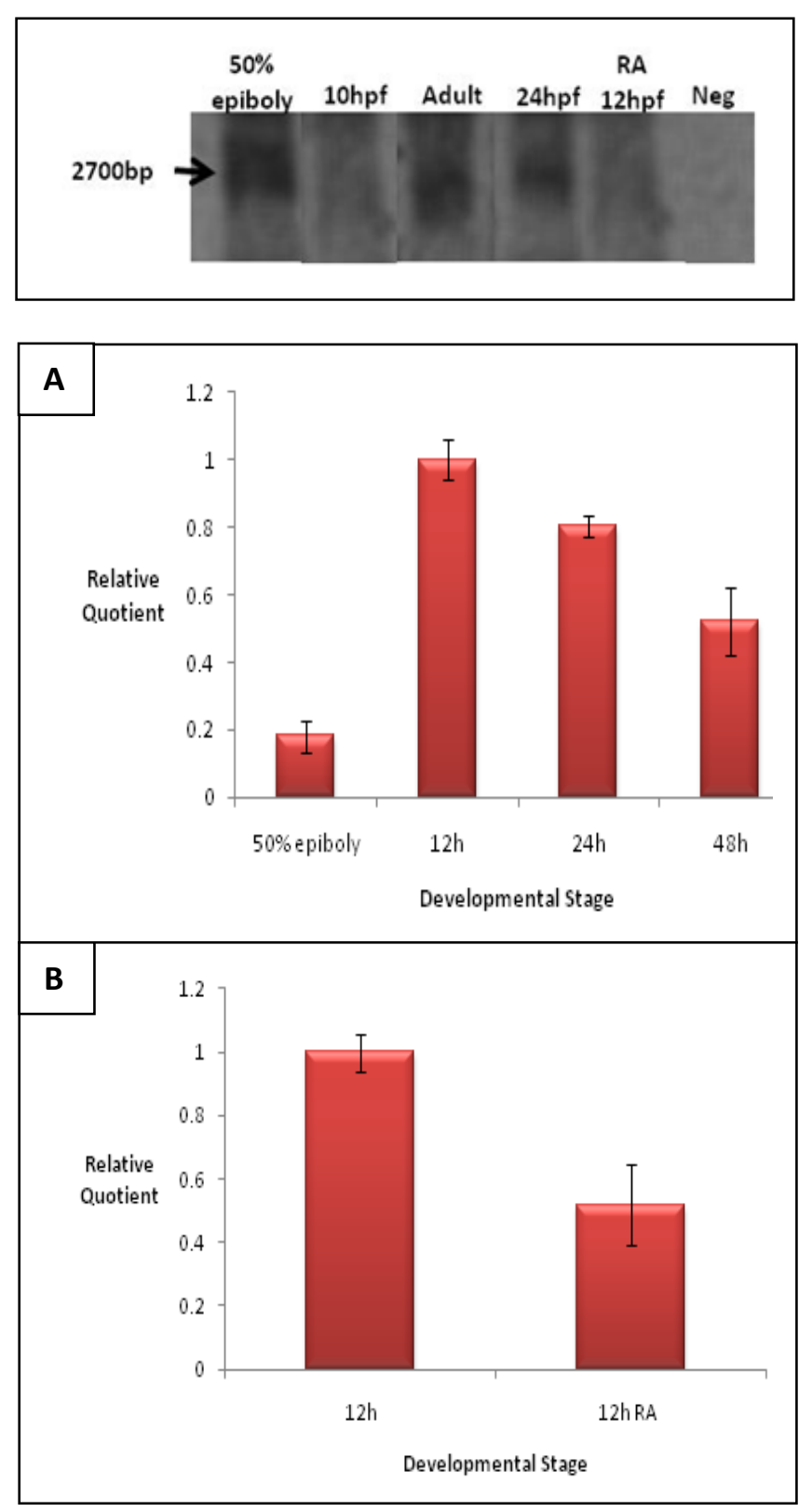

Figure 6A. Quantitative PCR of $b m p r 1 b b$ from a series of zebrafish developmental stages shows a peak expression at $12 \mathrm{hpf}$, slowly decreasing as development continues. 6B. Bmpr1bb expression at $12 \mathrm{hpf}$ relative to a retinoic acid treated embryo shows a marked RA-induced downregulation. The qPCR expression data was normalized to the odc control, and compared to the $12 \mathrm{hpf} \mathrm{RQ}$. The data was analyzed with a relative quotient, where the Bmppr1bb amplification was compared to the odc control at each timeframe, and then relative to 12hpf. Error bars show standard error of the mean.
Figure 5. Northern blot of Bmpr1bb from zebrafish developmental timeframes demonstrates a dynamic regulation of Bmpr1bb expression, and a large downregulation upon treatment with RA. Hybridization to the blot was performed overnight at $65^{\circ} \mathrm{C}$, and washed in $1 \% \mathrm{SSC}, 0.1 \% \mathrm{SDS}$ for 20 minutes (three times), and again with $0.3 \% \mathrm{SSC}$, $0.1 \%$ SDS for 20minutes (two times). The Kodak film was developed after 72 hours exposure at $-80^{\circ} \mathrm{C}$.

these proteins differ in their regulation, and only a close analysis of the Bmpr1a expression pattern will confirm this hypothesis. Our characterization of the RA-induced downregulation of Bmpr1bb suggests a possible regulatory divergence that could be investigated in other systems. Of note, a study by $\mathrm{Li}$ et al reported that RA induces the expression of Smad1 and Smad5 (Li et al. 2003). They shower that this was a BMPR specific process, but independent of Bmpr1a. These studies, along with the results described here, suggest that Bmpr1b/Bmpr1bb might be the BMPR responsive to RA levels in many different tissues.

\section{Materials and Methods}

\section{Cloning Bmpr1bb}

Total RNA was harvested from WT zebrafish at $11 \mathrm{hpf}$ using TRIZOL reagent and standard protocols. A first strand cDNA synthesis was performed from $5 \mu \mathrm{g}$ of total RNA, using an oligo dT primer and Superscript III Reverse Transcriptase (Invitrogen, CA) according to the manufacturers specifications. Bmpr1bb was amplified with Phusion polymerase (New England Biolabs, MA), using primers specific for the full length ORF (Bmpr1bbF: 5' ATGGAGCTCCGGGTACGGAC, Bmpr1bbR:

5' TCACAGTTTAATGTCCTGCGACAC) (also see Figure 2). The full length Bmpr1bb gene was cloned into the pGEX-GR expression plasmid using a blunt-ended EcoRV ligation, with the NTD fused to GST. PCR and sequencing confirmed the correct orientation of the gene and that it was in frame with the GST tag. 


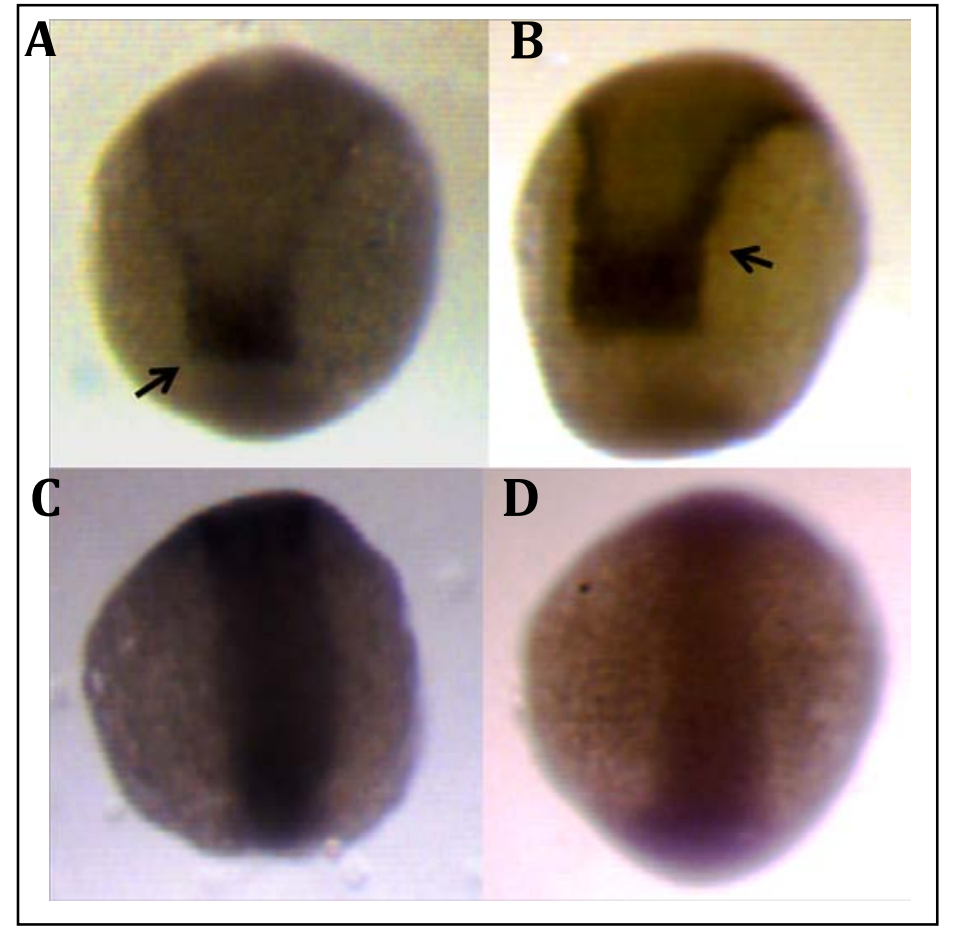

Figure 7. Whole-mount in situ hybridization of wild-type embryos at the 1-somite stage, untreated $(\mathbf{A}, \mathbf{C})$ or treated with RA $(\mathbf{B}, \mathbf{D})$. A. Vhnf1 is expressed at the r4/5 boundary at 10hpf. B. Vhnf1 expression is expanded along the AP axis upon treatment with RA. C. Bmpr1bb is expressed maternally and ubiquitously, and is consistently downregulated upon treatment with RA.

\section{Northern blot analysis of Bmpr1bb}

Fish lines were maintained under standard conditions at $28.5^{\circ} \mathrm{C}$ at the University of Alberta Fish Facility. RNA was extracted from WT whole fish embryos at specific developmental stages (50\% epiboly, 10hpf, 12hpf, 24hpf, 48hpf, adult, and $12 \mathrm{hpf}$ with $0.33 \mu \mathrm{M}$ RA treatment) using TRIZOL reagent standard protocols. $10 \mu \mathrm{g}$ total RNA was loaded for each stage, run on a 3\% formaldehyde $0.8 \%$ agarose gel before being transferred to GeneScreen Plus overnight. The RNA was then crosslinked to the membrane with a UV Stratalinker (120mJ, 30 seconds). The probe for Bmpr1bb was made from a full length linear fragment, digested out of the pGEX-GR vector with BamHI, and

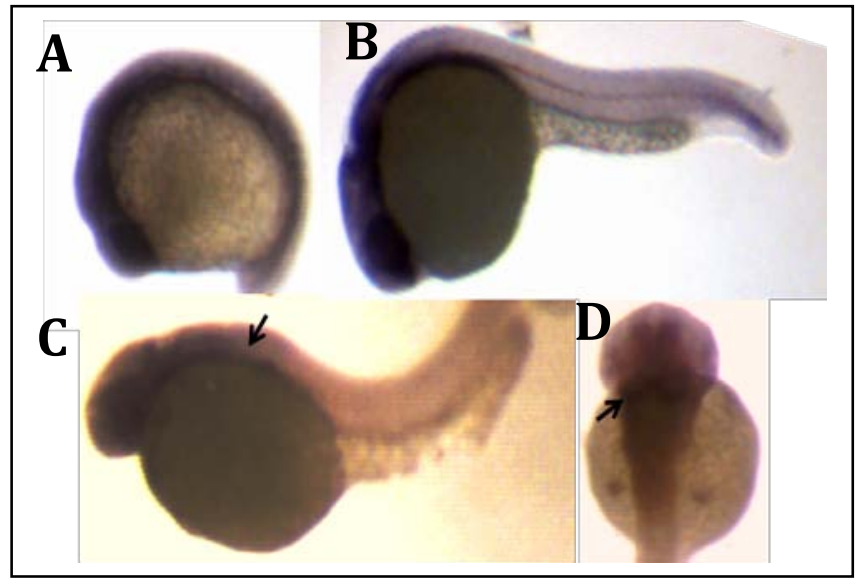

Figure 8. Whole-mount in situ hybridization of wild-type embryos, probed for Bmpr1bb. Bmpr1bb maintains ubiquitous expression at 18hpf (A), and only becomes more restricted at the 24hpf (B). At 24hpf, Bmpr1bb shows distinct expression in the eye and hindbrain, but is absent in the forebrain. At 48hpf, Bmpr1bb is further downregulated (C), but maintains a sharp expression in a distinct region of the hindbrain (D).

synthesized with $\alpha^{32} \mathrm{P}-\mathrm{dCTP}$ and Klenow by standard protocol. (Abu-Abed et al. 2001).

\section{Quantitative PCR of Bmpr1bb}

The qPCR was performed in triplicate on an ABI StepOne Real time cycler $\left(95^{\circ} \mathrm{C} 2\right.$ ', $95^{\circ} \mathrm{C} 15 \mathrm{~s}$, $\left.60{ }^{\circ} \mathrm{C} 1^{\prime}, 40 \mathrm{X}\right)$. A standard curve was created using a serial dilution of Bmpr $1 b b$ and ornithine decarboxylase (odc) constructs, to assess the PCR efficiency (Bmpr1bb F: 5' CCGCTCACGCGAACGT, Bmpr1bb R: 5' GACAGTGATGGTAACAGTGGCATAATA), also see Fig 2) (Odc F: 5' TGAACCTCCTTGGCTGTCTGA, Odc R: 5' TGCAAAAGAAACAGACGAATGG. Both efficiencies were $\sim 100 \%$ (data not shown), and odc was deemed an appropriate control. Products were visualized on a $2.0 \%$ agarose gel and a melting curve was performed to assure appropriate amplification. 


\section{In situ hybridization}

Whole mount in situ hybridization was performed essentially as described (Prince et al. 1998) with the following modifications: probes were not hydrolyzed, and various proteinase $\mathrm{K}$ $(10 \mu \mathrm{g} / \mathrm{mL})$ treatments were used. Proteinase K was used for 3min (18hpf), 5min (24hpf), and 10min (48hpf) and then fixed so the total treatment time was 30min. Probes were made from full length Vhnf1 and Bmpr1bb, and hybridized overnight at $65^{\circ} \mathrm{C}$. Anti-DIG antibody was used 1:5000 overnight at $4^{\circ} \mathrm{C}$, and then stained for 6 hours. Embryos were photographed with an Olympus stereoscope and a Qimaging micropublisher camera. Embryos were raised at $25^{\circ} \mathrm{C}$ and staged according to published hallmarks (Kimmel et al. 1995).

\section{Acknowledgements}

We are grateful to Dr. David Pilgrim, Gary Ritzel, and Danielle French-Kielley for assistance in conducting each experiment.

\section{References}

Abu-Abed, S., Dolle, P., Metzger, D., Beckett, B., Chambon, P. \& Petkovich, M. 2001, "The retinoic acidmetabolizing enzyme, CYP26A1, is essential for normal hindbrain patterning, vertebral identity, and development of posterior structures", Genes \& development, vol. 15, no. 2, pp. 226-240.

Alsayed, Y., Uddin, S., Mahmud, N., Lekmine, F., Kalvakolanu, D.V., Minucci, S., Bokoch, G. \& Platanias, L.C. 2001, "Activation of Rac1 and the p38 mitogenactivated protein kinase pathway in response to all-transretinoic acid", The Journal of biological chemistry, vol. 276, no. 6, pp. 4012-4019.

Balmer, J.E. \& Blomhoff, R. 2002, "Gene expression regulation by retinoic acid", Journal of lipid research, vol. 43, no. 11, pp. 1773-1808.

Duester, G. 2008, "Retinoic acid synthesis and signaling during early organogenesis", Cell, vol. 134, no. 6, pp. 921-931.

Durston, A.J., Timmermans, J.P., Hage, W.J., Hendriks, H.F., de Vries, N.J., Heideveld, M. \& Nieuwkoop, P.D. 1989, "Retinoic acid causes an anteroposterior transformation in the developing central nervous system", Nature, vol. 340, no. 6229, pp. 140-144.
Feng, L., Hernandez, R.E., Waxman, J.S., Yelon, D. \& Moens, C.B. 2009, "Dhrs3a Regulates Retinoic Acid Biosynthesis through a Feedback Inhibition Mechanism", Developmental biology, .

Feng, X.H. \& Derynck, R. 2005, "Specificity and versatility in tgf-beta signaling through Smads", Annual Review of Cell and Developmental Biology, vol. 21, pp. 659-693.

Gupta, P., Ho, P.C., Huq, M.M., Ha, S.G., Park, S.W., Khan, A.A., Tsai, N.P. \& Wei, L.N. 2008, "Retinoic acid-stimulated sequential phosphorylation, PML recruitment, and SUMOylation of nuclear receptor TR2 to suppress Oct4 expression", Proceedings of the National Academy of Sciences of the United States of America, vol. 105, no. 32, pp. 11424-11429.

Hernandez, R.E., Rikhof, H.A., Bachmann, R. \& Moens, C.B. 2004, "vhnf1 integrates global RA patterning and local FGF signals to direct posterior hindbrain development in zebrafish", Development (Cambridge, England), vol. 131, no. 18, pp. 4511-4520.

Kessel, M. \& Gruss, P. 1991, "Homeotic transformations of murine vertebrae and concomitant alteration of Hox codes induced by retinoic acid", Cell, vol. 67, no. 1, pp. 89-104.

Kimmel, C.B., Ballard, W.W., Kimmel, S.R., Ullmann, B. \& Schilling, T.F. 1995, "Stages of embryonic development of the zebrafish", Developmental dynamics: an official publication of the American Association of Anatomists, vol. 203, no. 3, pp. 253-310.

Langston, A.W. \& Gudas, L.J. 1994, "Retinoic acid and homeobox gene regulation", Current opinion in genetics \& development, vol. 4, no. 4, pp. 550-555.

Li, X., Schwarz, E.M., Zuscik, M.J., Rosier, R.N., Ionescu, A.M., Puzas, J.E., Drissi, H., Sheu, T.J. \& O'Keefe, R.J. 2003, "Retinoic acid stimulates chondrocyte differentiation and enhances bone morphogenetic protein effects through induction of Smad1 and Smad5", Endocrinology, vol. 144, no. 6, pp. 2514-2523.

Little, S.C. \& Mullins, M.C. 2009, "Bone morphogenetic protein heterodimers assemble heteromeric type I receptor complexes to pattern the dorsoventral axis", Nature cell biology, vol. 11, no. 5, pp. 637-643.

Mark, M., Ghyselinck, N.B. \& Chambon, P. 2009, "Function of retinoic acid receptors during embryonic 
development", Nuclear receptor signaling, vol. 7, pp. e002.

Masia, S., Alvarez, S., de Lera, A.R. \& Barettino, D. 2007, "Rapid, nongenomic actions of retinoic acid on phosphatidylinositol-3-kinase signaling pathway mediated by the retinoic acid receptor", Molecular endocrinology (Baltimore, Md.), vol. 21, no. 10, pp. 2391-2402.

Norlin, E.M., Alenius, M., Gussing, F., Hagglund, M., Vedin, V. \& Bohm, S. 2001, "Evidence for gradients of gene expression correlating with zonal topography of the olfactory sensory map", Molecular and cellular neurosciences, vol. 18, no. 3, pp. 283-295.

Poon, M.M. \& Chen, L. 2008, "Retinoic acid-gated sequence-specific translational control by RARalpha", Proceedings of the National Academy of Sciences of the United States of America, vol. 105, no. 51, pp. 2030320308.

Prince, V.E., Moens, C.B., Kimmel, C.B. \& Ho, R.K. 1998, "Zebrafish hox genes: expression in the hindbrain region of wild-type and mutants of the segmentation gene, valentino", Development (Cambridge, England), vol. 125, no. 3, pp. 393-406.

Sakai, Y., Meno, C., Fujii, H., Nishino, J., Shiratori, H., Saijoh, Y., Rossant, J. \& Hamada, H. 2001, "The retinoic acid-inactivating enzyme CYP26 is essential for establishing an uneven distribution of retinoic acid along the anterio-posterior axis within the mouse embryo", Genes \& development, vol. 15, no. 2, pp. 213-225.
Simeone, A., Acampora, D., Arcioni, L., Andrews, P.W., Boncinelli, E. \& Mavilio, F. 1990, "Sequential activation of HOX2 homeobox genes by retinoic acid in human embryonal carcinoma cells", Nature, vol. 346, no. 6286, pp. 763-766.

Thompson, D.L., Gerlach-Bank, L.M., Barald, K.F. \& Koenig, R.J. 2003, "Retinoic acid repression of bone morphogenetic protein 4 in inner ear development", Molecular and cellular biology, vol. 23, no. 7, pp. 22772286.

Wan, D.C., Shi, Y.Y., Nacamuli, R.P., Quarto, N., Lyons, K.M. \& Longaker, M.T. 2006, "Osteogenic differentiation of mouse adipose-derived adult stromal cells requires retinoic acid and bone morphogenetic protein receptor type IB signaling", Proceedings of the National Academy of Sciences of the United States of America, vol. 103, no. 33, pp. 12335-12340.

White, J.C., Highland, M., Kaiser, M. \& Clagett-Dame, M. 2000, "Vitamin A deficiency results in the dosedependent acquisition of anterior character and shortening of the caudal hindbrain of the rat embryo", Developmental biology, vol. 220, no. 2, pp. 263-284.

Wilson, L.J., Myat, A., Sharma, A., Maden, M. \& Wingate, R.J. 2007, "Retinoic acid is a potential dorsalising signal in the late embryonic chick hindbrain", BMC developmental biology, vol. 7, pp. 138. 
IMMOBILIZED ARTIFICIAL MEMBRANE (IAM) LIQUID CHROMATOGRAPHY AS A MODEL FOR ANTIMICROBIAL PEPTIDE PARTITIONING INTO CELL MEMBRANES: AN EVALUATION

Matthew G K Benesch, Ruthven N. A. H. Lewis, Ronald N. McElhaney

Department of Chemistry, University of Alberta
Eureka

Volume 1, Number 1 (2010)

\begin{abstract}
Non-covalent immobilized artificial membrane reverse-phase high performance liquid chromatography was previously evaluated as a means whereby elution times for antimicrobial peptides from columns mimicking the lipid bilayers of different membrane systems might be used as a fast-screening method to compare relative binding effectiveness. Such a system would aid in the development of antimicrobial peptides that bind preferentially to model pathogenic systems and leave the host's membranes reasonably unaffected. A non-covalent approach allows for flexibility in membrane composition but was found to be inadequate for analysis of most peptides due to significant lipid loss at high acetonitrile concentrations. A covalent approach where phosphatidylcholine was amide-linked to the silica surface was examined to evaluate its use as a fast-screening method and compare its data to that collected from the non-covalent columns. Initial work with a 1-cm column proved ineffective due to problems with balancing flow rates with retention times, and work was shifted to a longer $10-\mathrm{cm}$ column. Results suggested that peptides bind much more strongly to covalent columns than non-covalent ones, with the binding especially enhanced by the presence of cationic residues. These columns had lipid packing densities much lower than true membranes, indicating that the peptides were partitioning deep into the bonded phase of the columns rather than into the interfacial region of the phosphate head groups, as expected in situations of biologicallyrelevant lipid packing densities.
\end{abstract}

\section{Introduction}

The ability of antimicrobial peptides (AMPs) to partition into the phospholipid bilayers of cell membranes is a key factor in determining their overall biological activity (Brogden, 2005). In addition to displaying antimicrobial activity, these peptides display anticancer, antifungal, antimalarial (Apponyi, Pukala, Brinkworth, Masselli, Bowie, Tyler, Booker, et al., 2004), and even antiviral characteristics, including against the HIV virus (Lorin, Saidi, Belaid, Zairi, Baleux, Hocini, Belec, et al., 2005). Major public health concerns of today include the emergence of pathogenic bacteria having resistance to conventional antibiotics. As a result, there is significant research into novel alternatives to such treatments, one of them being antimicrobial peptides (Jiang, Vasil, Hale, Hancock, Vasil, \& Hodges, 2008). These peptides are particularly attractive because they are usually part of the innate immune response of higher organisms and appear to act by degrading the barrier properties of cell membranes, leading to cytoplasmic leakage and ultimately death (Prenner, Kiricsi, Jelokhani-Niaraki, Lewis, Hodges, \& McElhaney, 2005). The mode of action of AMPs via membrane disruption also poses a problem in their tendency to promote hemolysis (Jiang et al., 2008; Prenner et al., 2005). Hence, these peptides need to have their lipid specificity tuned in order to maximize their therapeutic value by increasing their antimicrobial activity and particularly by reducing their hemolytic activity. To gauge the effectiveness of AMPs, they are often introduced into a bacterial culture and the minimal inhibitory concentrations and $\mathrm{LD}_{50}$ values are determined (Prenner et al., 2005). However, an easy way of measuring the therapeutic index (preference for bacterial versus animal membranes) is required before these peptides are ready for animal trials and further drug development. 
What is needed to study AMP activity is a fast-screening method that simulates in vitro the partitioning process of AMPs into the phospholipid bilayers of cell membranes (Fig. 1A). One option is to correlate reverse-phase high-performance liquid chromatography (RPHPLC) retention times to AMP membrane activity. However, this technique represents only the hydrophobic component of the partitioning process. Other studies have shown that RPHPLC relates poorly to biological assays such as drug-intestinal absorption, but the correlation is much improved with use of phospholipids as a bonded phase (Pidgeon, Ong, Liu, Qiu, Pidgeon, Dantzig, Munroe, et al., 1995). Phospholipids are amphipathic molecules, meaning that their interactions with amphipathic AMPs are also influenced by interactions with the lipid glycerol backbone and polar head groups, as well as with the non-polar hydrocarbon chains.

Non-covalent immobilized artificial membrane (NC-IAM) RP-HPLC was previously evaluated in our laboratory to determine whether elution of AMPs from columns mimicking different membrane systems could be used to compare relative binding effectiveness. Such a technique could aid in the development of AMPs that bind relatively strongly to systems resembling pathogens while leaving the host's cell membranes reasonably unaffected. These columns were prepared by passing solutions containing the lipid(s) of interest through the columns and allowing monolayers to form. The main advantage of NC-IAM RP-HPLC is that it is easy to change the lipid composition of these columns. By not covalently linking lipids, a single column may be used to gather retention times from numerous lipid systems. The absence of covalent linkages ensures that the lipids are free to laterally diffuse as they would in a real membrane. Results indicated that retention times increased with increasing membrane fluidity, but for peptides that elute with less than thirty percent acetonitrile (B), the times were always less than for a control column without a lipid monolayer. Further, the monolayers became unstable beyond forty percent $B$, resulting in significant lipid loss over sequential runs. This suggested that NC-IAMs were not suitable for analysis of either high molecular weight $(>1000$ $\mathrm{Da})$ or highly lipophilic peptides. Also, for peptides that could be eluted beyond $40 \% \mathrm{~B}$, retention times were slightly greater than those on the control column. A plausible explanation is discussed by Qiu and Pidgeon (1993). As Fig 1B shows, at high \%B, the eluent becomes sufficiently non-polar and the head groups aggregate to exclude the solvent while maximizing the solvation of their non-polar chains. As a result, after a peptide partitions into the interfacial region, the head groups effectively shield the peptide from exposure to the eluent. A direct consequence of this is that the solvent system must become disproportionably non-polar in order to elute the peptide. This suggests that at high \%B the elution time for these lipid columns may not accurately reflect relative retention behaviours on comparison to low \%B-eluting peptides.

The limitations presented by NC-IAM RP-HPLC lead to an evaluation of a covalent approach where phosphatidylcholine (PC) was amide-linked to the silica surface (Fig. 1C). This column system was designed by Charles Pidgeon and commercialized by Regis Technologies of Morton Grove, IL, USA (Pidgeon et al., 1995). The inability for PC to lateral diffuse as in a real membrane and on a NC-IAM was proposed to not be a problem, as other researchers have demonstrated that most of the interaction with these ligands occurs at the head group-backbone boundary (Ong, Liu, Qiu, Bhat, \& Pidgeon, 1995). Further, conformational freedom provided by the glycerol backbone, and in particular the head group region, makes the motional characteristics of the PC head groups the same whether or not the PC is immobilized (Qiu \& Pidgeon, 1993). Hence, retention times for AMPs on the PC covalent column were studied with the expectation that retention times would mirror those obtained from the noncovalent PC column. 
A

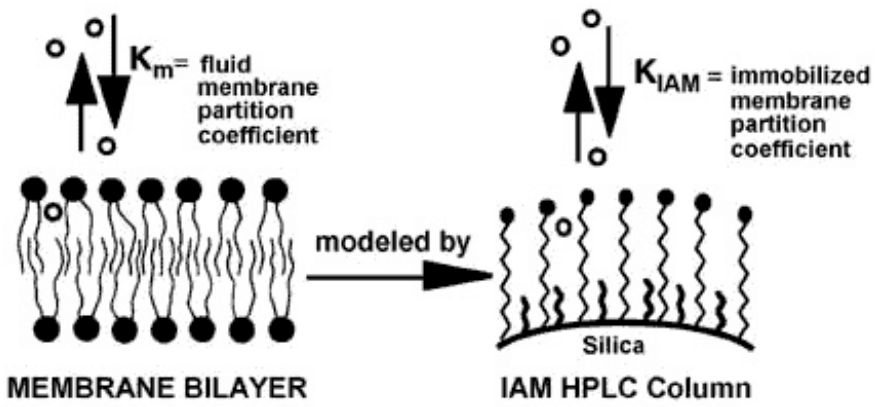

C

B

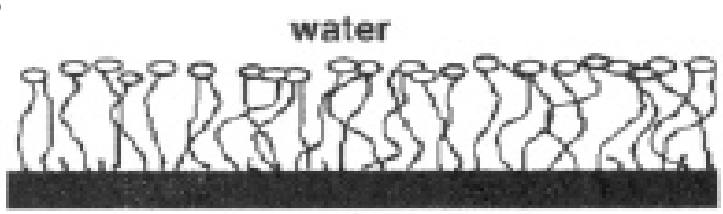

less polar solvent
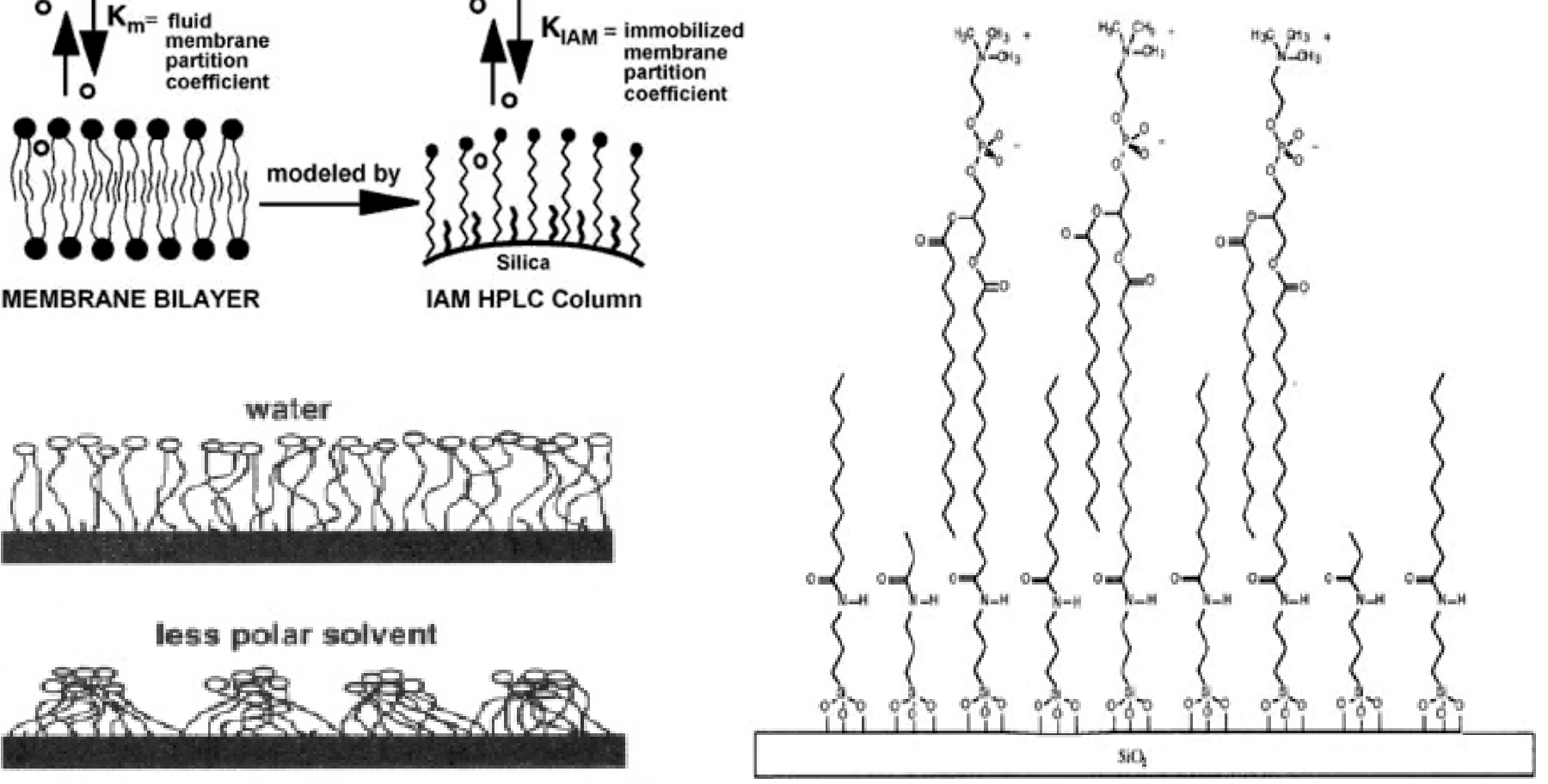

D

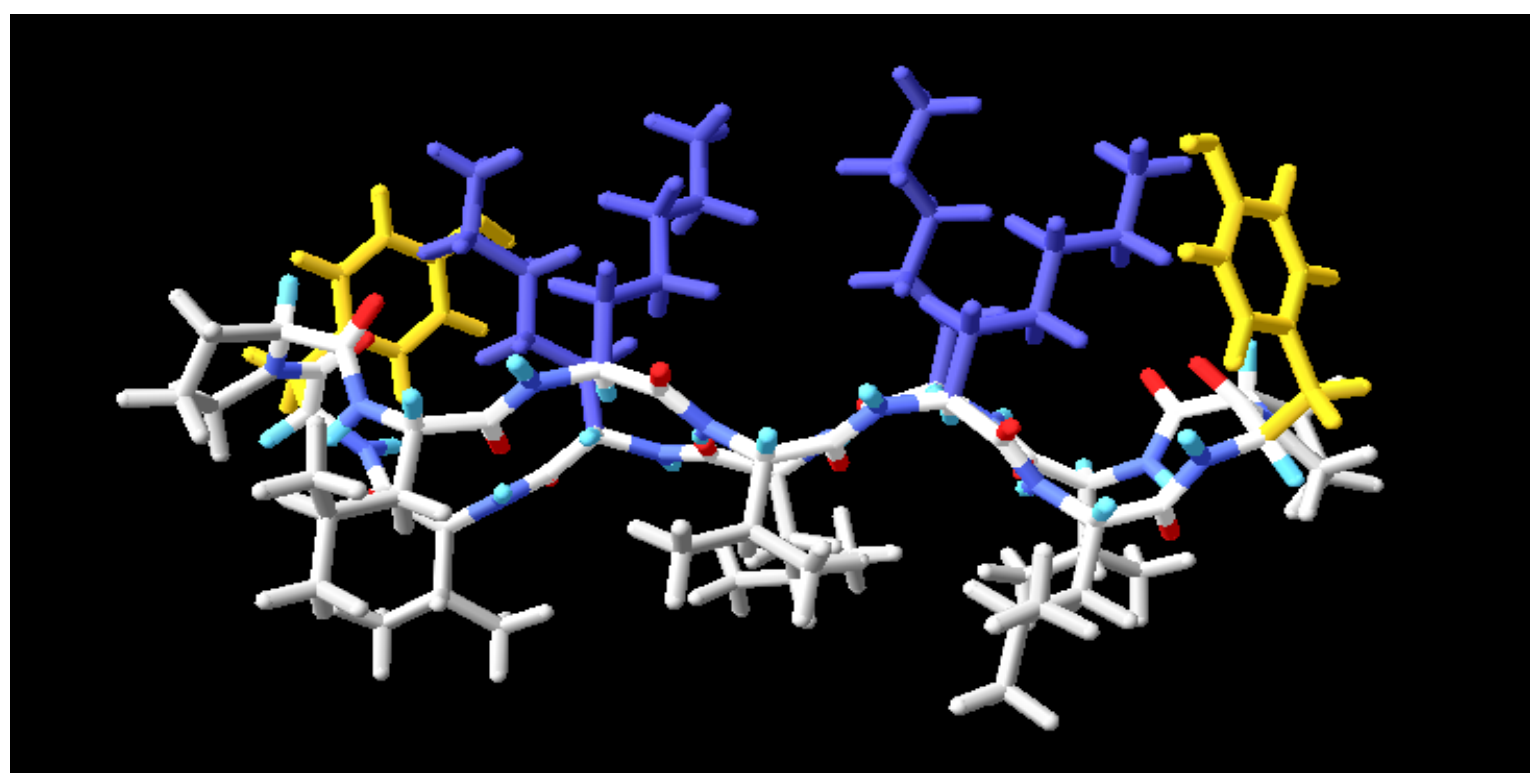

FIGURE 1: Overview of IAM Chromatography. A: The partitioning of a ligand, like a peptide, into a real biological membrane is mimicked by an IAM HPLC column. B: Effects of high concentrations of non-polar solvents (B) on artificial membranes. If a peptide has not eluted at low \% B, the head groups aggregate to maximize the exposure of their non-polar chains to the solvent. As a result, after a peptide partitions into the interfacial region, the head groups shield the peptide, meaning that the solvent system must become disproportionably non-polar in order to elute the peptide. C: Structure of the IAM.PC.DD.2 column. Phosphatidylcholine is amide linked to the silica surface, and unreacted propyl-amine groups are first C10 end-capped and then C3 end-capped. D: Model of GS 14dk4. Positively charged (lysine) residues are in blue, polar residues in yellow, hydrophobic residues in white, and the main chain is coloured CPK. The peptide has a clear hydrophilic side and a hydrophobic side. 


\section{Experimental Procedures}

The AMPs used in this investigation were synthesized by the Alberta Peptide Institute (University of Alberta, Edmonton, Canada) and Dr. R.S. Hodges (University of Colorado, CO, USA) by solid-phase techniques using Fmoc chemistry, and were shown to be $>95 \%$ pure by HPLC and mass spectrometry. Peptides were dissolved in methanol at $1 \mathrm{mg} / \mathrm{mL}$ concentration. All solvents were of HPLC grade. In particular, four peptides were investigated: Gramicidin (GS) 4 [cyclo- $(d \mathrm{YP} d \mathrm{YP})$ ], GS 6 [cyclo- $(d \mathrm{YPK} d \mathrm{YPK})$ ], GS 14-dK4-V1A-L3A-V5A-L8A-V-10A-L12A (GS A) [cyclo-(AKAdKAdYPAKAKAdYP)], and GS 14dk4 [cyclo(VKLdKVdYPLKVKLdYP)] (Fig.1D). The GS14 family is a ring-expanded analog of Gramicidin S, [cyclo-(VOLdFPVOLdFP)], a cyclic 10 amino acid peptide derivative of gramicidin, produced by the Gram-positive bacteria Bacillus Brevis. As Fig. 1D shows, a common structural motif of these peptides is the presence of charged residues on one side of the peptide and hydrophobic residues on the other, with $d$-tyrosine and proline residues forming the corners.

An IAM Fast-Screen Mini Column Kit was obtained from Regis Technologies (Morton Grove, IL, USA) containing a $1 \mathrm{~cm}$ x $3 \mathrm{~mm}$ inner diameter (i.d.), $10 \mu \mathrm{m}, 300 \AA$ IAM.PC.DD.2packed column (Fig. 1C), as well as a $10 \mathrm{~cm} \mathrm{x}$ $4.6 \mathrm{~mm}$ i.d. version of the same column. Columns were cleaned of lipophilic residue by eluting $100 \%$ acetonitrile at $1 \mathrm{~mL} / \mathrm{min}$ and $25^{\circ} \mathrm{C}$ and then equilibrated in various $\mathrm{pH} 6.5$ phosphate buffers (A) under the same conditions using a Hewlett Packard Agilent 1100 Series chromatograph (Waldbronn, Germany) and/or a Millipore Waters 600E System Control chromatograph with a Millipore Waters LambdaMac Model 401 LC Spectrophotometer (Milform, MA, USA). Peptides were injected on the column as $20 \mu \mathrm{L}$ samples and eluted using either a $0-100 \%$ B (5 mM sodium phosphate $\mathrm{pH} 6.5$ $60 \% / 40 \%$ acetonitrile/water) 0 -36 min gradient; 0-100\% B (30 mM ammonium phosphate pH 6.5
$60 \% / 40 \%$ acetonitrile/water) 0 -36 min gradient; 0-100\% B (10 mM sodium phosphate pH 6.5 $50 \% / 50 \%$ acetonitrile/water) $0-30 \mathrm{~min}$ gradient with $0 \%, 1 \%, 2 \%$, or $5 \% \mathrm{v} / \mathrm{v}$ glycerol; or a 0 100\% B (unbuffered acetonitrile) 0-60 min gradient. Due to its greater solubility, ammonium phosphate was used in place of sodium phosphate for preparing solvents with higher ionic strength. The elution was monitored by charting absorbance readings at $210 \mathrm{~nm}$, and this data was analyzed and presented using the Origin software package (Microcal Software Inc., Northampton, MA, USA).

\section{Results}

Initial work with the 1-cm IAM.PC.DD2 mini-column proved ineffective due to problems balancing flow rates with retention times. Normal flow rates for these columns, according to the manufacturer's use guide, are $0.2-0.5 \mathrm{~mL} / \mathrm{min}$. However, the peptides studied would not elute in reasonable times at these rates. Elutions did occur when the flow rate was increased to 1 $\mathrm{mL} / \mathrm{min}$, but samples often appeared to elute as a non-reproducible series of aggregates or the signal from the peptide was lost in the fluctuations of the baseline due to uneven back pressure. As Fig. 2 shows, the signal for GS $14 \mathrm{dk} 4$, if present, is indistinguishable from the baseline. To rule out the possibility that the nonrepeatable aggregate behaviour with multiple peaks appearing at greater than $40 \%$ acetonitrile concentrations might be due to interaction of the peptide with the silica base, the column was overloaded with Gramicidin S, one of the most hydrophobic peptides in our lab, eluting at 58\% acetonitrile on the control column (data not shown), then equilibrated in phosphate buffer. Retention times though did not change (data not shown). Hence, the idea that reducing the column length from 15-cm (the length of the column used in previous NC-IAM studies) to $1-\mathrm{cm}$ could be compensated by reducing the flow rate was shown to be invalid.

Further work proceeded with the $10-\mathrm{cm}$ IAM.PC.DD.2 column and problems with the 
uneven back pressure and noisy baselines were eliminated. However, for all peptides studied, regardless of secondary structure or amino acid composition, retention times were significantly increased compared to the NC-IAM columns with or without phospholipid (1-palmitoyl-2oleoyl-phosphatidylcholine - POPC), as seen in Table 1. Peptides in the GS 14dk4 family would not elute in either unbuffered or 5-mM sodium phosphate solutions, unlike the NC-IAM columns. Fig. 3 shows chromatograms for GS A. GS A has the same structure as GS 14dk4 except that all of the hydrophobic amino acids have been replaced with alanine, making it the least hydrophobic peptide in the GS $14 \mathrm{dk} 4$ family. However, the peptide would not elute unless the eluent contained salt in the order of $30 \mathrm{mM}$ concentration. Hence, the study of peptide interactions on this column became limited to GS 4, a hydrophobic tetrapeptide modeling the corners of GS $14 \mathrm{dk} 4$, and GS 6, a hexapeptide with two lysine residues inserted into the GS 4 sequence, modeling the cationic face of the GS 14dk4 family.

Fig. 4 compares retention times between the NC-IAM column and the covalent column for GS 4. Consistent with low \%B eluting peptides, GS 4 elutes more quickly on the POPC NC-IAM relative to the same column without lipid, but is retained more strongly on the covalent column. The presence of $5 \mathrm{mM}$ sodium phosphate in the eluent only slightly decreases the retention time compared to the unbuffered run, but this is starkly contrasted by GS 6 in Fig. 5. Unbuffered, GS 6 elutes at $78.5 \%$ acetonitrile, while in $5 \mathrm{mM}$ sodium phosphate the retention is nearly halved, eluting at $43.1 \%$ acetonitrile. With two lysine residues, GS 6 is not as hydrophobic as GS 4, and this is confirmed by its elution at $18.6 \%$ acetonitrile on the non-lipid NC-IAM column compared to $19.7 \%$ for GS 4 (Table 1).

These initial results suggested that there were significant dissimilarities in the retention behaviour between the NC and covalent systems, prompting an investigation into the role ionic strength has on the binding properties of peptides on the covalent column. The effects of ionic strength on the retention of GS 4 (Fig. 6) were found to be relatively insignificant. Compared to the unbuffered run, higher ionic strength solutions increased elution times. This is the opposite result to when the same treatments were applied to GS 6 in Fig. 7. As ionic strength increased, retention time decreased, and the use of either sodium phosphate or ammonium phosphate led to the same effect. A $5 \mathrm{mM}$ solution was sufficient to reduce the retention time by nearly half compared to the unbuffered run, and increasing ionic concentrations marginally enhanced this behaviour. These results were consistent with GS 6 interacting electrostatically as well as hydrophobically with the column's bonded phase, indicating that the two lysine residues determined a large component of the partitioning nature of the peptide.

Further, investigations into hydrogenbonding effects on the retention behaviours of both GS 4 and GS 6 on the covalent column showed similar results (Fig. 8 and 9). Glycerol was added to the eluents as $1 \%, 2 \%$, and $5 \% \mathrm{v} / \mathrm{v}$ concentrations at constant ionic strength $(10 \mathrm{mM}$ sodium phosphate). Higher concentrations were not studied because beyond 5\%, the eluents became too viscous to pump and presented problems with clogging the chromatograph. For GS 4 , the $1 \%$ solution had no effect, whereas a small decrease in retention time was seen for the $2 \%$ and $5 \%$ solutions, with the 5\% retention time being marginally less than the $2 \%$. For GS 6 , all mixtures slightly decreased retention times with increasing glycerol concentrations, with the greatest decrease occurring between the $2 \%$ and $5 \%$ solutions. Overall, the decrease in retention times was not as significant as the effect seen with increasing ionic concentration. 


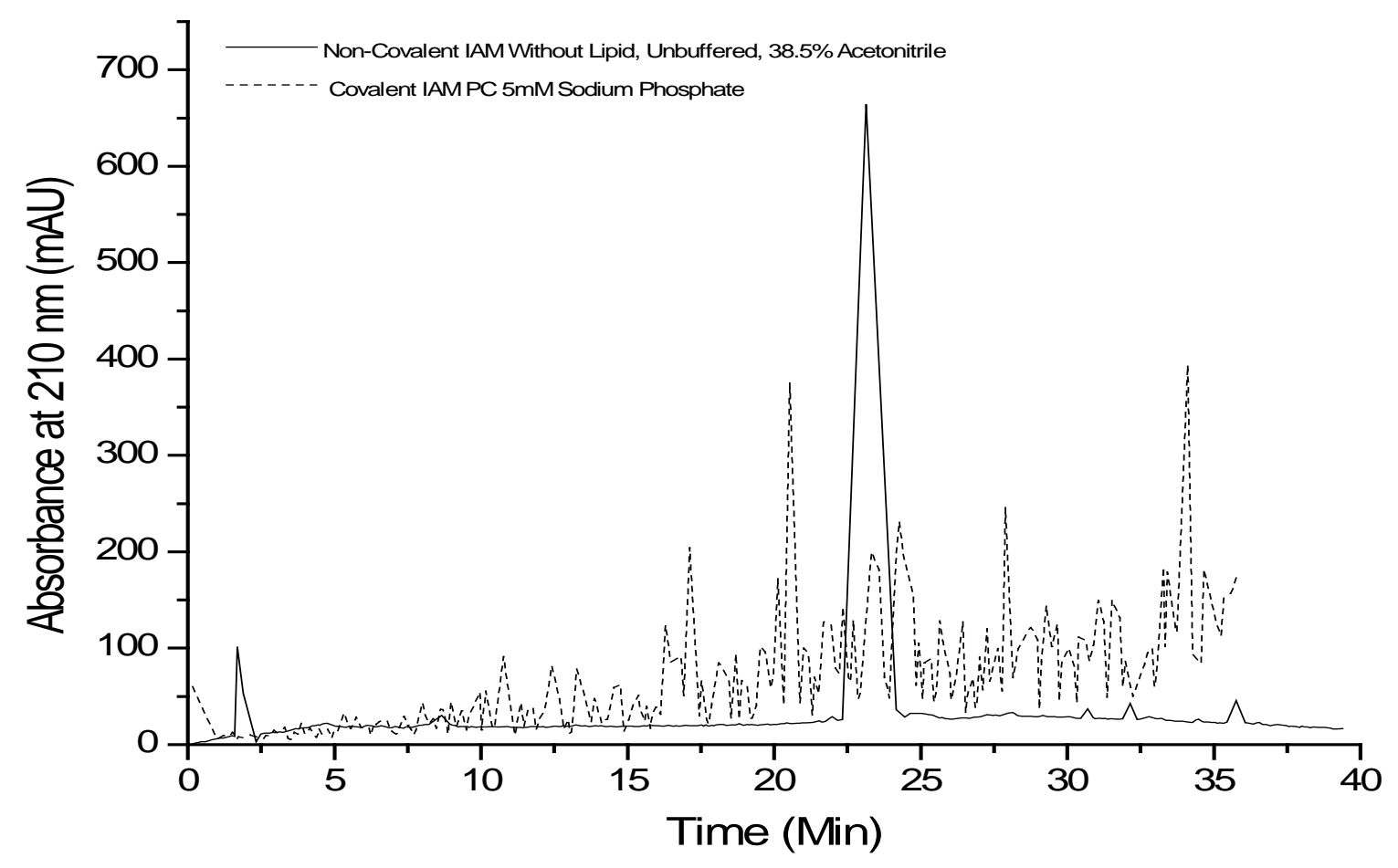

FIGURE 2: Comparison of non-covalent 15-cm column (without lipid) to 1-cm IAM.PC.DD.2 mini-column for GS $14 \mathrm{dk4}$. Samples run on a $0-100 \%$ acetonitrile $0-60$ min linear gradient at $25^{\circ} \mathrm{C}$ and $1 \mathrm{~mL} / \mathrm{min}$ flow rate. Buffered runs carried out at $\mathrm{pH}$ 6.5. The chromatogram for the mini-column has an extremely noisy baseline which would mask any signal from the peptide. A flow rate of at least $1 \mathrm{~mL} / \mathrm{min}$ was required on the mini-column in order to see any peptide elution, however, this flow rate led to uneven back pressure resulting in problems obtaining a stable baseline, particularly at higher acetonitrile concentrations.

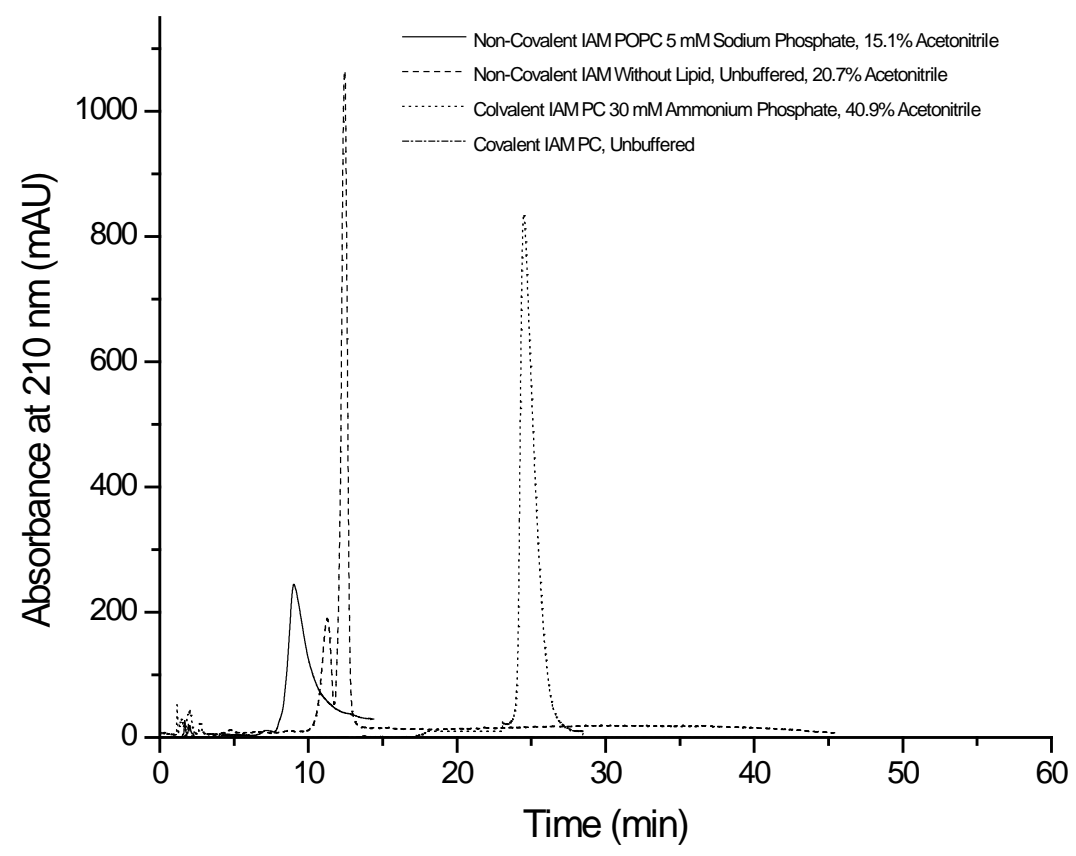

FIGURE 3: Comparison of retention times between non-covalent and covalent IAM columns for GS A. All samples run on a $0-100 \%$ acetonitrile $0-60 \mathrm{~min}$ linear gradient at $25^{\circ} \mathrm{C}$ and $1 \mathrm{~mL} / \mathrm{min}$ flow rate. Buffered runs carried out at $\mathrm{pH}$ 6.5. The decrease in retention time for GS A for the non-covalent-IAM compared to the same column without lipid is consistent with the peptide partitioning into the lipid backbone interface rather than partitioning deeper into the column's bonded phase. For the covalent column, eulents needed to contain upwards of $30 \mathrm{mM}$ of salt before elution would take place, suggesting that electrostatic interactions are very prevalent in GS A's interaction with the covalent column's bonded phase. The presence of salt competes with the head groups for interaction with the peptide, significantly decreasing the retention time. 


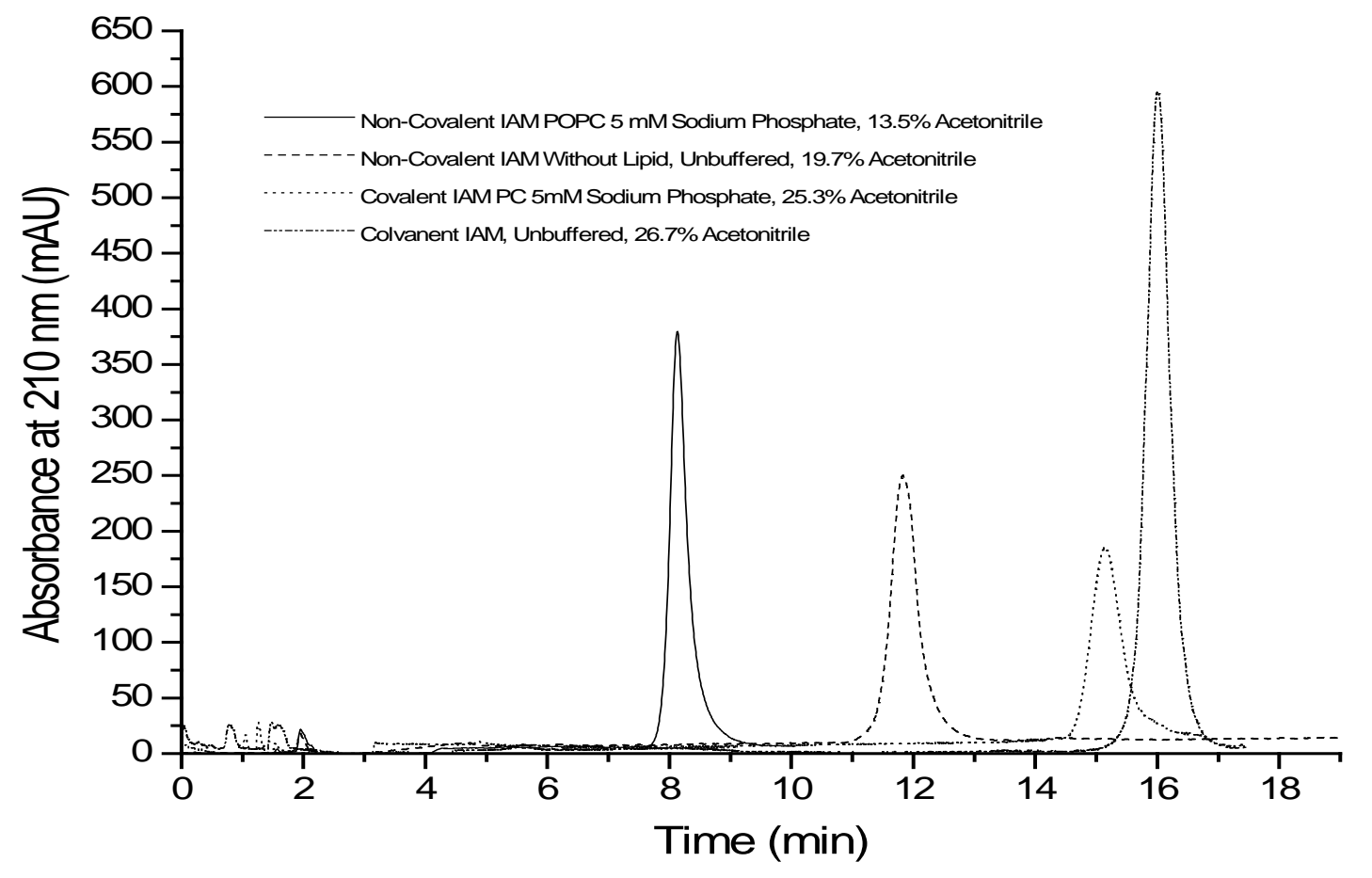

FIGURE 4: Comparison of retention times between non-covalent and covalent IAM columns for GS 4. All samples run on a $0-100 \%$ acetonitrile $0-60 \mathrm{~min}$ linear gradient at $25^{\circ} \mathrm{C}$ and $1 \mathrm{~m} \mathrm{~L} / \mathrm{min}$ flow rate. Buffered runs carried out at $\mathrm{pH} 6.5$. The decrease in retention time for GS4 for the non-covalent-IAM compared to the same column without lipid is consistent with the peptide partitioning into the lipid backbone interface rather than partitioning deeper into the column's bonded phase. For the covalent IAM, the presence of salt decreases the retention only slightly, suggesting that this overall hydrophobic peptide has little interaction with the phosphate head groups.

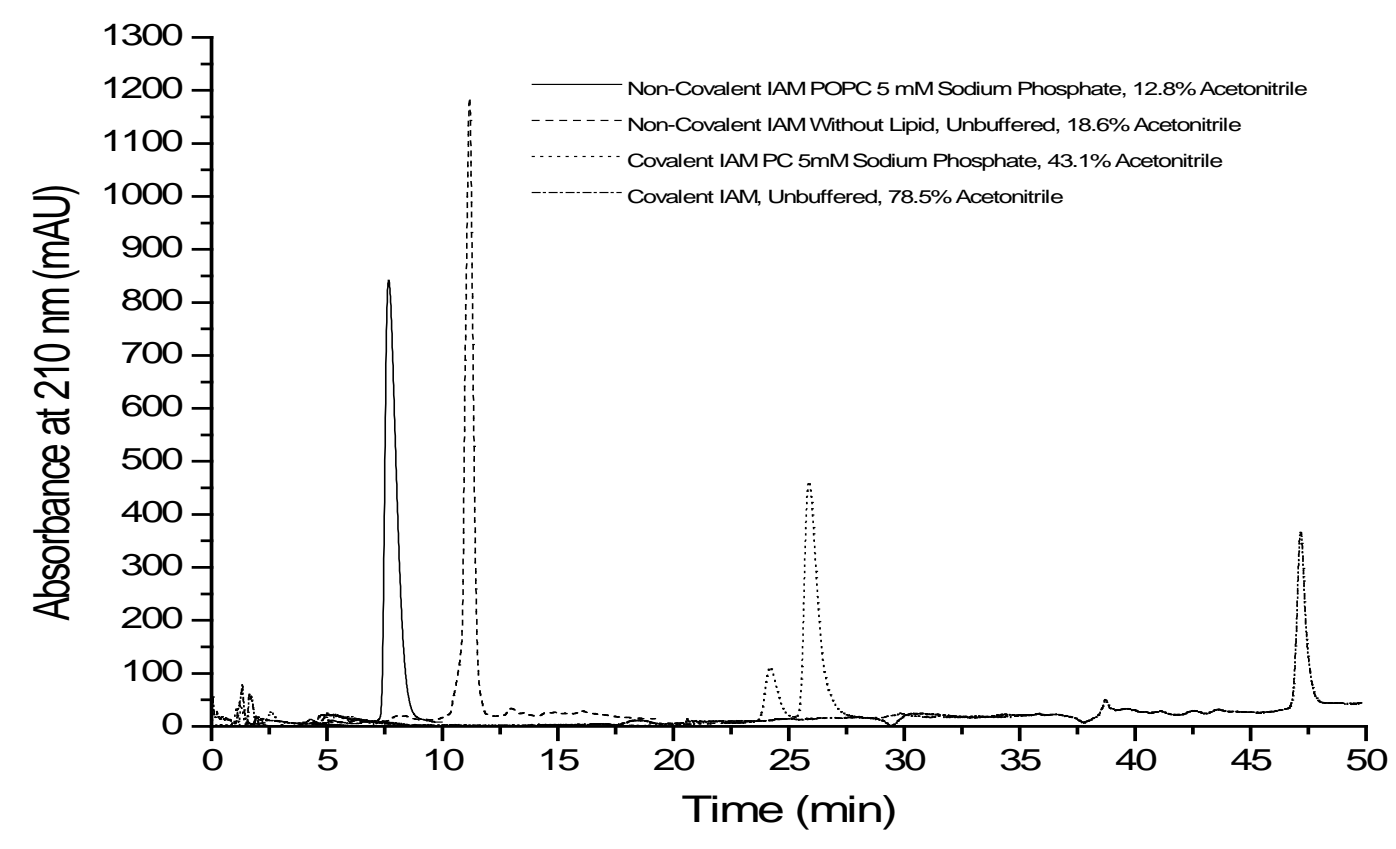

FIGURE 5: Comparison of retention times between non-covalent and covalent IAM columns for GS 6. All samples run on a $0-100 \%$ acetonitrile $0-60 \mathrm{~min}$ linear gradient at $25^{\circ} \mathrm{C}$ and $1 \mathrm{~mL} / \mathrm{min}$ flow rate. Buffered runs carried out at pH 6.5. The decrease in retention time for GS 6 for the non-covalent-IAM compared to the same column without lipid is consistent with the peptide partitioning into the lipid backbone interface rather than partitioning deeper into the column's bonded phase. The retention times for both runs on this column are less than that for GS 4, since the addition of two lysine residues decreases the overall hydrophobicity of the peptide. For the covalent IAM, retention times for both the buffered and unbuffered runs are increased and dramatically different, suggesting partitioning deep into the bonded phase and interaction of the lysine residues with the negative charge of the phosphate head groups. The presence of salt competes with the head groups for interaction with the peptide, significantly decreasing the retention time. 


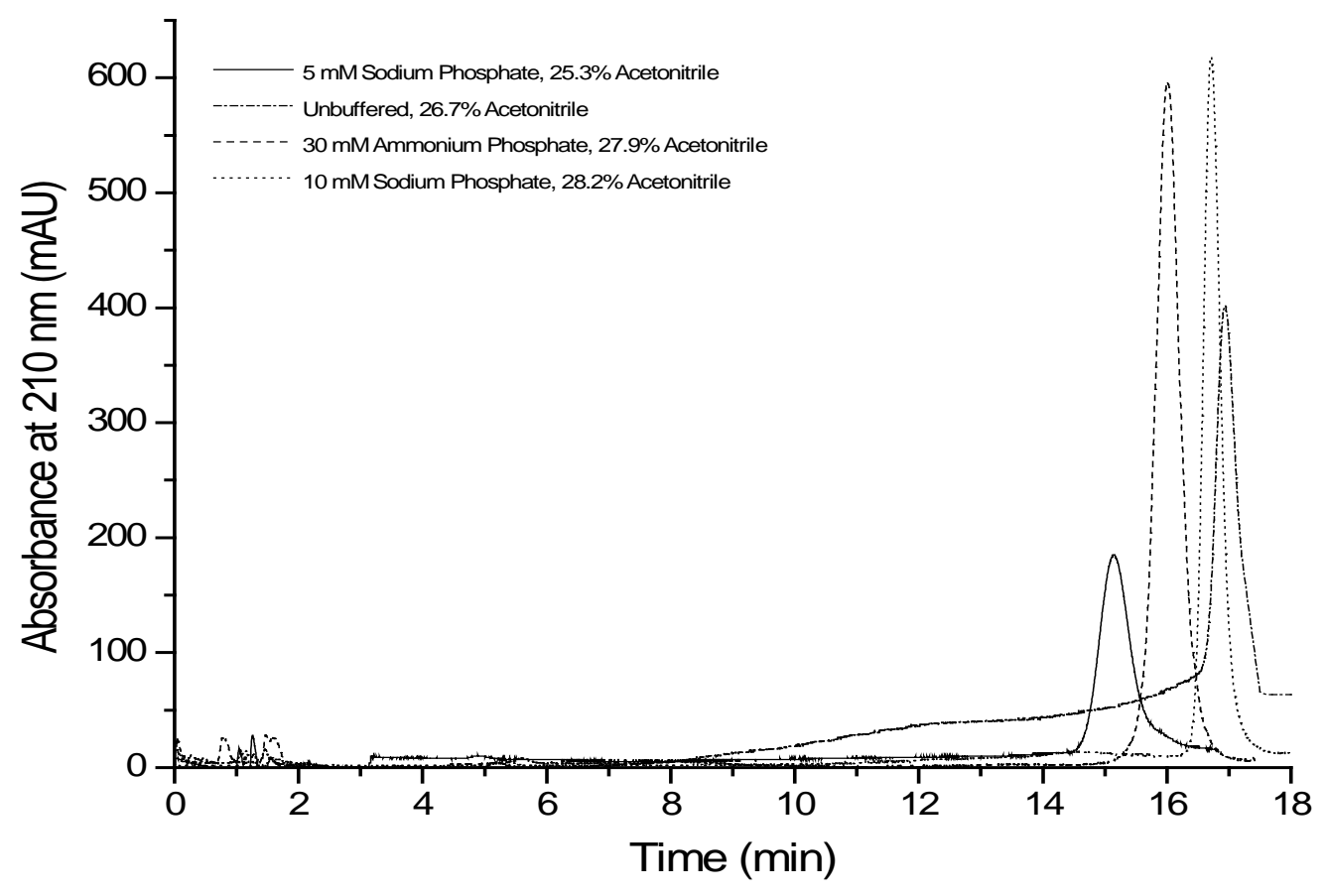

FIGURE 6: Comparison of retention times for the IAM.PC.DD.2 covalent column with changing ionic strength for GS 4. All samples run on a $0-100 \%$ acetonitrile $0-60$ min linear gradient at $25^{\circ} \mathrm{C}$ and $1 \mathrm{~mL} / \mathrm{min}$ flow rate. Buffered runs carried out at pH 6.5. Overall, increasing the ionic strength slightly increases the retention time, consistent with the eluent becoming more polar and GS 4 being an overall hydrophobic peptide. Ionic interactions do not appear to play a significant role in the partitioning of GS 4 into the membrane.

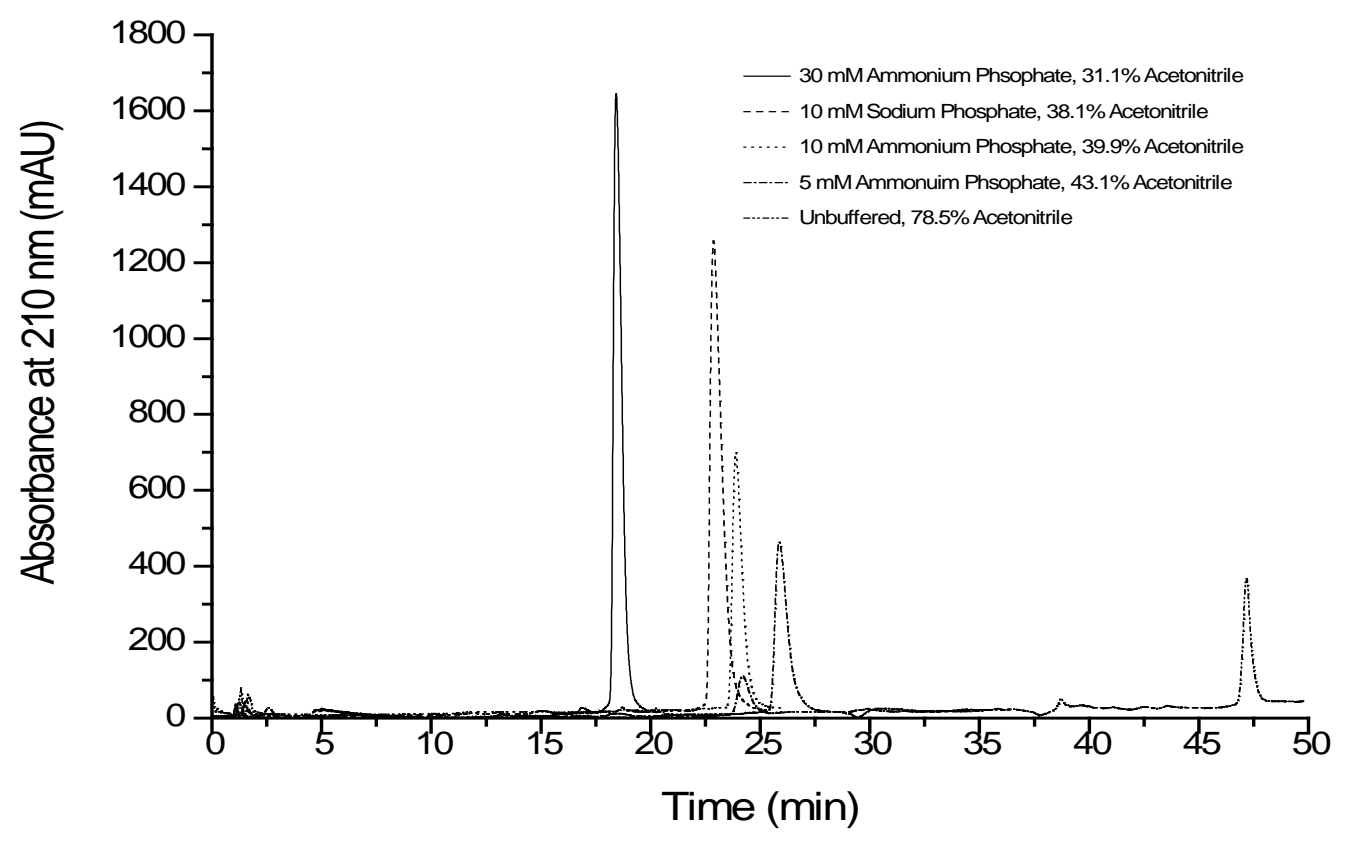

FIGURE 7: Comparison of retention times for the IAM.PC.DD.2 covalent column with changing ionic strength for GS 6. All samples run on a $0-100 \%$ acetonitrile $0-60$ min linear gradient at $25^{\circ} \mathrm{C}$ and $1 \mathrm{~mL} / \mathrm{min}$ flow rate. Buffered runs carried out at $\mathrm{pH}$ 6.5. As ionic strength is increased, the retention time for GS 6 decreases, indicating that the presence of salt competes with the negative charge of the phosphate head group for interaction with the peptide's charged (lysine) side chains. Ammonium phosphate is more soluble than sodium phosphate and was used for the $30 \mathrm{mM}$ run since the upper limit of solubility for sodium phosphate in the eluent used was approximately $10 \mathrm{mM}$. There is little difference in retention time between the $10 \mathrm{mM}$ ammonium phosphate and $10 \mathrm{mM}$ sodium phosphate runs. More significant is the drastic decrease in retention time by nearly half upon addition of $5 \mathrm{mM}$ of sodium phosphate when compared to the unbuffered run. 


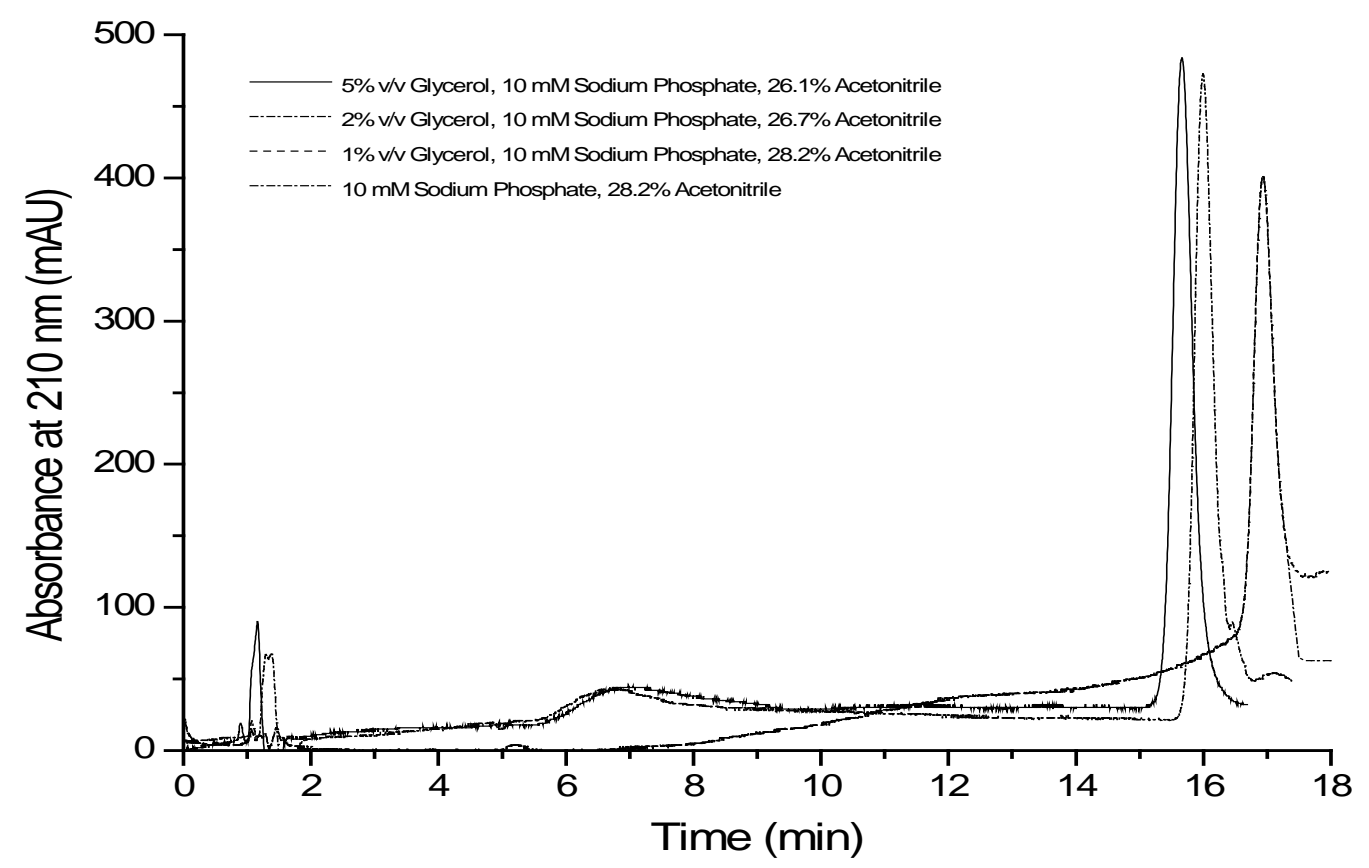

FIGURE 8: Comparison of retention times for the IAM.PC.DD.2 covalent column with changing glycerol concentrations for GS 4. All samples run on a $0-100 \%$ acetonitrile $0-60$ min linear gradient at $25^{\circ} \mathrm{C}, \mathrm{pH} 6.5$, and $1 \mathrm{~mL} / \mathrm{min}$ flow rate. Glycerol is a potent hydrogen-bond donor and was added to the solvent system to compete with the peptide for hydrogen-bond acceptor sites on the phosphate head groups. No effect was observed at $1 \% \mathrm{v} / \mathrm{v}$ glycerol, while very slight decreases in retention time were seen with the $2 \%$ and $5 \% \mathrm{v} / \mathrm{v}$ glycerol solutions, suggesting that hydrogen bonding plays only a small role in the peptides interaction with the column's bonded phase.

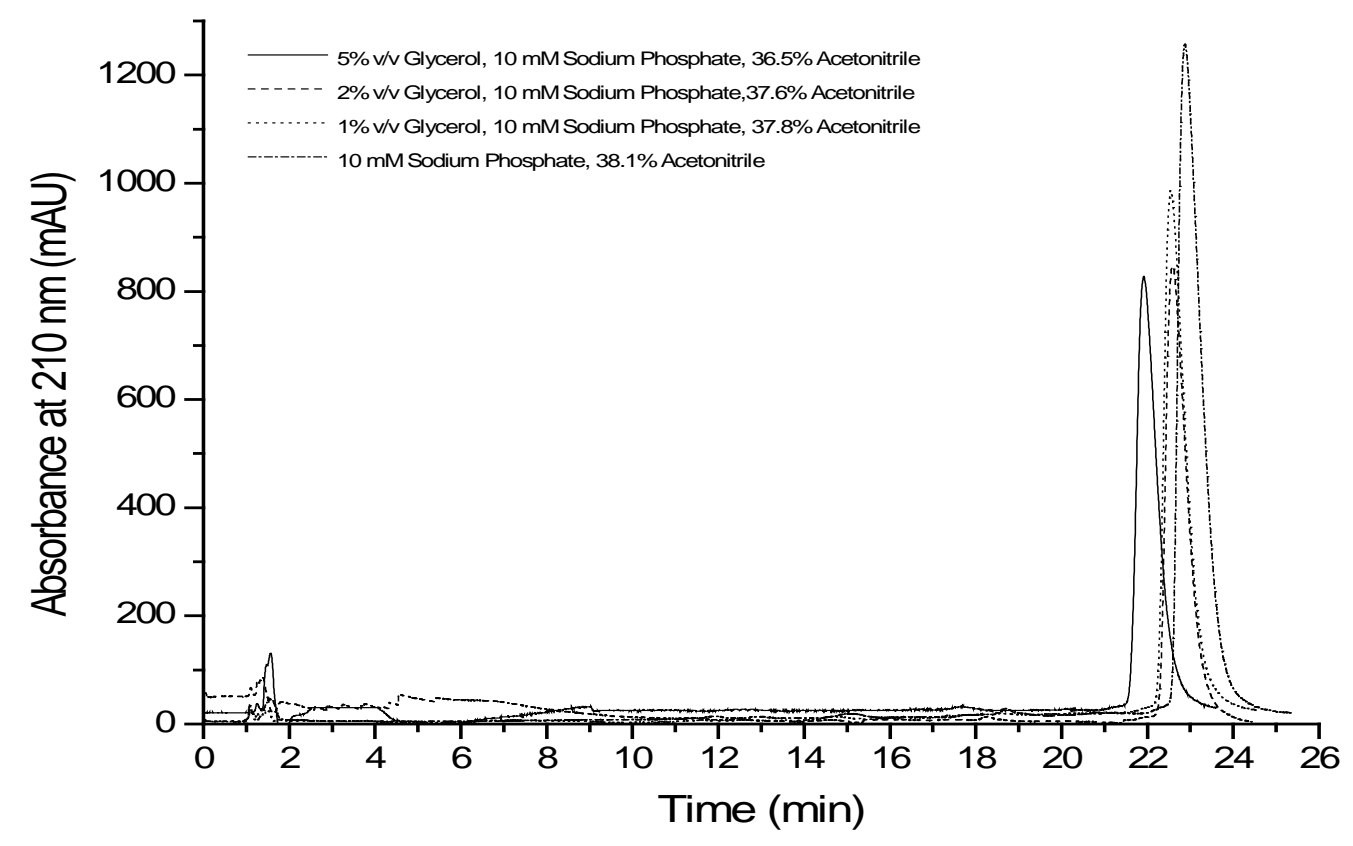

FIGURE 9: Comparison of retention times for the IAM.PC.DD.2 covalent column with changing glycerol concentrations for GS 6. All samples run on a $0-100 \%$ acetonitrile $0-60$ min linear gradient at $25^{\circ} \mathrm{C}, \mathrm{pH} 6.5$, and $1 \mathrm{~mL} / \mathrm{min}$ flow rate. Glycerol is a potent hydrogen-bond donor and was added to the solvent system to compete with the peptide for hydrogen-bond acceptor sites on the phosphate head groups. Very slight decreases in retention times occurred with increasing glycerol concentrations, suggesting hydrogen bonding has a limited role in the peptides interaction with the column's bonded phase compared to ionic and hydrophobic effects. 


\begin{tabular}{|c|c|c|c|c|c|}
\hline Peptide & Column & “A” Solvent System & “B” Solvent System & $\begin{array}{c}\text { Linear AB } \\
\text { Gradient }\end{array}$ & Elution \% $\mathrm{CH}_{3} \mathrm{CN}$ \\
\hline GS A & non-covalent POPC & $5 \mathrm{mM}$ sodium phosphate $\mathrm{H}_{2} \mathrm{O}$ & $5 \mathrm{mM}$ sodium phosphate $60 / 40 \mathrm{H}_{2} \mathrm{O} / \mathrm{CH}_{3} \mathrm{CN}$ & $0-100 \%$ B 36-min & 15.1 \\
\hline GS A & non-covalent no lipid & Unbuffered $\mathrm{H}_{2} \mathrm{O}$ & Unbuffered CH3CN & 0-100\% B 60-min & 20.7 \\
\hline GS A & IAM.PC.DD. 2 & Unbuffered $\mathrm{H}_{2} \mathrm{O}$ & Unbuffered CH3CN & $0-100 \%$ B $60-\min$ & no elution \\
\hline GS A & IAM.PC.DD.2 & $30 \mathrm{mM}$ ammonium phosphate $\mathrm{H}_{2} \mathrm{O}$ & $30 \mathrm{mM}$ ammonium phosphate $60 / 40 \mathrm{H}_{2} \mathrm{O} / \mathrm{CH}_{3} \mathrm{CN}$ & 0-100\% B 36-min & 40.9 \\
\hline GS 4 & non-covalent POPC & 5 mM sodium phosphate $\mathrm{H}_{2} \mathrm{O}$ & $5 \mathrm{mM}$ sodium phosphate $60 / 40 \mathrm{H}_{2} \mathrm{O} / \mathrm{CH}_{3} \mathrm{CN}$ & $0-100 \%$ B 36-min & 13.5 \\
\hline GS 4 & non-covalent no lipid & Unbuffered $\mathrm{H}_{2} \mathrm{O}$ & Unbuffered $\mathrm{CH}_{3} \mathrm{CN}$ & 0-100\% B 60-min & 19.7 \\
\hline GS 4 & IAM.PC.DD.2 & Unbuffered $\mathrm{H}_{2} \mathrm{O}$ & Unbuffered $\mathrm{CH}_{3} \mathrm{CN}$ & $0-100 \%$ B 60-min & 26.7 \\
\hline GS 4 & IAM.PC.DD.2 & $5 \mathrm{mM}$ sodium phosphate $\mathrm{H}_{2} \mathrm{O}$ & 5 mM sodium phosphate $60 / 40 \mathrm{H}_{2} \mathrm{O} / \mathrm{CH}_{3} \mathrm{CN}$ & $0-100 \%$ B 36-min & 25.3 \\
\hline GS 4 & IAM.PC.DD.2 & $10 \mathrm{mM}$ sodium phosphate $\mathrm{H}_{2} \mathrm{O}$ & $10 \mathrm{mM}$ sodium phosphate $50 / 50 \mathrm{H}_{2} \mathrm{O} / \mathrm{CH}_{3} \mathrm{CN}$ & $0-100 \%$ B 30-min & 28.2 \\
\hline GS 4 & IAM.PC.DD.2 & $30 \mathrm{mM}$ ammonium phosphate $\mathrm{H}_{2} \mathrm{O}$ & $30 \mathrm{mM}$ ammonium phosphate $60 / 40 \mathrm{H}_{2} \mathrm{O} / \mathrm{CH}_{3} \mathrm{CN}$ & 0-100\% B 36-min & 27.9 \\
\hline GS 4 & IAM.PC.DD.2 & $\begin{array}{l}10 \mathrm{mM} \text { sodium phosphate } \mathrm{H}_{2} \mathrm{O} \\
1 \% \text { v/v glycerol }\end{array}$ & $\begin{array}{c}10 \mathrm{mM} \text { sodium phosphate } 50 / 50 \mathrm{H}_{2} \mathrm{O} / \mathrm{CH}_{3} \mathrm{CN} \text {, } \\
1 \% \text { v/v glycerol }\end{array}$ & 0-100\% B 30-min & 28.2 \\
\hline GS 4 & IAM.PC.DD.2 & $\begin{array}{l}10 \mathrm{mM} \text { sodium phosphate } \mathrm{H}_{2} \mathrm{O} \text {, } \\
2 \% \text { v/v glycerol }\end{array}$ & $\begin{array}{c}10 \mathrm{mM} \text { sodium phosphate } 50 / 50 \mathrm{H}_{2} \mathrm{O} / \mathrm{CH}_{3} \mathrm{CN} \text {, } \\
2 \% \text { v/v glycerol }\end{array}$ & 0-100\% B 30-min & 26.7 \\
\hline GS 4 & IAM.PC.DD.2 & $\begin{array}{l}10 \mathrm{mM} \text { sodium phosphate } \mathrm{H}_{2} \mathrm{O} \text {, } \\
5 \% \mathrm{v} / \mathrm{v} \text { glycerol }\end{array}$ & $\begin{array}{c}10 \mathrm{mM} \text { sodium phosphate } 50 / 50 \mathrm{H}_{2} \mathrm{O} / \mathrm{CH}_{3} \mathrm{CN} \text {, } \\
5 \% \text { v/v glycerol }\end{array}$ & 0-100\% B 30-min & 26.1 \\
\hline GS 6 & non-covalent POPC & $5 \mathrm{mM}$ sodium phosphate $\mathrm{H}_{2} \mathrm{O}$ & $5 \mathrm{mM}$ sodium phosphate $60 / 40 \mathrm{H}_{2} \mathrm{O} / \mathrm{CH}_{3} \mathrm{CN}$ & $0-100 \%$ B 36-min & 12.8 \\
\hline GS 6 & non-covalent no lipid & Unbuffered $\mathrm{H}_{2} \mathrm{O}$ & Unbuffered $\mathrm{CH}_{3} \mathrm{CN}$ & 0-100\% B 60-min & 18.6 \\
\hline GS 6 & IAM.PC.DD. 2 & Unbuffered $\mathrm{H}_{2} \mathrm{O}$ & Unbuffered $\mathrm{CH}_{3} \mathrm{CN}$ & $0-100 \%$ B 60-min & 78.5 \\
\hline GS 6 & IAM.PC.DD.2 & 5 mM sodium phosphate $\mathrm{H}_{2} \mathrm{O}$ & 5 mM sodium phosphate $60 / 40 \mathrm{H}_{2} \mathrm{O} / \mathrm{CH}_{3} \mathrm{CN}$ & $0-100 \%$ B 36-min & 43.1 \\
\hline GS 6 & IAM.PC.DD.2 & $10 \mathrm{mM}$ sodium phosphate $\mathrm{H}_{2} \mathrm{O}$ & $10 \mathrm{mM}$ sodium phosphate $50 / 50 \mathrm{H}_{2} \mathrm{O} / \mathrm{CH}_{3} \mathrm{CN}$ & $0-100 \%$ B 30-min & 38.1 \\
\hline GS 6 & IAM.PC.DD.2 & $10 \mathrm{mM}$ ammonium phosphate $\mathrm{H}_{2} \mathrm{O}$ & $10 \mathrm{mM}$ ammonium phosphate $50 / 50 \mathrm{H}_{2} \mathrm{O} / \mathrm{CH}_{3} \mathrm{CN}$ & $0-100 \%$ B 30-min & 39.9 \\
\hline GS 6 & IAM.PC.DD.2 & $30 \mathrm{mM}$ ammonium phosphate $\mathrm{H}_{2} \mathrm{O}$ & $30 \mathrm{mM}$ ammonium phosphate $60 / 40 \mathrm{H}_{2} \mathrm{O} / \mathrm{CH}_{3} \mathrm{CN}$ & $0-100 \%$ B 36-min & 31.1 \\
\hline GS 6 & IAM.PC.DD.2 & $\begin{array}{l}10 \mathrm{mM} \text { sodium phosphate } \mathrm{H}_{2} \mathrm{O} \\
1 \% \mathrm{v} / \mathrm{v} \text { glycerol }\end{array}$ & $\begin{array}{c}10 \mathrm{mM} \text { sodium phosphate } 50 / 50 \mathrm{H}_{2} \mathrm{O} / \mathrm{CH}_{3} \mathrm{CN} \text {, } \\
1 \% \text { v/v glycerol }\end{array}$ & 0-100\% B 30-min & 37.8 \\
\hline GS 6 & IAM.PC.DD.2 & $\begin{array}{l}10 \mathrm{mM} \text { sodium phosphate } \mathrm{H}_{2} \mathrm{O} \text {, } \\
2 \% \mathrm{v} / \mathrm{v} \text { glycerol }\end{array}$ & $\begin{array}{c}10 \mathrm{mM} \text { sodium phosphate } 50 / 50 \mathrm{H}_{2} \mathrm{O} / \mathrm{CH}_{3} \mathrm{CN} \text {, } \\
2 \% \text { v/v glycerol }\end{array}$ & 0-100\% B 30-min & 37.6 \\
\hline GS 6 & IAM.PC.DD.2 & $\begin{array}{l}10 \mathrm{mM} \text { sodium phosphate } \mathrm{H}_{2} \mathrm{O} \text {, } \\
5 \% \mathrm{v} / \mathrm{v} \text { glycerol }\end{array}$ & $\begin{array}{c}10 \mathrm{mM} \text { sodium phosphate } 50 / 50 \mathrm{H}_{2} \mathrm{O} / \mathrm{CH}_{3} \mathrm{CN} \text {, } \\
5 \% \text { v/v glycerol }\end{array}$ & 0-100\% B 30-min & 36.5 \\
\hline
\end{tabular}

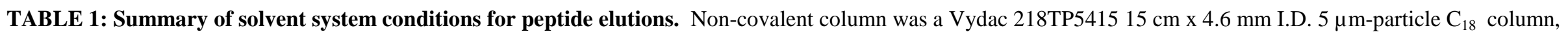

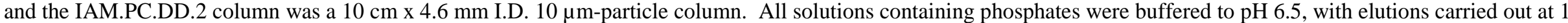
$\mathrm{mL} / \mathrm{min}$ and $25^{\circ} \mathrm{C}$. The rate of change in effective $\mathrm{CH}_{3} \mathrm{CN}$ concentrations in all runs was $1.67 \% / \mathrm{min}$, with elution \% $\mathrm{CH}_{3} \mathrm{CN}$ being the \% $\mathrm{CH}_{3} \mathrm{CN}$ of the system at the moment of peptide elution. 


\section{Discussion}

From the covalent IAM retention times gathered on the IAM.PC.DD.2 column, the peptides studied bind much more strongly to the covalent columns than both the non-covalent and non-lipid control columns, with the binding especially enhanced by the presence of cationic residues. This suggests that there is a distinct difference in the partitioning behaviours of AMPs into the covalently bonded phase relative to the non-covalent system.

It was postulated that the $1-\mathrm{cm}$ minicolumn could be used as an economical means of comparing the retention behaviours of covalent columns to the NC-IAM data previously obtained. Even though the NC-IAM column was $15 \mathrm{~cm}$ long, it was assumed that the shorter column length could be compensated for by reducing the flow rate. Nevertheless, at low flow rates, the elution times were significantly increased. At $1 \mathrm{~mL} / \mathrm{min}$, the retention times did decrease, however they were not consistent from run to run. Further, the uneven back pressure at this rate may explain the apparent aggregate elution and/or noisy baseline. Even after the column was overloaded with the very hydrophobic Gramicidin S peptide, the lack in change of retention time ruled out silica interactions. Further, if silica interactions were a significant contributor to the increase in retention times, the effect should have been decreased with increased peptide size, as it would be more difficult for a large peptide compared to a small peptide to partition through the bonded phase to the silica base. However, the increase in retention times was consistent for all peptides studied, suggesting that these columns are not suitable for peptide elution requiring flow rates of at least $1 \mathrm{~mL} / \mathrm{min}$.

It is for this reason that the evaluation was continued with a $10 \mathrm{~cm} \times 4.6 \mathrm{~mm}$ version of the mini-column. Problems with irregular back pressure at $1 \mathrm{~mL} / \mathrm{min}$ were eliminated, and as a result, the multiple-peak behaviour seen in the 1cm column disappeared. However, retention times were still much greater than non-lipid control and NC-IAM columns, presenting a paradox. Given that the particle size of the IAM.PC.DD2 was $10 \mu \mathrm{m}$, larger than the $5 \mu \mathrm{m}$ particle of the NC-IAM column, and the overall hydrophobicity was reduced by the presence of zwitterionic head groups, the retention times from the IAM.PC.DD2 column were anticipated to mirror those obtained from the NC-IAM column when it was loaded with POPC. Such times would also be less than those for peptides eluted from the NC-IAM column without the phospholipid monolayer. This agreement was seen by Luo, Zheng, and Cheng (2007) on comparison of retention times for pyrimidine derivatives. However, analytes with highly polar substituents capable of significant hydrogen bonding or electrostatic interactions were retained longer on the IAM column, leading the authors to conclude that the retention behaviour of such compounds on biomembrane-mimic IAM phases were complex.

The difference in retention behaviors between the covalent and non-covalent systems may be due to different lipid packing densities. Ideally, an in vitro model of a biological membrane should have a packing density analogous to a real membrane in order to draw valid conclusions from ligand-lipid partitioning experiments. The non-covalent column was shown by Krause, Dathe, Wieprecht, and Bienert (1999) to have a density of $85 \AA^{2}$ per molecule of phospholipid, reasonably close to the value of 60 $70 \AA^{2}$ in phospholipid bilayers. This corresponds to a ratio of $158 \mu \mathrm{mol}$ PC per gram of stationary phase. According to Ong and Pidgeon (1995), the developers of the covalent IAM technology, the IAM.PC.DD.2 column (referred to as ${ }^{\text {ester }}$ IAM.PC ${ }^{\mathrm{C} 10 / \mathrm{C} 3}$ ) contained $98 \mu \mathrm{mol}$ PC per gram of stationary phase. However, contact with Regis Technologies indicated that the PC concentration of the column used is this experiment was $16 \mu \mathrm{mol}$ PC per gram of stationary phase, or ten percent of the density in the Krause columns. This would suggest that these covalent columns, as commercialized by Regis Technologies, are not appropriate for 
comparing the partitioning behaviours between the two models, given the enormous difference in lipid packing between the two systems.

A densely-packed membrane is necessary in order to establish compartmentalization of ions, proteins, and other cell components, and prevent non-specific transport across the bilayer. More specific to the context of this project, a lower immobilized PC density results in a lower interfacial barrier to solute transport into the hydrocarbon region of the bonded phase (Ong \& Pidgeon, 1995). With a tight packing, the phosphate head groups effectively limit peptide partitioning into only the interfacial region. Further, the phosphates themselves shield their own charges from ligands that partition into such membranes. Hence, in a biological membrane, electrostatic and hydrophobic interactions with a peptide are reduced largely by the increased resistance to penetration.

With a reduced lipid packing density, peptides can penetrate beyond the interfacial head groups and embed within the bonded phase. The higher hydrocarbon surface area available for contact with the peptide can increase the van der Waals interactions between the hydrophobic components of the peptides and the bonded phase, amplifying the affinity of the peptide to the column (11). It is largely for this reason that all peptides studied were retained much longer on the IAM.PC.DD.2 column than the NC-IAM columns. Electrostatic effects appeared to be much more crucial in describing the partitioning than van der Waals forces when cationic residues were present within the peptide, as particularly seen in the inability to elute GS A with unbuffered eluents, and the large increase in acetonitrile concentration required for elution of GS 6 in unbuffered conditions relative to buffered runs. If the partitioning was only into the interfacial region as predicted in a normal membrane, the cationic charge of the choline portion of the head groups should have attenuated the electrostatic interaction and minimized the vast difference in retention times seen for cationic residues.
The difference between the GS 4 and GS 6 peptides was related to the presence of two lysine residues in GS 6, which reduced the overall hydrophobicity of the peptide relative to GS 4. Hence, GS 6 should have eluted more quickly than GS 4 under identical conditions, and this conclusion was observed for the NC-IAM columns, but not on the IAM.PC.DD2 column. The reduction in retention time by almost half for GS 6 in the $5 \mathrm{mM}$ sodium phosphate run compared to the unbuffered run suggested that the lysine residues of GS 6 interacted electrostatically with the negative charge of the phosphate head groups of the zwitterionic PC moiety. Addition of salt to the eluent introduced electrostatic competition for the phosphate head groups, meaning that the ionic component of the partitioning of GS 6 was decreased. This is plausible because GS 4, a purely hydrophobic peptide, showed little change in retention times under the same circumstances. The overall increased retention times for both GS 4 and 6 on the IAM.PC.DD2 column relative to the NC-IAM columns indicated that hydrophobic interactions played a more significant role in the partitioning process on the covalently bonded phase.

Taillardat-Bertschinger, Marca Martinet, Carrupt, Reist, Caron, Fruttero, and Testa (2002) also argued that there is dissimilar partitioning of hydrophilic solutes into the IAM.PC.DD.2 bonded phase and PC liposomes. In their study, the interactions of $\beta$-blockers with the two systems were examined, and it was concluded that electrostatic effects played only a minor role in IAM retentions. Their justification was based on the smaller density of phospholipids in IAMs compared to liposomes, as well as the lack of lateral and axial mobility in IAM columns and their monolayer nature. This is in contrast to the conclusions from this investigation with peptides. However, the authors did suggest that hydrogen bonding played only a minor role in IAM retentions, which is in agreement with the glycerol runs for GS 4 and 6. However, it may be that the hydrophobic and electrostatic interactions observed in the IAM.PC.DD.2 
system overwhelmed the nature of the peptide partitioning, and that hydrogen bonding may play a much more significant role when the ability for electrostatic interactions is muted with higher lipid densities in normal membranes.

The key difference between this study and those conducted by others like Luo et al. (2007) and Taillardat-Bertschinger et al. (2002) on the IAM.PC.DD2 system rests in the size of the solutes studied. Virtually all published research for these models makes use of small drugs such as pyrimidine derivatives that are often smaller than 300 Da. However, in our circumstance, solutes being examined contain 14 to 26 amino acids with molecular weights spanning 1700 to 3000 Da. Even though retention data correlated well for these drugs to intestinal absorption studies while the same is not true for retention data on ODS (octodecyl) (non-lipid NC-IAM) columns (Pidgeon et al., 1995), the question arises whether there is a critical lipid density required to perform a valid in vitro experiment that is dependent on the parameters of the solute of interest, such as size, overall hydrophobicity, and charge. If so, then the possibility exists that a lower packing density is sufficient for the study of small analytes. Hence, because the majority of research has been focused on this area, inadequacies with the IAM.PC.DD2 system and similar models may only begin to be become apparent when the range of solutes examined starts to include very large and/or charged ligands like AMPs.

Another fundamental difference between this evaluation and other on small solutes rests in the nature of the eluents used. For small solutes with limited van der Waals surfaces and/or low charge densities, eluents are typically aqueous sodium phosphate buffers (8) or contain low proportion of organic solvent, such as 20:80 (v/v\%) methanol/sodium phosphate buffers (9). At low organic solvent concentrations, the eluent still behaves much like water and is only capable of solvating the interfacial region on the IAM. As described earlier and illustrated in Fig. 1B, as the eluent becomes increasingly non-polar, such as upon the addition of a large volume percentage of acetonitrile, the polar head groups begin to cluster together to exclude the eluent while the non-polar lipid chains become solvated (Qiu \& Pidgeon, 1993). Elution of most peptides examined in this study required acetonitrile concentrations well beyond 40\%. Therefore, while Taillardat-Bertschinger et al. argue that electrostatic interactions are not very important in the IAM.PC.DD.2 system due to low lipid packing, the head group aggregation effect can increase the overall charge density available for interaction with individual solute molecules as acetonitrile concentration increases. Hence, the entrapment of solute deep within the bonded phase by aggregated head groups makes understanding the elution process of cationic peptides on the IAM.PC.DD.2 column even more intricate.

Overall, determining the complex retention behavior of AMPs based on size, charge, and hydrophobicity requires an in vitro model that mimics a real biological membrane as closely as possible in order to minimize extraneous effects. Questions like what are the dominating forces behind peptide/lipid interactions will remain improperly answered until columns packed with a lipid density matching true membranes, or other systems providing accurate fast-screening models that are stable under high organic solvent concentrations, are developed.

\section{Acknowledgements}

I would like to thank Dr. Ronald $\mathrm{N}$. McElhaney for giving me the opportunity to be in his laboratory during the 2008 summer and for BIOCH 498. His lab's work on lipids, membranes, and antimicrobial peptides has provided me with a strong background in biochemical research. Next, I would like to thank Dr. Ruthven N.A.H. Lewis, my direct supervisor for this project. Whenever difficulties with obtaining results or problems with equipment would arise, he would try his best to ensure that I would not be down for too much time and 
troubleshoot technical details. I would also like to thank Dr. David A. Mannock for his invaluable assistance and witty humor that keeps the lab interesting, as well as the rest of the members of our lab, past and present, including Ms. Katalin Korpany and Mr. Kyle Rogan for their assistance during the initial stages of my HPLC work. Finally, I would like to thank Dr. Charles Lucy, Dr. Gregory Kima, and Mr. Stewart Chambers in the Department of Chemistry for facilitating my use of their HPLC equipment.

\section{References}

Apponyi, M. A., Pukala, T. L., Brinkworth, C. S., Maselli, V. M., Bowie, J. H., Tyler, M. J., Booker, G. W., Wallace, J. C., Carver, J.A., Separovic, F., Doyle, J., and Llewellyn, L. E. (2004) Peptides 25, 10351054.

Brogden, K. A. (2005) Nat. Rev. Microbiol. 3, 238250.

Jiang, Z., Vasil, A. I., Hale, J. D., Hancock, R. E. W., Vasil, M. L., and Hodges, R. S. (2008) Biopolymers 90, 369-383.

Krause, E., Dathe, M., Wieprecht, T., and Bienert, M., (1999) J. Chromotogr. A 849, 125-133.
Lorin C., Saidi, H., Belaid, A., Zairi, A., Baleux, F., Hocini, H., Belec, L., Haini, K., and Tangy, F. (2005) Virology 334, 264-275.

Luo, H., Zheng, C., and Cheng, Y. (2007) J.Chromatogr. B 853, 114-122.

Ong, S., and Pidgeon, C. (1995) Anal. Chem. 67, 2119-2128.

Ong, S., Liu, H., Qiu., X., Bhat, G., and Pidgeon, C. (1995) Anal. Chem. 67, 755-762.

Pidgeon, C., Ong, S., Liu, H., Qiu, X., Pidgeon, M., Dantzig, A. H., Munroe, J., Hornback, W. J., Kasher, J. S., Glunz, L., and Szczerba, T. (1995) J. Med. Chem. 38, 590-594.

Prenner, E. J., Kiricsi, M., Jelokhani-Niaraki, M., Lewis, R. N. A. L., Hodges, R. S., and McElhaney, R. N. (2005) J. Biol. Chem. 280, 2002-2011.

Qiu, X., and Pidgeon, C. (1993) J. Phys. Chem. 97, 12399-12407.

Taillardat-Bertschinger, A., Marca Martinet, C. A., Carrupt, P., Reist, M., Caron, G., Fruttero, R., and Testa, B. (2002) Pharm. Res. 19, 729-737. 


\title{
NEUROMARKETING:
}

\section{THE NEXT STEP IN MARKET RESEARCH?}

Christopher R Madan

Department of Psychology, University of Alberta

Eureka

Volume 1, Number 1 (2010)

\begin{abstract}
Neuromarketing is an emerging interdisciplinary field connecting psychology and neuroscience with economics. The goal of neuromarketing is to study how the brain is physiologically affected by advertising and marketing strategies. In order to evaluate the effectiveness of these strategies, brain activity resulting from viewing an advertisement is monitored and measured using neuroimaging techniques such as functional magnetic resonance imaging (fMRI) and electroencephalography (EEG). Neuromarketing studies usually measure preference between products in terms of brand familiarity or product preference. In traditional marketing studies, measures such as the product preference for a particular advertisement is sometimes difficult to measure, as a viewer may hold a cognitive bias. However, brand familiarity and product preference have been correlated with neural activity. The field of neuromarketing is still viewed with caution from consumer protection groups as well as many academics due to the possible ethical implications of designing advertisements to intentionally cause specific neurological effects.
\end{abstract}

\section{Introduction}

Neuromarketing is an emerging interdisciplinary field that combines psychology, neuroscience, and economics (Lee, Broderick, \& Chamberlain, 2007), with the term itself being coined just six years ago (Smidts, 2002). The goal of neuromarketing is to study how the brain is physiologically affected by advertising and marketing strategies. In order to evaluate the effectiveness of these strategies, brain activity resulting from viewing an advertisement is monitored and measured using neuroimaging techniques such as functional magnetic resonance imaging (fMRI) and electroencephalography (EEG) (Laybourne \& Lewis, 2005; Smidts, 2002). Neuromarketing studies usually measure preference between products in terms of brand familiarity or product preference. In traditional marketing studies, measures such as the product preference for a particular advertisement is sometimes difficult to measure, as a viewer may hold a cognitive bias. In neuromarketing studies, brand familiarity and product preference have been correlated with neural activity (McClure et al., 2004; Schaefer, Berens, Heinze, \& Rotte, 2006; Walter, Abler, Ciaramidaro, \& Erk, 2005).
The field of neuromarketing is viewed with caution from consumer protection groups as well as many academics due to the possible ethical implications of designing advertisements to intentionally cause specific neurological effects (Commercial Alert, 2003).

Intrinsic to neuromarketing are neuroimaging techniques - primarily functional magnetic resonance imaging (fMRI) and electroencephalography (EEG) - that comprise the neuroscience aspect of the field (Laybourne \& Lewis, 2005; Smidts, 2002). fMRI involves the participant lying on a bed, with their head positioned inside the large magnetic ring of a scanner. By monitoring the participant's brain with fMRI, researchers can measure the neural activity throughout the brain in terms of blood flow via oxygen usage. Contrasting this technique, EEG equipment is relatively light and portable. EEGs measure brain activity in terms of electrical activity at the scalp using numerous electrodes that are placed on the participant's scalp in a net-like fashion. Using neuroimaging, researchers can then conduct conditioning and marketing studies and monitor the participant's response, using both behavioural responses as 
well as neural activations. In layman's terms, Fugate (2007) describes neuromarketing to "managers and executives" as: "The process involves wiring subjects to various electronic devices and asking them to perform experimental tasks and control tasks. These devices generate instant, colorful images of a working brain and the researcher is able to compare differences in the images produced during the respective tasks. It then becomes apparent which parts of the brain have responded to the stimuli used." Fugate (2007) continues on to more subtle details of the mechanics behind neuromarketing, painting a picture of a revolution in the marketing field, however, some critical scientific concepts are overlooked by Fugate (2007), including the corollary nature to neuromarketing research.

Despite suggestions otherwise, 'neuromarketing' as a concept emerged prior to the word actually being coined in 2002 (Smidts, 2002). However, due to limitations of neuroimaging techniques conducted in the past few decades, many studies lacked the spatial resolution (ability to differentiate different regions of the brain) to make any useful claims as to the mechanisms behind effective and ineffective advertising techniques. For example, in an EEG study, Reeves, Lang, Thorson, and Rothschild (1989), claim that television scenes with positive messages cause greater left hemisphere activity in the frontal region, while negative content causes activation of the frontal portion of the right hemisphere. It is important to note that cortical arousal was only monitored in terms of frontal versus occipital, as only four electrodes were used (in addition to the two reference electrodes). Current EEG systems often have up to 256 electrodes to monitor brain activity, making them much more precise. Many other studies from the same time period also employ 'hemisphere' activations as key findings (i.e., Krugman, 1971; Rothschild, Hyun, Reeves, Thorson, \& Goldstein, 1988; Rothschild \& Hyun, 1990; Weinstein, Appel, \& Weinstein, 1980), including subtitles on papers reading broad statements such as, "Each medium had about the same effect on the left brain as on the right." (Weinstein et al., 1980). Nonetheless, it is not the fact that earlier 'neuromarketing' research has been imprecise that is of greatest importance, but rather how quickly the field has evolved over the last few years.

\section{Conditioning \& Marketing}

In neuromarketing research, two methods are typically employed as means of evaluating an individual's preference between products: brand familiarity and product preference.

\section{Brand Familiarity}

Brand familiarity involves comparisons between familiar and unfamiliar products. Campbell and Keller (2003) describe familiarity as habituating to a brand, as in mere exposure. When a consumer first sees an advertisement for an unfamiliar brand, they feel negative uncertainty towards it as it is unfamiliar. However, repetition of an advertisement message, at low levels, increases the effectiveness and decreases this uncertainty. One way that brands can become more familiar and earn the trust of the consumer is through the use of celebrity endorsements (Fugate, 2007). Advertisers must keep in mind not to advertise too much though, as the tedium of repeated exposures can decrease the effectiveness of the advertisement by annoying the viewer (Campbell \& Keller, 2003). For an already familiar product, repeated exposures provide more time for the consumer to process the advertisement and their associated experiences (i.e., experiences from using the product) as consumers can only store knowledge for the familiar, but not the unfamiliar. As such, for unfamiliar brands there is less knowledge to process, causing the consumer to become bored, and even annoyed, more easily. In essence, new brands just breaking into the market need to be conservative in their marketing efforts in so as to not overdo it, but also enough to cause consumers to recognize their brand. More seasoned brands (i.e., Coca-Cola) are able to advertise more often 
with less concern of annoying their audience (Campbell \& Keller, 2003).

\section{Product Preference}

Unlike brand familiarity, product preference comparisons involve two known brands or products. For example, Walter et al. (2005) asked male participants to rate a car's attractiveness irrespective of cost and practical considerations, given the choice between a sports car, a medium-sized car, and a small car. Participants ranked the sports car first, followed by the medium-sized car, with the small car ranked last. Walter et al. (2005) described sports cars as a primary reinforcer for social dominance, representing speed, power, and independence. In this instance, the sports car acted as a secondary reward. Secondary rewards are described as items such as cultural goods or money that reinforce behaviour only after prior learning, through associations with primary rewards (innate reinforcers including food, water, and sexual stimuli). Walter et al. (2005) also outlined three main functions of rewards. Rewards can: (a) induce learning via positive reinforcement, (b) induce consuming behaviour for acquiring the reward, and (c) induce positive affect. As seen from Walter et al.'s study (2005) sports cars are preferred as they represents characteristics that our culture values, and that we believe to be correlated with primary rewards that we innately seek. This study was also adapted from a previous study of social hierarchy and dominance involving monkeys (Morgan et al., 2002, as cited by Walter et al., 2005). In summary, given two known products, preference for one over the other is due primarily to the preferred product exhibiting more reinforcing qualities in terms of secondary reinforcers relevant to us personally, as well as to our cultural background.

\section{Neural Correlates}

Neuromarketing, is based on finding a neural correlates for buying behaviours such as brand familiarity and product preference. It is important to acknowledge that researchers are only able to seek a 'correlate' as most studies are only able to monitor neural activity observationally, and do not induce product preference via neural stimulation. With this in mind, compelling evidence has been found linking the medial prefrontal cortex with both brand familiarity and product preference. Damasio (1996) implicates the medial prefrontal cortex (mPFC) as a "repository of linkages between factual knowledge and bioregulatory states". In the more specific instance of advertising, this translates into product information and experiences being linked to positive affect, via the mPFC.

Studies that point to the medial prefrontal cortex (mPFC) as the locus of interest for neuromarketing studies are quite notable. Kable and Glimcher (2007) have also correlated mPFC activity, along with several other regions, directly with subject preference. Similarly, product preference (in the 'sports car' study outlined earlier) has been correlated with the activation of several brain regions in the reward circuitry of the brain, including the mPFC (Walter et al., 2005). Preference has also been correlated with mPFC activity independent of prices, and was found to be predictive of subsequent purchasing (Knutson, Rick, Wimmer, Prelec, \& Loewenstein, 2007). A simpler preference judgement study was also conducted prior to the aforementioned studies by (Paulus \& Frank, 2003), using a visual discrimination task as a control and found coinciding results.

One of the most compelling neuromarketing studies was that conducted by McClure et al. (2004). In the study, the researchers monitored neural activity when drinking either Coca-Cola or Pepsi. McClure et al. (2004) used an fMRI experiment with two conditions, (a) blind taste test and (b) brand-cued delivery. With blind taste test, brain activity between the Coca-Cola and Pepsi was nearly identical. However, in the brand-cued condition, dramatic differences were found in neural activity, primarily in the ventromedial prefrontal cortex. The important finding was that no neural activation differences were found when no brand information was 
available, but when brands were known, brand familiarity and product preference come into play and Coca-Cola was found to be generally preferred in the participants and caused significantly more activity in the ventromedial prefrontal cortex. One key aspect of the study is that no choices are actually made by the participant; the drink was delivered directly to the participant in the fMRI in small quantities, the manipulation was based on if the brand was announced first, and the finding is based on the resulting activated regions as measured by the fMRI. Previous conditioning and brand preference is only demonstrated in the brandcued delivery, and only then is there significant ventromedial prefrontal cortex activation.

A follow-up to the McClure et al. (2004) study sheds more light on the paradox of cola preference (Koenigs \& Tranel, 2008). Koenigs and Tranel (2008) explain that there is a "Pepsi paradox", which basically explains that in a blind-taste test, subjects tend to prefer Pepsi over Coca-Cola, or have no reliable preference, yet Coca-Cola consistently outsells Pepsi. The paradox is that when brand information is available, Coca-Cola is preferred, however, when brand information is not provided, no reliable preferences can be made. In the McClure et al. (2004) study, cola preference was counterbalanced. Koenigs and Tranel (2008) confirm predictions from previous correlative data by using subjects with prefrontal cortex damage, finding that even when these patients are presented with brand information, it makes no difference on their preferences. Thus this finding mirrors effects found in normal individuals in blind-taste tests, as well as in their own blindtaste test condition. Explained elegantly by Montague (2006), McClure et al. (2004) used a design very similar to Pavlov's original classical conditioning studies, however, they were not interested in a subject's brain response to each drink, but rather the responses that predicted subject's choices prior to being in the MRI scanner. McClure et al. (2004) were not interested specifically in the choices between the two colas, but rather in the valuation of the two choices, prior to the decision itself. Taste itself is not the reason Coca-Cola is preferred over Pepsi; rather it is the strong brand image of Coca-Cola (Gladwell, 2005).

Brand familiarity has also been connected with the mPFC in several studies. Differences in neural activity when comparing familiar and unfamiliar products has been associated with mPFC activity (Schaefer et al., 2006, Schaefer \& Rotte, 2007), which can also be connected to 'neurolearning' literature of novelty detection in rat lesion studies (Dias \& Honey, 2002). Relative to behavioural principles, Campbell and Keller (2003) suggest that brand familiarity is of extreme importance to advertisers. Consumers tend to fear the unknown, and in advertising, this fear materializes in an uncertainty of the product and instead they choose a known analogous product. Schaefer and Rotte (2007) demonstrate this as increased $\mathrm{mPFC}$ and superior frontal gyri activity for culturally familiar brands relative to unfamiliar brands.

In summary, medial prefrontal cortex (mPFC) activation has been linked to preference judgements by many studies (McClure et al., 2004; Paulus \& Frank, 2003; Walter et al., 2005). In addition, 'preference' for the familiar over the unfamiliar can also be attributed to the mPFC (Schaefer et al., 2006; Schaefer \& Rotte, 2007). Assuming that the consumer is going to buy a product either way (i.e., a car), preferences between the available choices in terms of their relative value is the next step in the decision making proces (Montague, 2008). By weighing the pros and cons of all the available choices, consumers can evaluate their choices. Research indicates that this process is undertaken primarily by the medial prefrontal cortex, which some have dubbed the 'liking centre' of the brain (Sutherland, 2004).

Other than the medial prefrontal cortex, several other areas have been implicated as key brain regions relevant to neuromarketing research (Walter et al., 2005). Some of these regions include the amygdala, ventral striatum, and 
orbitofrontal cortex. The amygdala is commonly known for its role in processing emotional information, however, it has also been correlated with reward intensity in neuromarketing studies (Walter et al., 2005). The ventral striatum, which includes the nucleus accumbens - the reward center of the brain, has been correlated with selfreported self arousal (salience) but only as an indicator of the predicted value of the reward (Knutson et al., 2007; Walter et al., 2005). This is thought of as 'prediction error' and is used as a mechanism for learning. The orbitofrontal cortex (OFC) is mainly thought of as a measure of preference, and consists of mainly two regions: the medial and lateral (Walter et al., 2005). The medial OFC, which includes the medial prefrontal cortex, is activated by rewarding stimuli. Lateral OFC activity is correlated with punishing stimuli. However, the use of neuroimaging techniques is not solely limited to neural activation measures. For example, neuroimaging quantitatively measure affect in terms of hormonal secretions such as dopamine (Fugate, 2007). Even still, there is much to discover in terms of neural correlates of interest to neuromarketing, though the field is expanding rapidly.

\section{Ethics of Neuromarketing}

A major issue for research in neuromarketing is the ethical concerns of neuroimaging in order to enhance commercial gain. From a scientific standpoint, neuromarketing is nowhere near being able to allow researchers to design a marketing campaign so addictive that overrides an individual's free will, though concerns are being allayed regarding this, founded or unfounded. In the United States, a consumer protection group, Consumer Alert, has filed complaints to universities, the US federal government, as well as a US senate committee, protesting the ethics of neuromarketing. They describing neuromarketing as "find[ing] a buy button inside the skull" (Commercial Alert, 2003). Commercial Alert (2003) claims: "Our children are suffering from extraordinary levels of obesity, type 2 diabetes, anorexia, bulimia, and pathological gambling, while millions will eventually die from the marketing of tobacco." According to Consumer Alert (2003), the rise of neuromarketing will bring an end to free will.

Many academics are also hesitant to embrace the field, Lee et al. (2007) posits: "Unfortunately, the barely concealed disdain for the idea of 'neuromarketing' in the neuroscience literature is clearly based on the opinion that marketing research is a commercial activity purely designed to sell products to the public...” Though there are many journals dedicated to economics and marketing, key aspects of neuromarketing, neuroscience academics tend to focus on more medically relevant, or abstract, questions (Thompson, 2003). As such, some believe that "brain imaging will be used in ways that infringe personal privacy to a totally unacceptable degree" (Editorial, 2004b). A similar stance was also made by an anonymous author in Nature Neuroscience, "Neuromarketing is little more than a new fad exploited by scientists and marketing consultants to blind corporate clients with science.” (Editorial, 2004a; Laybourne \& Lewis, 2005).

Research into neuromarketing may actually help reduce the problems raised by Commercial Alert (2003). For example, by examining the differences between the brain activity of compulsive overpurchasers relative to those who maintain more appropriate levels of purchasing may help us understand why these compulsive individuals tend to spend outside of their means. In addition, correlations between buying behaviour and clinical disorders can provide useful information for how clinicians can treat these disorders. For example, the medial prefrontal cortex and nucleus accumbens are quite important in value-based decision-making and the reward circuitry of the brain. These areas have also been implicated as areas relevant in schizophrenia (Montague, Hyman, \& Cohen, 2004).

Murphy, Illes, and Reiner (2008) believe that two major ethical issues are present in 
neuromarketing research: (a) protecting vulnerable parties from harm, and (b) protection of consumer autonomy if neuromarketing reaches critical effectiveness. Murphy et al. (2008) also outline recommendations for a 'code of ethics' to be adopted by the neuromarketing industry. Some of their recommendations include protecting research subjects from coercion, full disclosure of ethical principles used in the study, and accurate representation of scientific methods to businesses and the media.

\section{Free will \& Decision-making}

However, if neuromarketing ever does reach critical effectiveness as Murphy et al. (2008) suggests, the concerns of Commercial Alert (2003) may not be unfounded after all, and neuromarketing may come to infringe on an individual's free will. The significance of neuromarketing is not confined to neuroimaging techniques, but also encompasses computational neuroscience, the study of quantifying the component steps that underlie a given behavioural process. For example, value-based decision-making can be broken down into five steps: (a) identifying the decision problem; (b) weighing the possible choices; (c) making a decision based upon the evaluation of the choices available; (d) after carrying out the decision, consider the resulting consequences; and (e) learn from the decision-making process in order to make better decisions in the future (Rangel, Camerer, \& Montague, 2008). "Viewed this way, it's easy to see why 'free' choice is an unconstructive way to conceptualize the way humans choose...” (Montague, 2008). Free will, and the ability to manipulate an individual's perception of it have also recently come to light (Vohs \& Schooler, 2008). However, it has been many years since neuroimaging studies have suggested that neural activity does precede conscious intention, calling the issue of free will into question, especially if it can be monitored by an outside observer (Libet, Gleason, Wright, \& Pearl, 1983). Welberg (2007) describes that in the context of neuromarketing, Knutson et al. (2007) showed that the decision of whether to buy a product or not results from a balancing act of the gain of obtaining the product, offset by the downside of actually having to pay for the product - in essence an interplay of choices and the corresponding valuations.

Walvis (2008) further connects neuroscience with common marketing principles using computational neuroscience, rather than neuroimaging. Walvis (2008) suggests three propositions of neural cortical representation, or how the brain organizes information. These three propositions function similarly to the basis of an artificial neural network model, implicating the importance of what other 'elements' the brand is associated with, the strength of these associations, and the sheer number of associations that are present between the brand and other 'elements' in the network (Walvis, 2008). These correlate into "Three Branding Laws", based upon how personally relevant the brand's marketing strategy is to the consumer, how repetitive and targeted the branding efforts are, and how engaging the branding environment is to the consumer. The stronger these connections and 'pathways' are, the more likely a given brand will be chosen by the consumer. By using these 'laws', we can again quantify factors involved in choice behaviour, through the use of an artificial neural network With these techniques we not only can observe the interacting elements intrinsic to decision-making in terms of neural activations, but even to a more basic level, though the weightings of different choice options does start to become conjecture. Nonetheless, factors such as choice assortment and notions of an ideal point can be examined, weighing each product's valuations with the Hebbian-like theories presented by Walvis (2008). Using a strong neuroscientific basis for a branding, as suggested by Walvis (2008), neuromarketing can greatly improve marketing techniques, even without the use of neuroimaging, but rather employing other aspects of neuroscience. 


\section{Conclusion}

Fugate (2007) suggests several key implications of neuromarketing that suggest a revolution will soon overcome current market research. Using neuromarketing, researchers can evaluate an advertisement's effectiveness much more scientifically, in terms of the viewer's attention to the ad, as well as how the ad affects the viewer's emotional state (i.e., excitement or humour). Product appeal, and the 'sports car' study (Walter et al., 2005) are also implicated regarding their findings with the reward circuitry of the brain. Fugate (2007) continues on to celebrity endorsements and how neuromarketing can connect and quantify the effects of the auditory and visual stimuli of the celebrity as they translate into hormonal secretions which lead to a positive emotional response and feelings of trust. Also important is logo/brand selection, as researched by McClure et al. (2004) with their findings involving brand recognition and emotional attachment, with the result that CocaCola outperforms Pepsi. The future implications of neuromarketing show great potential and only time will tell how much of an effect these new techniques will have on marketing success.

At its current stage, neuromarketing is by no means adequate in determining if an advertisement is effective. Simply causing activation in regions such as the medial prefrontal cortex does not necessarily indicate that an advertisement is effective as it is only a corollary measure. Also, the region is the focus of many other research studies including those in fear conditioning (Baratta, Lucero, Amat, Watkins, \& Maier, 2008), eating disorders provocation (Uher et al., 2004), and startle responses (Day-Wilson, Jones, Southam, Cilia, \& Totterdell, 2006). Despite the current flaws in neuromarketing research, the field shows great promise as being the next step in market research. If advertisers took advantage to the many psychology studies that have been previously conducted, they would undoubtedly be more successful in both making a longer lasting impression on the consumer, as well as being able to better direct their efforts towards a target demographic. By adding the techniques of neuroimaging to their arsenal, in the form of neuromarketing, advertising agencies could perform much better. If improved marketing capabilities is good or bad for the consumer is quite debatable, but with proficient ethics being enforced upon the field (as they are with most other scientific research disciplines) only good can come from the pairing of the commercial principles of economics with the learning principles of psychology and neuroscience.

\section{References}

Baratta, M. V., Lucero, T. R., Amat, J., Watkins, L. R., \& Maier, S. F. (2008). Role of the ventral medial prefrontal cortex in mediating behavioral control-induced reduction of later conditioned fear. Learning \& Memory, 15(2), 84-87.

Campbell, M., \& Keller, K. L. (2003). Brand familiarity and ad repetition effects. Journal of Consumer Research, 30, 292-304.

Commercial Alert. (2003, Dec 1). Commercial alert asks emory university to halt neuromarketing experiments. Commercial Alert News Release. retrieved october 15, 2008, from the world wide web: http://www.commercialalert.org/PDFs/neuromarketin grel.pdf.

Damasio, A. R. (1996). The somatic marker hypothesis and the possible functions of the prefrontal cortex. Philosophical transactions of the Royal Society of London, Series B, Biological sciences, 351, 1413-1420.

Day-Wilson, K. M., Jones, D. N. C., Southam, E., Cilia, J., \& Totterdell, S. (2006). Medial prefrontal cortex volume loss in rats with isolation rearinginduced deficits in prepulse inhibition of acoustic startle. Neuroscience, 141(3), 1113-1121.

Dias, R., \& Honey, R. C. (2002). Involvement of the rat medial prefrontal cortex in novelty detection. Behavioral Neuroscience, 116(3), 498-503.

Editorial. (2004a). Brain scam? Nature Neuroscience, 7(10), 1015.

Editorial. (2004b). Neuromarketing: beyond branding. The Lancet Neurology, 3, 71. 
Fugate, D. L. (2007). Neuromarketing: a layman’s look at neuroscience and its potential application to marketing practice. Journal of Consumer Marketing, 24(7), 385-394.

Gladwell, M. (2005). Blink. New York: Time Warner Book Group.

Kable, J. W., \& Glimcher, P. W. (2007). The neural correlates of subjective value during intertemporal choice. Nature Neuroscience, 10(12), 1625-1633.

Knutson, B., Rick, S., Wimmer, G. E., Prelec, D., \& Loewenstein, G. (2007). Neural predictors of purchases. Neuron, 53, 147-157.

Koenigs, M., \& Tranel, D. (2008). Prefrontal cortex damage abolishes brand-cued changes in cola preference. Social Cognitive \& Affective Neuroscience, 3(1), 1-6.

Krugman, H. E. (1971). Brain wave measures of media involvement. Journal of Advertising Research, 11, 3-9.

Laybourne, P., \& Lewis, D. (2005). Neuromarketing: the future of consumer research? Admap, 461, 28-30.

Lee, N., Broderick, A. J., \& Chamberlain, L. (2007). What is 'neuromarketing'? A discussion and agenda for future research. International Journal of Psychophysiology, 63, 199-204.

Libet, B., Gleason, C. A., Wright, E. W., \& Pearl, D. K. (1983). Time of conscious intention to act in relation to onset of cerebral activity (readinesspotential). the unconscious initiation of a freely voluntary act. Brain, 106(Pt 3), 623-642.

McClure, S. M., Li, J., Tomlin, D., Cypert, K. S., Montague, L. M., \& Montague, P. R. (2004). Neural correlates of behavioral preference for culturally familiar drinks. Neuron, 44, 379-387.

Montague, R. (2006). Why choose this book? : How we make decisions. Toronto: Penguin Group.

Montague, R. (2008). Free will. Current Biology, 18(4), R584-R585.

Montague, R., Hyman, S. E., \& Cohen, J. D. (2004). Computational roles for dopamine in behavioural control. Nature, 431, 760-767.

Murphy, E., Illes, J., \& Reiner, P. B. (2008). Neuroethics of neuromarketing. Journal of Consumer Behavior, 7, 293-302.
Paulus, M. P., \& Frank, L. R. (2003). Ventromedial prefrontal cortex activation is critical for preference judgments. Neuroreport, 14, 1311-1315.

Rangel, A., Camerer, C., \& Montague, P. R. (2008). A framework for studying the neurobiology of valuebased decision making. Nature Reviews Neuroscience, 9(7), 545-556.

Reeves, B., Lang, A., Thorson, E., \& Rothschild, M. (1989). Emotional television scenes and hemispheric specialization. Human Communication Research, 15(4), 493-508.

Rothschild, M., \& Hyun, Y. J. (1990). Predicting memory for components of TV commercials from EEG. Journal of Consumer Research, 16, 472-478.

Rothschild, M., Hyun, Y. J., Reeves, B., Thorson, E., \& Goldstein, R. (1988). Hemispherically lateralized EEG as a response to television commercials. Journal of Consumer Research, 15, 185-198.

Schaefer, M., Berens, H., Heinze, H., \& Rotte, M. (2006). Neural correlates of culturally familiar brands of car manufacturers. Neuroimage, 31, 861-865.

Schaefer, M., \& Rotte, M. (2007). Favorite brands as cultural objects modulate reward circuit. Neuroreport, 18, 141-145.

Smidts, A. (2002). Kijken in het brein: Over de mogelijkheden van neuromarketing. (Brain imaging: Opportunities for neuromarketing). Inaugural Address Erasmus University: ERIM EIA-12-MKT.

Sutherland, M. (2004, July 24). Synopsis of reported neuromarketing studies. Retrieved October 12, 2008, from the World Wide Web:

http://www.sutherlandsurvey.com/Columns_Papers/S ynopsis $\backslash \% 20$ of $\ \% 20$ Neuromarketing $\backslash \% 20$ Studies.pdf.

Thompson, C. (2003, Oct 26). There's a sucker born in every medial prefrontal cortex. New York Times. Retrieved November 8, 2008, from the World Wide Web:

http://www.nytimes.com/2003/10/26/magazine/26BR AINS.html.

Uher, R., Murphy, T., Brammer, M. J., Dalgleish, T., Phillips, M. L., Ng, V. W. (2004). Medial Prefrontal Cortex Activity Associated With Symptom Provocation in Eating Disorders. American Journal of Psychiatry, 161(7), 1238-1246. 
Vohs, K. D., \& Schooler, J. W. (2008). The value of believing in free will: Encouraging a belief in determinism increases cheating. Psychological Science, 19(6), 49-54.

Walter, H., Abler, B., Ciaramidaro, A., \& Erk, S. (2005). Motivating forces of human actions:

Neuroimaging reward and social interaction. Brain Research Bulletin, 67, 368-381.
Walvis, T. H. (2008). Three laws of branding: Neuroscientific foundations of effective brand building. Journal of Brand Management, 16, 176-194.

Weinstein, S., Appel, V., \& Weinstein, C. (1980). Brain-activity responses to magazine and television advertising. Journal of Advertising Research, 20(3), 57-63.

Welberg, L. (2007). Shopping centres in the brain. Nature Reviews Neuroscience, 8(2), 84-85.

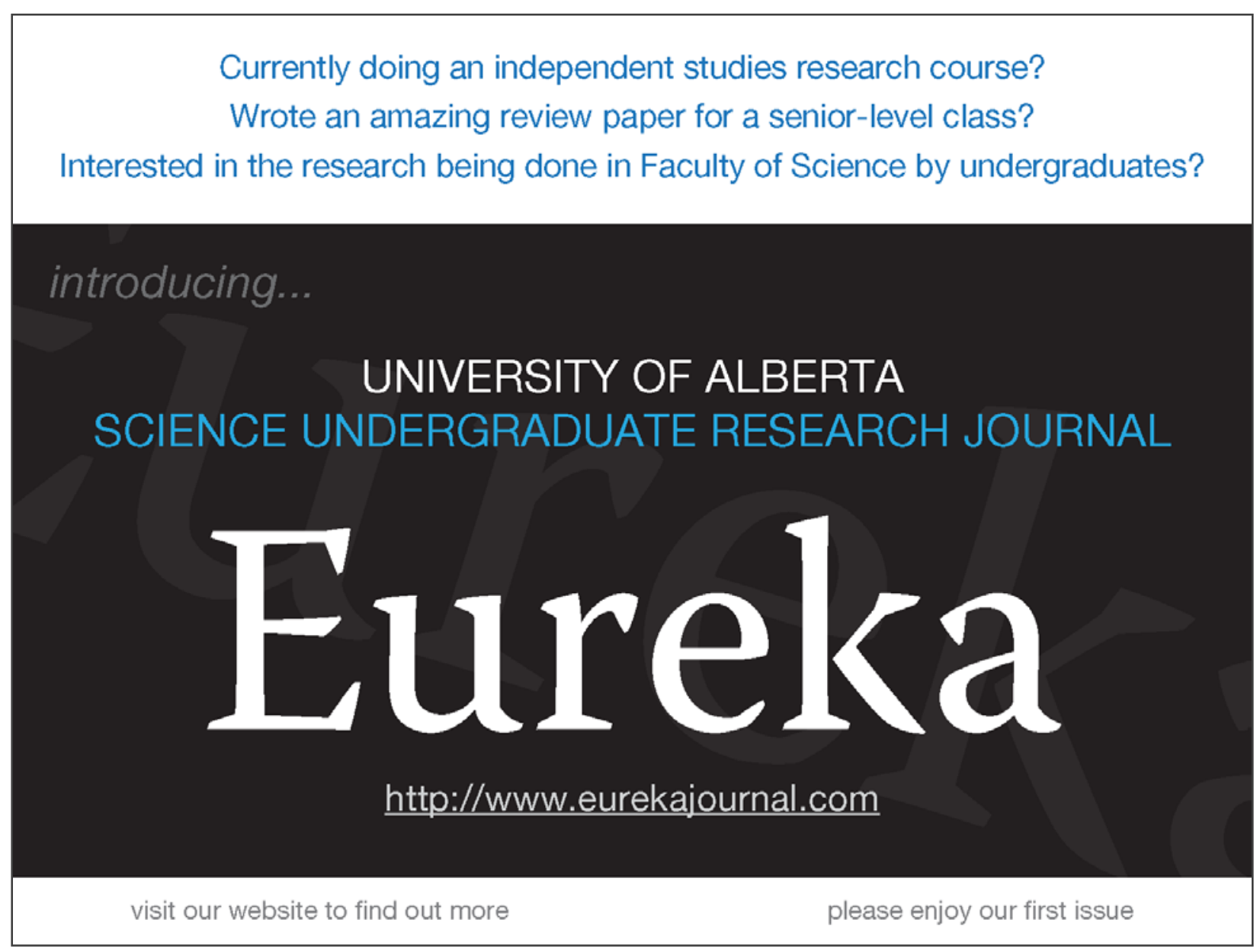




\title{
REAL RESEARCH OR SHAM SCIENCE?
}

\section{A REVIEW OF JAPAN'S SCIENTIFIC WHALING}

Patrick Robertson

Department of Biological Sciences, University of Alberta

Eureka

Volume 1, Number 1 (2010)

\begin{abstract}
Centuries of unregulated hunting lead to the decimation of whale populations globally. A moratorium on whaling allowed some stocks to start recovering, but others are not as promising. The Japanese lethal research on whales is permitted under the International Whaling Commission's regulations allowing for scientific sampling of cetaceans, despite the 1982 moratorium on whaling. However, many in the scientific community suggest that the Japanese research is really a front for commercial whaling. The research programs in both the Antarctic and North Pacific (JARPA and JARPN) are not meeting their objectives and non-lethal techniques would be more effective. The Japanese government's agenda at the IWC is to restart commercial whaling and appears to be actively promoting the consumption of whale meat from the research vessels. Japans internal market is not properly regulated and meat packaged for consumption has been found with pathogens and extremely high levels of toxins and heavy metals. Genetic analysis has indicated whale meat in markets contains internationally protected species, as well as nonwhale tissues. Due to the extreme deficiency in our knowledge of global cetacean populations and the lack of infrastructure to monitor and enforce quotas, whale conservation should take priority over premature harvesting or unscientific research.
\end{abstract}

\section{Introduction}

For centuries, aboriginal groups around the world have hunted whales for meat and oil. According to Best (1993) and Feldhamer et al. (2007), commercial whaling began as early as $1100 \mathrm{AD}$, and with advances in boat and hunting technology, whalers were soon killing significant numbers of whales for the valuable meat, oil, and baleen. Due to a completely unregulated industry, many whale stocks were severely overexploited, with many populations dropping below $10 \%$ of pre-whaling levels (Best 1993). In 1949, the International Whaling Commission (IWC) was established to manage international cetacean stocks. By the 1970s, many species had received protection under international laws due to critically low population levels. In 1982, the IWC passed a moratorium on all commercial whaling (Best 1993; Iliff 2007). Aboriginal sustenance (local use only) whaling is permitted by the IWC for native groups in the United States, St. Vincent and the Grenadines, Russia, and Greenland. However, some nations, primarily Japan, Norway, Greenland, and Iceland continue to legally hunt whales through reservations against the moratorium or for scientific research. Currently, Japan has two major research programs through the IWC's special permit clause: JARPA II (Antarctic research) and JARPN II (North Pacific research).

In the time since the moratorium was put in place, several whale species such as the North Atlantic Right whales (Eubalaena glacialis) and Blue whales (Balaenoptera musculus) have not demonstrated significant levels of recovery (Best 1993; Kraus and Rolland 2007). The IUCN (2008) currently identifies nine species as least concern, two as near-threatened, and one as vulnerable. Sei $(B$. borealis), Blue, Fin (B. physalus), and both North Atlantic and North Pacific species of Right whales ( $E$. glacialis and E. japonica respectively) have been given endangered status. Thirty-one of the 48 cetaceans on the Red List are listed as Data Insufficient, so it is extremely likely that these numbers will rise as more information is gathered about different whale populations. Many others have shown signs of recovery, delighting both pro- and anti-whaling factions and fueling fierce debate about how whale stocks should be managed and conserved.

By drawing information from the primary literature in peer-reviewed journals, as well as technical documents and reviews, I hope to present and compare the arguments from both sides of the scientific whaling controversy, with a focus on the 
science involved. In an attempt to use the most accurate and objective information possible, I have tried to avoid publications from lobby groups and NGOs on both sides and focus on work from scientists in the field. It is my intent to address flaws in the science as well as try to gain a perspective on how the science interacts with other aspects of this highly contentious and political issue. Through investigating the most recent primary literature regarding cetacean ecology and conservation from different species and oceans, I will examine Japan's scientific whaling program and compare their results with others from around the world.

\section{Discussion}

Japan recently completed an 18-year study in the southern ocean (JARPA I) to improve cetacean management by gaining information on Antarctic Minke whale (B. bonaerensis) stock structure, natural mortality rates, the effects of environmental changes on whales and the role of whales in the Antarctic ecosystem (IWC 2009) The JARPA II study is ongoing, with the stated purpose of studying Antarctic Minke, Humpback (Megaptera novaeangliae), and Fin whales to examine the ecosystem, study interspecific competition, monitor changes in population structure, and enhance Minke management. Likewise, JARPN investigated Minke whale population structure in the North Pacific. Now, Japan is on the second phase of the experiments looking at feeding ecology with special interest in competition between whales and commercial fisheries. Japanese researchers have lethally sampled 10,579 whales under special permits since the moratorium was enacted (IWC 2009). This is $86 \%$ of the 12,309 whales taken by all IWC members for research since the moratorium took effect.

\section{Criticisms of the scientific whaling programs}

These programs have received a great deal of criticism, from both within the IWC and without, as little more than commercial whaling disguised as science to exploit a loophole in the moratorium. In a letter to the journal Nature, members of the IWC's scientific committee outline numerous concerns about the JARPA II and JARPN II studies and their scientific relevance (Gales et al. 2005). They point out that 63 members of the scientific committee contested the claims of the Japanese scientific plans and have repeatedly urged Japan to use more effective nonlethal methods. In his critique of the Japanese scientific program, Corkeron (2009) indicates that the JARPA failed to provide any useful data on its objective of Minke mortality rates while other nonlethal studies have provided similar data for other species. He also describes how the JARPN II program was compromised due to improper sampling techniques, ignoring protocols to avoid sampling bias by collecting specimens off of transect lines and moving sample points to find more whales, artificially elevating estimates of abundance.

One main reason for lethal sampling is to obtain information on feeding ecology from stomach content analysis. However, stomach contents give a short term view of an organism's diet, and more and more ecological studies are using stable isotope analysis to gain a better understanding of long-term feeding and trophic interactions (e.g. Huckstadt et al. 2007). This technique effectively addresses the objectives of the JARPN II program and can be done with a simple, non-lethal, tissue sample. In 2001, the deputy director of Japan's Fisheries Agency, Joji Morishita, praised the use of non-lethal techniques and models in cetacean research, yet the Japanese government refused to incorporate them into JARPA II and JARPN II when the IWC scientific committee recommended using non-lethal techniques in 2005, instead doubling the previous catch limits and including endangered Fin whales and vulnerable Humpback whales in the quotas (Morishita and O’Regan, 2001; Gales et al. 2005).

Another common criticism of the Japanese research program is that, for a project that ran for more than 18 years, few publications have come out of it. Fukui et al. (2005) defend their work with JARPA and JARPN in an open letter published in the journal Marine Mammal Science, claiming that journals are refusing to publish the research due to the political and ethical nature of the whaling debate, rather than objectively reviewing their scientific contributions.

\section{Beyond 'scientific' research}

Each year at the IWC meetings, Japan pushes to lift the moratorium, openly expressing a desire to restart commercial whaling on sustainable stocks (IWC 2009). According to the Japanese government, Japan is culturally linked to the sea. (Morishita and O’Regan 2001). According to Morishita (2001), Japan is only $41 \%$ self-sufficient in food production, and whaling is a viable way to improve food security. He argues for managing cetacean stocks to protect 
commercially-important fisheries and exploiting whales as a sustainable food source is a Japanese cultural right.

There is evidence in the literature that cetaceans feed at levels that impact human fisheries. Whales are viewed as apex predators in marine ecosystems, with Mysticeti species generally considered generalist predators, consuming large volumes of zooplankton (eg. Copepods, krill), fish, and squid. Kenney et al. (1997) found that each year, cetaceans off the east coast of North America consumed the equivalent of between one-third to just over three times the commercial harvest. They also suggest that if whales predate selectively on certain species, they could negatively affect fish stock recovery from over-exploitation. Witteveen et al. (2006) suggest that recovering Pacific Humpback whale populations are responsible for declines in pinniped and piscivorous bird populations off Kodiak Island, Alaska and the whales in the study area consume as much as $30 \%$ of the commercial harvest. However, the United Nations Food and Agriculture Organization (2008) found that $52 \%$ of fisheries are being exploited at their maximum while a further $28 \%$ are already over-exploited or collapsed wholly as a result of human actions. It further identifies anthropogenic over-fishing as the biggest threat to fisheries. Kenney et al. (1997) conclude that there is likely little direct competition between cetaceans and fisheries, as whales tend to feed at lower trophic levels than those commercial fisheries exploit. They also conclude that fisheries have a greater impact on primary productivity due to fisheries harvesting higher trophic levels.

An investigation by an independent journalist in Japan discovered that demand for whale meat has been declining, resulting in increasing levels of surplus whale meat going unsold, contradicting the government's assertion of the importance of whale meat to Japanese culture (Junko 2006). Despite the Japanese people buying less whale meat, the government approved higher quotas. Junko (2006) found that Japanese eat approximately $30 \mathrm{~g}$ of whale meat per person per year, compared to $\sim 27 \mathrm{~kg}$ of beef per person per year and the trend is decreasing. Public opinion polls seem to reflect her findings, with one major poll finding $61 \%$ of respondents had not eaten whale meat since they were children and only $8 \%$ supported the whaling industry, although it should be noted that a government poll found $77 \%$ supported whaling (Morishita and O’Regan 2001). I suspect the truth of public opinion lies somewhere in between.

The Japanese government may be acting overzealously in an attempt to create a domestic market for whale meat, and are not using precautionary science. Whale meat being sold in Japan is not being properly inspected and controlled. Parsons et al. (2006) report the discovery of the zoonotic pathogen Brucella sp., in packaged whale meat from markets and in 38\% of Minke Whales from the JARRPN study. Brucellosis can cause a range of health issues from joint and muscle pain and severe fever to meningitis and liver disease (Parsons et al. 2006). They found tissues containing organochlorines and mercury in whale meat at concentrations 18 and 22 times higher than government limits. The government started a whale meat lunch program for children in schools that critics say is to create a future market for whale products in the Japanese school children, but at the risk of feeding the children bacterially and/or chemically contaminated meat (Parsons et al. 2006). Genetic work by Baker et al. (2000) also found problems with Japanese control of domestic whale markets. They found haplotypes of internationally protected cetacean species, as well as non-cetacean meat packaged as whale meat. Baker (2000) and Parsons' (2006) work suggest that despite the government's desires, the Japanese marketplace is not prepared for the return to commercial whaling, as there is insufficient quality control of products to ensure consumer safety and to enforce quotas on species harvests.

\section{Conclusions}

The general consensus among scientists outside of Japan is that lethal sampling is unnecessary to answer the stated objectives of the Japanese program and is less efficient than current non-lethal techniques. The hard line the government has taken to restart commercial whaling and refusal to conduct non-lethal research despite international requests leads me to believe that the government is basing its research programs on motives beyond scientific interests, degrading the potential quality of their research. Little is known of whale biology, as shown by the vast proportion of data-deficient whales on the IUCN's Red List, so it is impossible to responsibly harvest cetacean populations commercially in a sustainable manner, or even to be lethally sampling critically endangered species when non-lethal alternatives are more effective for answering the same 
questions. In the face of the uncertainty in the data available, to be a responsible resource manager, the IWC should adhere to the precautionary principle and work to prevent cetacean harvesting to ensure the long term survival of the different species. Unfortunately, little is likely to change in the near future on the whaling front. Unless the IWC undergoes significant internal changes, the highly polarized factions will continue to be at a stalemate, with the moratorium remaining and Japan whaling under the cover of pseudoscientific research.

\section{Literature Cited}

Baker, C. S., G. M. Lento, F. Cipriano, \& S. R. Palumbi. 2000. Predicted declines of protected whales based on molecular genetic monitoring of Japanese and Korean markets. Proceedings of the Royal Society of London Biological Sciences 267:11911199.

Best, P. B. 1993. Increase rates in severely depleted stocks of baleen whales. ICES Journal of Marine Science 50:169-186.

Corkeron, P. J. 2009. Reconsidering the science of scientific whaling. Marine Ecology Progress Series 375:305-309.

Feldhamer, G. A., L. C. Drickamer, S. H. Vessey \& C. Krajewski. 2007. Mammalogy: adaptation, diversity, ecology. 3rd ed. John Hopkins University Press, Baltimore, Maryland, United States of America.

Fukui, Y., H. Ishikawa, \& S. Ohsumi. 2005. Difficulties in publishing research results from scientific whaling. Marine Mammal Science 21:781783.

Gales, N. J., T. Kasuya, P. J. Clapham, \& R. L. Brownell JR. 2005. Japan's whaling plan under scrutiny. Nature 435:883-884.

Huckstadt, L. A., C. P. Rojas, \& T. Antezana. 2007. Stable isotope analysis reveals pelagic foraging by the Southern Sea Lion in central Chile. Journal of Experimental Marine Biology and Ecology 347:123133.
Iliff, M. 2008. The international whaling regime post 2007. Marine Policy 32:522-527.

International union for conservation of nature. 2008 IUCN Red List of Threatened Species.

$<$ www.iucnredlist.org>. Downloaded on 17 March 2009

International Whaling Commission 2009. Scientific permit whaling. $<$ http://iwcoffice.org/conservation/permits.html > Retrieved on 17 March, 2009

Junko, S. 2006. Investigating the sale of whale meat the "byproduct" of research whaling. Iruka \& Kujira Action Nework. Tokyo, Japan.

Kenney, R.D., G.P. Scott, T. J. Thompson, and H. E. Winn. 1997. Estimates of prey consumption and trophic impacts of cetaceans in the USA northeast continental shelf ecosystem. Journal of Northwestern Atlantic Fisheries Science 22:155-171.

Kraus, S.C., and R.M. Rolland. 2007. Right whales in the urban ocean. Pp. 1-38 in The urban whale: north atlantic right whale at the crossroads (S.C. Kraus and R.M. Rolland, eds.) Harvard University Press, Cambridge, Massachusetts, United States of America.

Morishita, J., \& F. O'regan. 2001. Whaling: should Japan be allowed to continue? The Ecologist 31:1821.

Parsons, E. C. M., N. A. Rose, C. Bass, and M. Simmonds. 2006. It's not just poor science - Japan's "scientific" whaling may be a human health risk too. Marine Pollution Bulletin 52:1118-1120.

Pulvenis de Seligny, J.F., A., Gumy, and R. Grainger. 2008. The state of world fisheries and aquaculture. (R. Grainger ed.) Food and Agriculture Organization of the United Nations, Rome, Italy.

Witeveen, B.H., R. J., Foy, and K.M. Wynne. 2006. The effect of predation (current and historical) by humpback whales (Megaptera nnovaeangliae) on fish abundance near Kodiak Island, Alaska. Fisheries Bulletin 104:10-20. 


\section{RESEARCH/FUNDING RELATED OPPORTUNITIES}

Eureka Team

For those who are interested in research but have not had previous experience, the best place to start is a summer research position. Although you could reach the professor of interest directly, it is helpful to get funding from various agencies at the same time. This is usually done between December and January, though some professors are willing to take summer students even later in the year. The following is a list of resources that undergraduate students interested in research could use:

\section{Alberta Heritage Foundation for Medical Research (AHFMR) - usually funds for summer positions; duration $2-4$ months. They also have a Research News subscription that is free, which gives highlights in various areas of research. \\ http://www.ahfmr.ab.ca/}

Natural Sciences and Engineering Research Council of Canada (NSERC) - funds summer positions as well as some co-op programs during the year.

http://www.nserc-crsng.gc.ca/

Canadian Institutes of Health Research (CIHR) - although most of these opportunities are for higher levels of research, there are usually a few undergraduate funding opportunities which are for restricted fields of research - your supervisor will most likely ask you to apply for this one if applicable.

http://www.cihr-irsc.gc.ca/
Eureka

Volume 1, Number 1 (2010)

ARDA International Foundation (AIF) - this is an industry-based foundation that provides some opportunities with funding for undergraduates, but is largely dependent on your supervisor's area of interest and associations.

http://www.arda.org/Content/NavigationMenu2/

Research/Research.htm

CAPS has an online newsletter that could be emailed to you upon subscription. Every now and then they have some workshops on how to write science research resumes. In their Online Job Postings site, there are also some summer research positions from sectors other than the University that you can apply for. Usually those do not require additional outside funding as the company will provide the salary.

There are also some Departmental funding available depending on which Department you approach, so don't forget to go to the departments' sites!!

Finally, if you are interested for research during the term, you can take courses such as Biol 498/499; the prior is one term, the latter is for 2 terms. This is a project based course where the entire course is carried out in a lab. Usually you have to find a supervisor that is willing overlook your project; some departments can arrange for a professor for you.

If I missed any other places where undergraduates can find research opportunities, please email us so we can share it with everyone!!

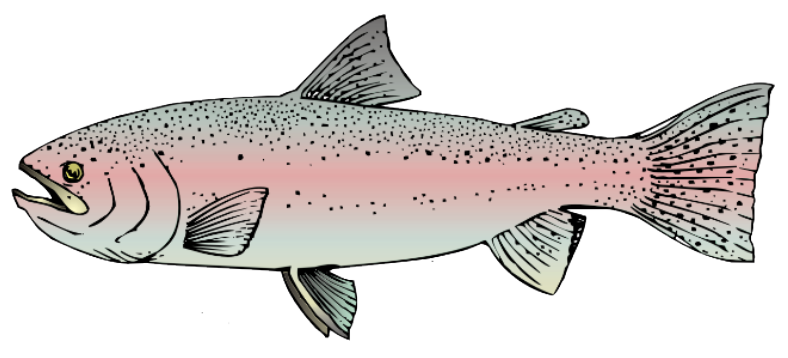




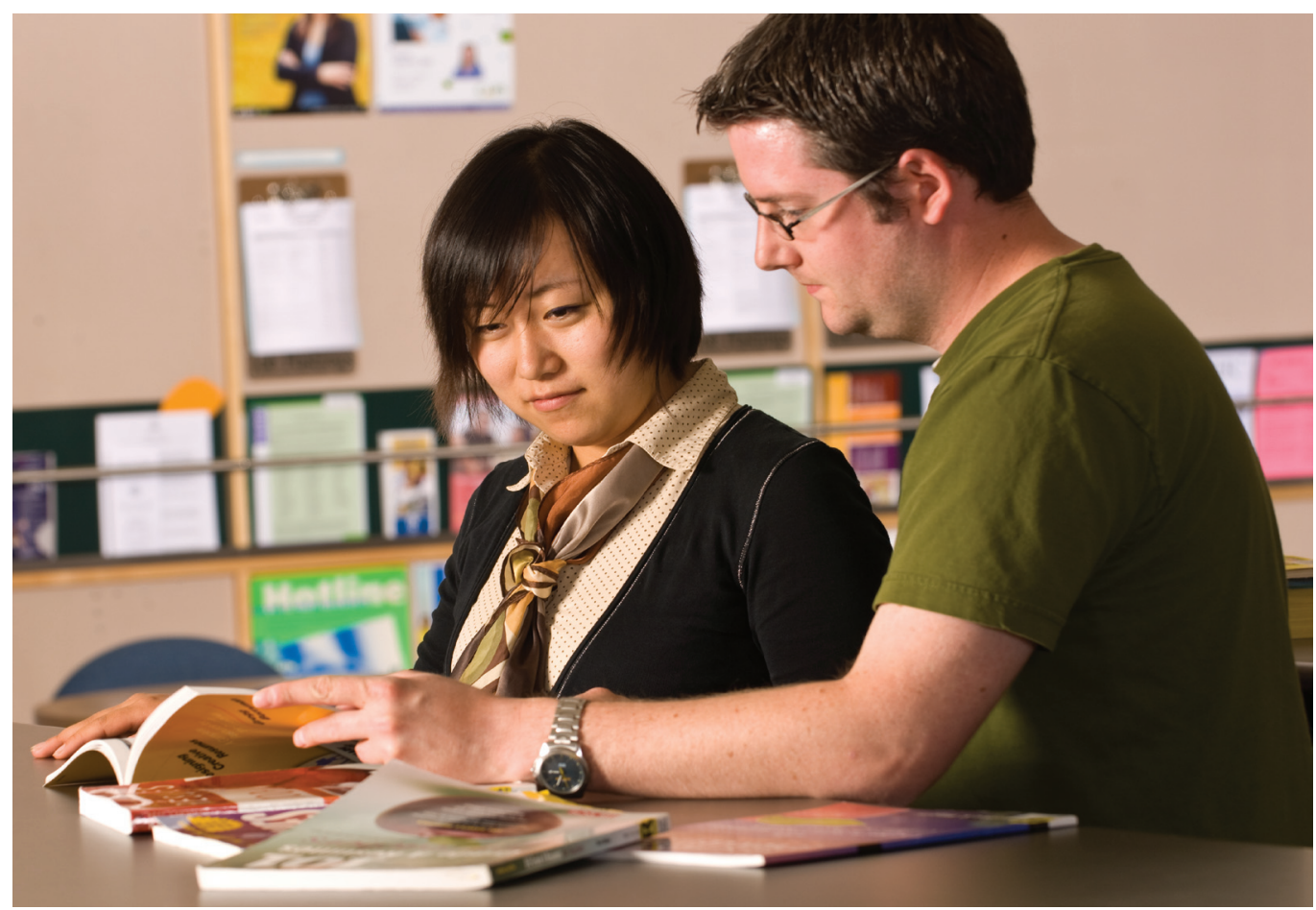

If you are interested in pursuing a career in research, there are a variety of ways CAPS can help including the following workshops and services:

- So, You Want to be an Academic?

- Writing an Effective CV and Cover Letter

- Writing a Personal Statement

- Medical School Interview Help

- Online Job Postings

- Print and Electronic Resources

- Birds of a Feather - connecting students with researchers (coming in Fall 2010) 


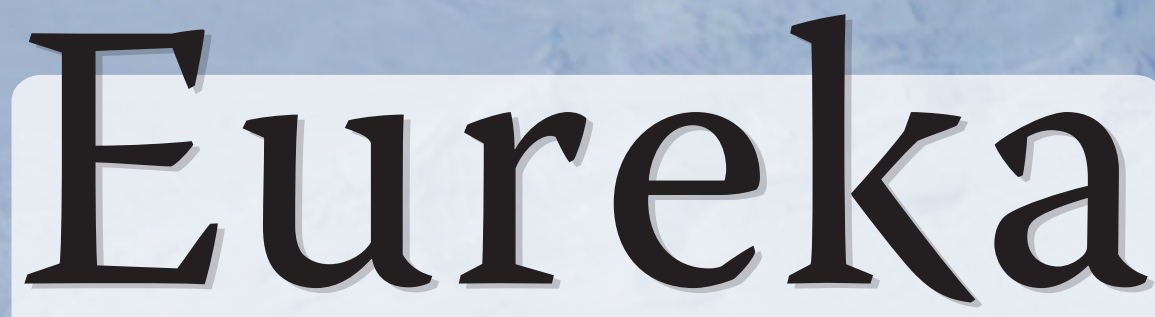

University of Alberta Science Undergraduate Research Journal http://www.eurekajournal.com

Volume 1, Number 1

Winter 2010

Want to join the Eureka team?

Want to submit your work to Eureka?

\section{Contact us!}

Website: www.eurekajournal.com

E-mail: eureka@ualberta.ca 